\title{
One-Pot Synthesis of Benzothiazole-Tethered Chromanones/ Coumarins via Claisen Rearrangement Using the Solid State Melt Reaction
}

\author{
Manickam Bakthadoss ${ }^{*} \dagger$ and Raman Selvakumar ${ }^{*}$ \\ ${ }^{\dagger}$ Department of Chemistry, Pondicherry University, Pondicherry 605 014, India \\ ${ }^{\ddagger}$ Department of Organic Chemistry, University of Madras, Guindy Campus, Chennai 600 025, Tamilnadu, India \\ bhakthadoss@yahoo.com
}

Contents

Page

1) Single crystal X-ray mesurements

$2-4$

2) ${ }^{1} \mathrm{H},{ }^{13} \mathrm{C}$ NMR and Mass spectra for compounds

(5a-p, 10a-i, 13a-c, 16a-c and 17a)

$5-106$ 


\section{$\mathrm{X}$-ray structure of $\mathbf{5 b}$}

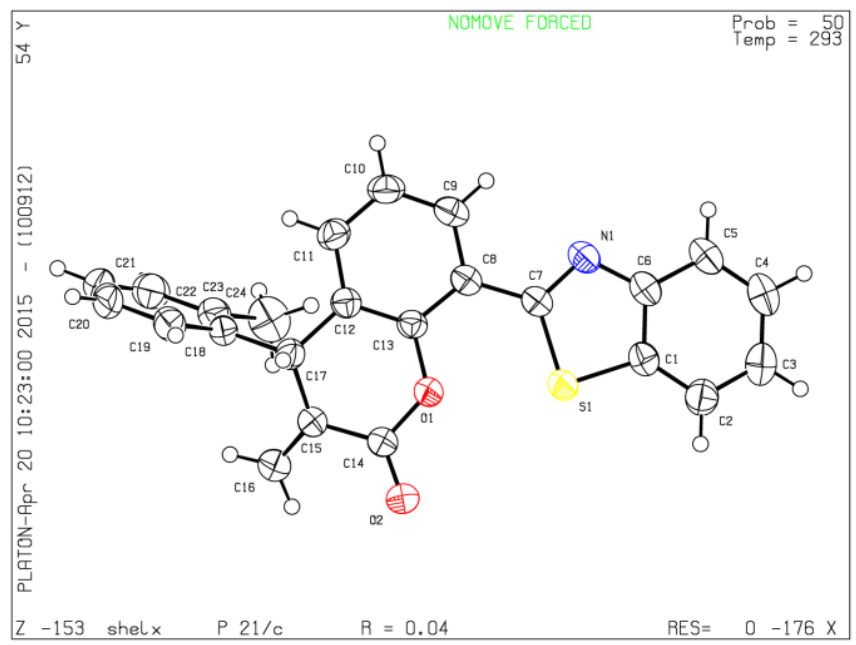

Figure S1. ORTEP diagram of compound $\mathbf{5 b}$ where thermal ellipsoids are drawn at the 50\% probably level.

Crystal structure determination: Single crystals suitable for X-ray studies were grown by slow evaporation of an ethyl acetate solution at room temperature. The X-ray diffraction intensity data were collected at room temperature $(293 \mathrm{~K})$ on a single crystal X-ray diffractometer equipped with graphite monochromatic $\operatorname{MoK} \alpha(\lambda=0.71073 \AA)$ radiation and using CCD detector.

\section{Table S1. Selected crystal parameters and refinement metrics}

\begin{tabular}{|l|l|}
\hline CCDC Number for 5b & 1036725 \\
\hline Chemical formula & $\mathrm{C}_{24} \mathrm{H}_{17} \mathrm{NO}_{2} \mathrm{~S}$ \\
\hline Formula weight & 383.45 \\
\hline Crystal system & Monoclinic \\
\hline Space group & $\mathrm{P} 2_{1} / \mathrm{c}$ \\
\hline Unit cell dimensions & $\begin{array}{l}\mathrm{a}=9.4196(2) \AA, b=20.2974(5) \AA, \mathrm{c}=10.6385(3) \AA . \\
\text { alpha }=90^{\circ}, \text { beta }=114.597(1)^{\circ}, \text { gamma }=90^{\circ} .\end{array}$ \\
\hline Volume $(\mathrm{A} 3)$ & $1849.44(8)$ \\
\hline$Z$ & 4 \\
\hline Reflections collected & 4642 \\
\hline R1, wR2 [I $\geq 2 \sigma(\mathrm{I})]$ & $0.0409,0.1224$ \\
\hline Goodness-of-fit on $F^{2}$ & 0.988 \\
\hline
\end{tabular}




\section{X-ray structure of 10d}

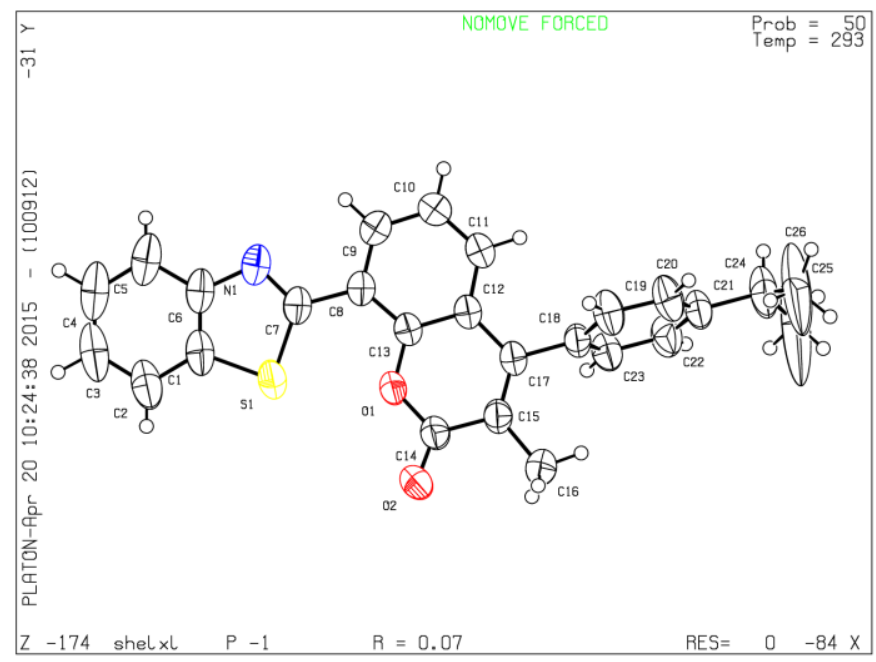

Figure S2. ORTEP diagram of compound 10d where thermal ellipsoids are drawn at the 50\% probably level.

Crystal structure determination: Single crystals suitable for X-ray studies were grown by slow evaporation of an ethyl acetate solution at room temperature. The X-ray diffraction intensity data were collected at room temperature $(293 \mathrm{~K})$ on a single crystal X-ray diffractometer equipped with graphite monochromatic $\operatorname{MoK} \alpha(\lambda=0.71073 \AA)$ radiation and using CCD detector.

Table S2. Selected crystal parameters and refinement metrics

\begin{tabular}{|l|l|}
\hline CCDC Number for 10d & 1036724 \\
\hline Chemical formula & $\mathrm{C}_{26} \mathrm{H}_{21} \mathrm{NO}_{2} \mathrm{~S}$ \\
\hline Formula weight & 411.50 \\
\hline Crystal system & Triclinic \\
\hline Space group & $\mathrm{P}-1$ \\
\hline Unit cell dimensions & $\begin{array}{l}\mathrm{a}=8.7107(2) \AA, \mathrm{b}=10.3413(3) \AA, \mathrm{c}=11.8345(3) \AA . \\
\text { alpha=95.821(2) }{ }^{\circ}, \text { beta }=97.715(2)^{\circ}, \text { gamma=93.790(2) }\end{array}$ \\
\hline Volume $(\mathrm{A} 3)$ & $1047.51(5)$ \\
\hline$Z$ & 2 \\
\hline Reflections collected & 4259 \\
\hline R1, wR2 [I $\geq 2 \sigma(\mathrm{I})]$ & $0.0720,0.2141$ \\
\hline Goodness-of-fit on $F^{2}$ & 1.037 \\
\hline
\end{tabular}




\section{$\mathrm{X}$-ray structure of $16 \mathrm{c}$}

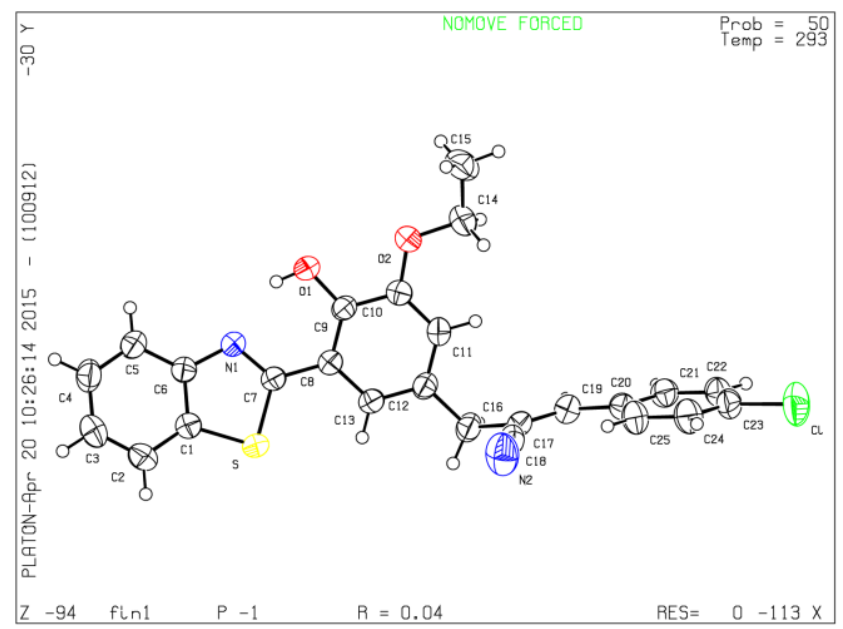

Figure S3. ORTEP diagram of compound 16c where thermal ellipsoids are drawn at the 50\% probably level.

Crystal structure determination: Single crystals suitable for X-ray studies were grown by slow evaporation of an ethyl acetate solution at room temperature. The X-ray diffraction intensity data were collected at room temperature $(293 \mathrm{~K})$ on a single crystal X-ray diffractometer equipped with graphite monochromatic $\operatorname{MoK} \alpha(\lambda=0.71073 \AA)$ radiation and using CCD detector.

\section{Table S3. Selected crystal parameters and refinement metrics}

\begin{tabular}{|l|l|}
\hline CCDC Number for 16c & 1036726 \\
\hline Chemical formula & $\mathrm{C}_{25} \mathrm{H}_{19} \mathrm{ClN}_{2} \mathrm{O}_{2} \mathrm{~S}$ \\
\hline Formula weight & 432.92 \\
\hline Crystal system & Triclinic \\
\hline Space group & $\mathrm{P}-1$ \\
\hline Unit cell dimensions & $\begin{array}{l}\mathrm{a}=9.5557(2) \AA, \mathrm{b}=10.2960(2) \AA, \mathrm{c}=11.4909(2) \AA . \\
\text { alpha=96.003(1) }{ }^{\circ}, \text { beta=104.156(1) }{ }^{\circ}, \text { gamma }=91.371(1)^{\circ} .\end{array}$ \\
\hline Volume $(\mathrm{A} 3)$ & $1088.76(4)$ \\
\hline$Z$ & 2 \\
\hline Reflections collected & 4474 \\
\hline R1, wR2 [I $\geq 2 \sigma(\mathrm{I})]$ & $0.0397,0.1221$ \\
\hline Goodness-of-fit on $F^{2}$ & 1.026 \\
\hline
\end{tabular}




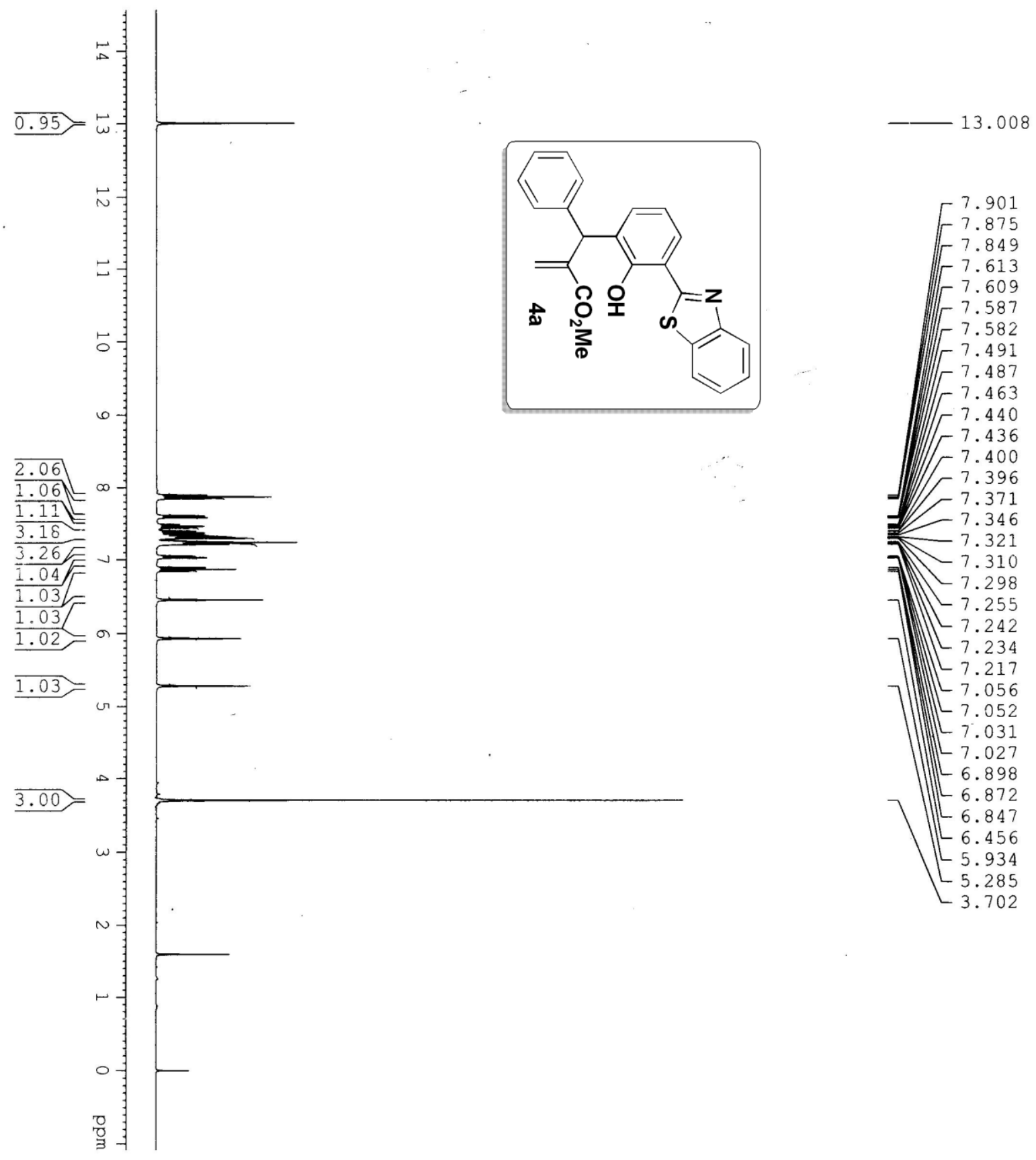



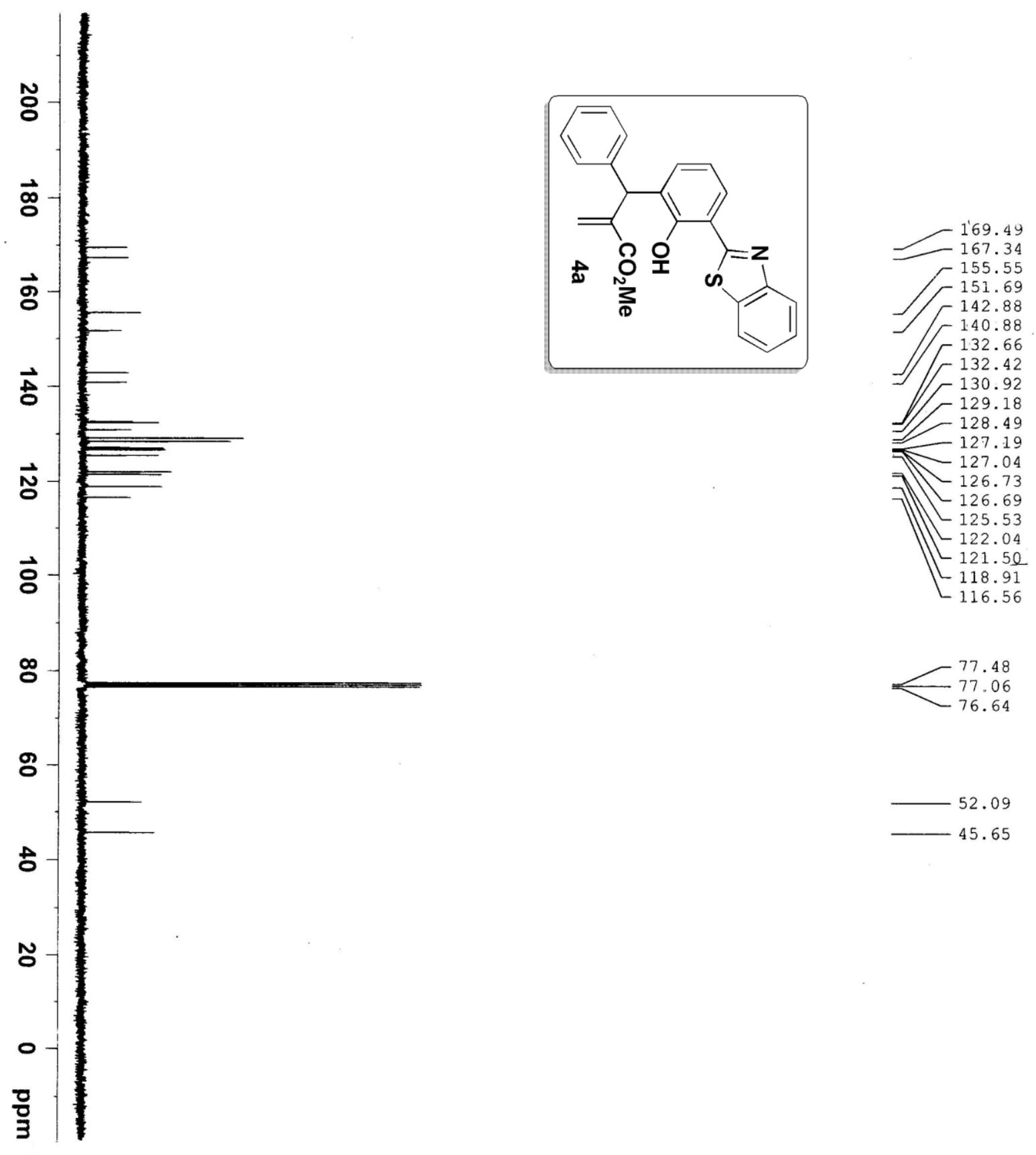

52.09

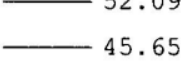




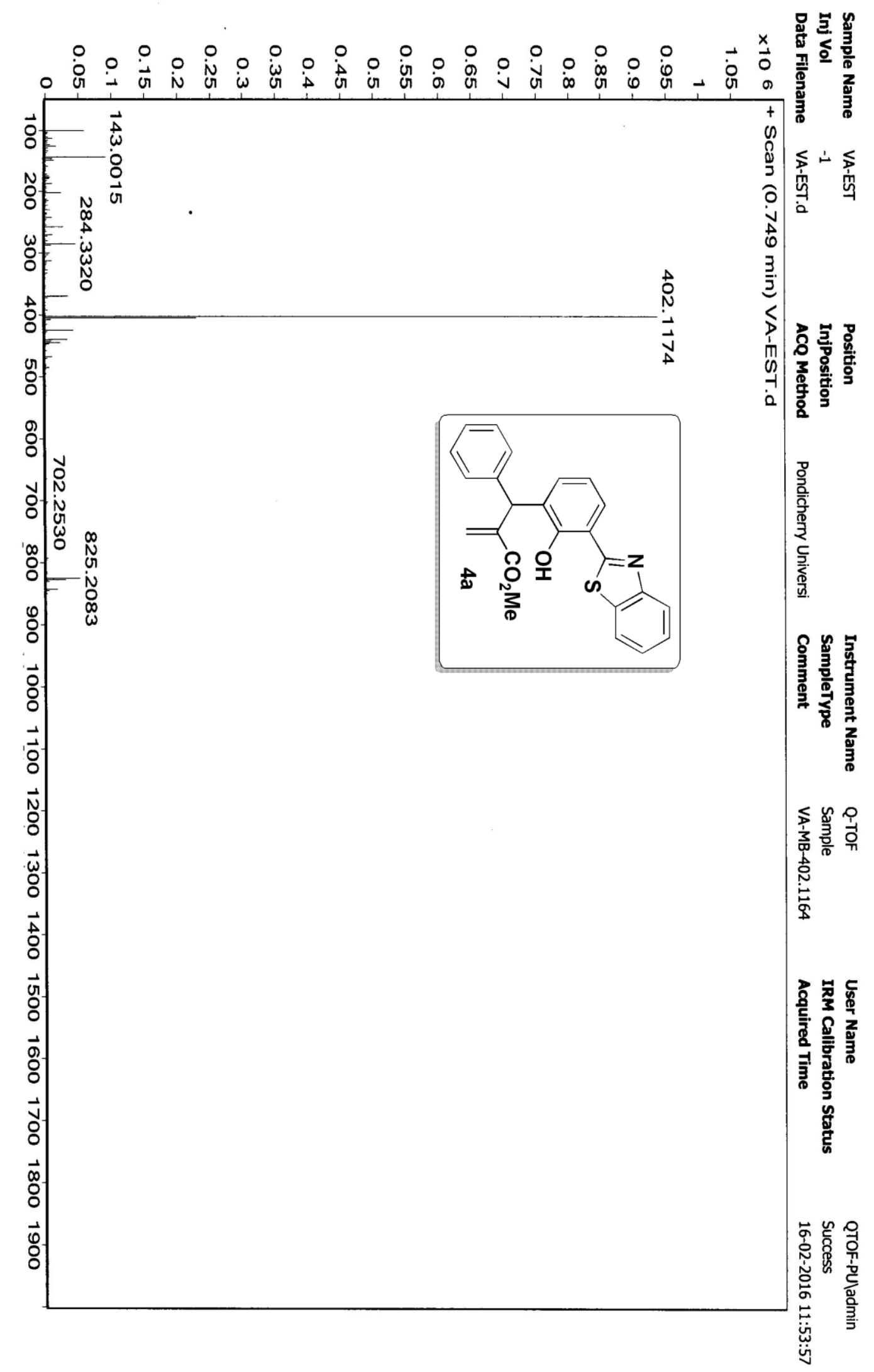



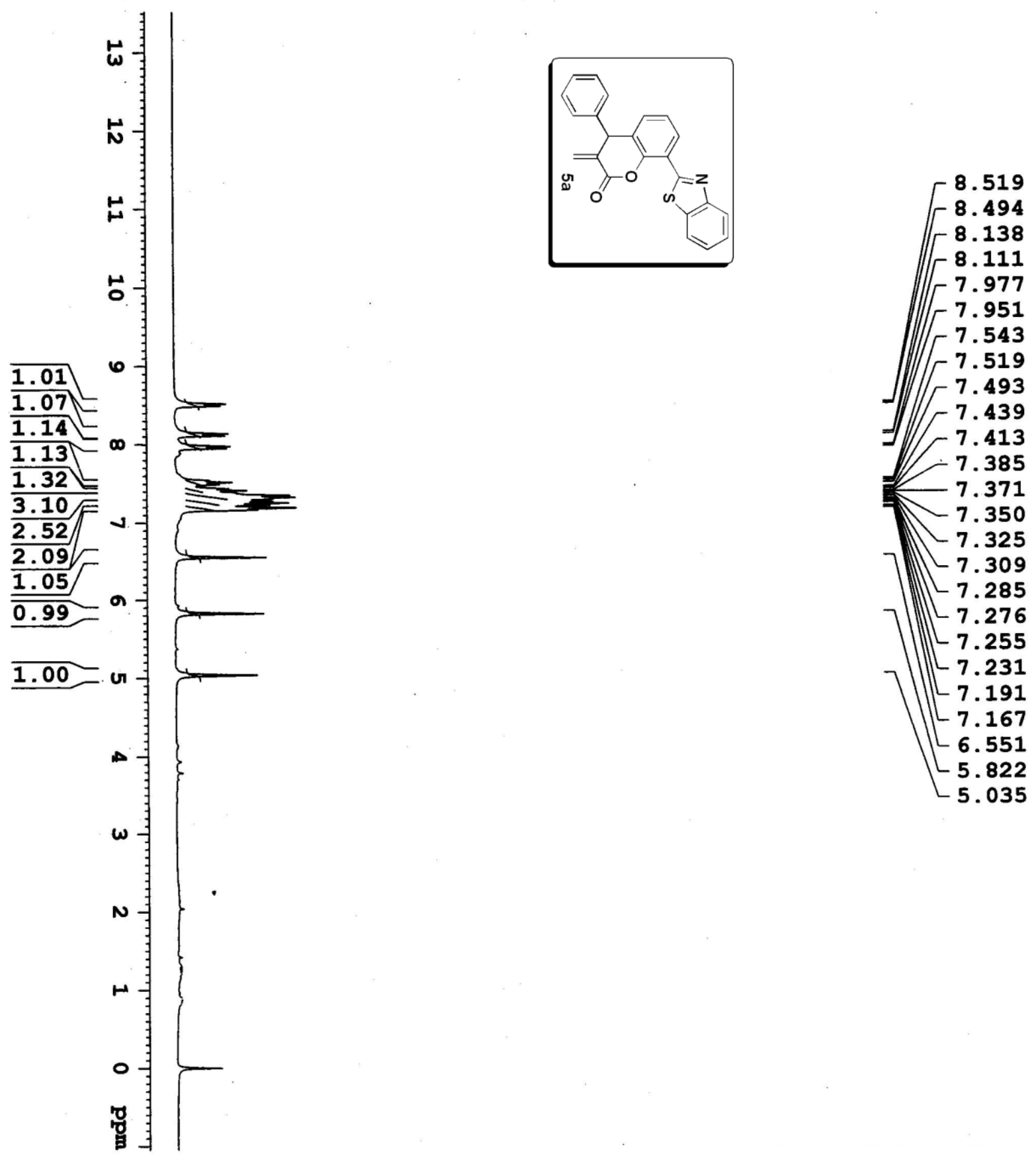


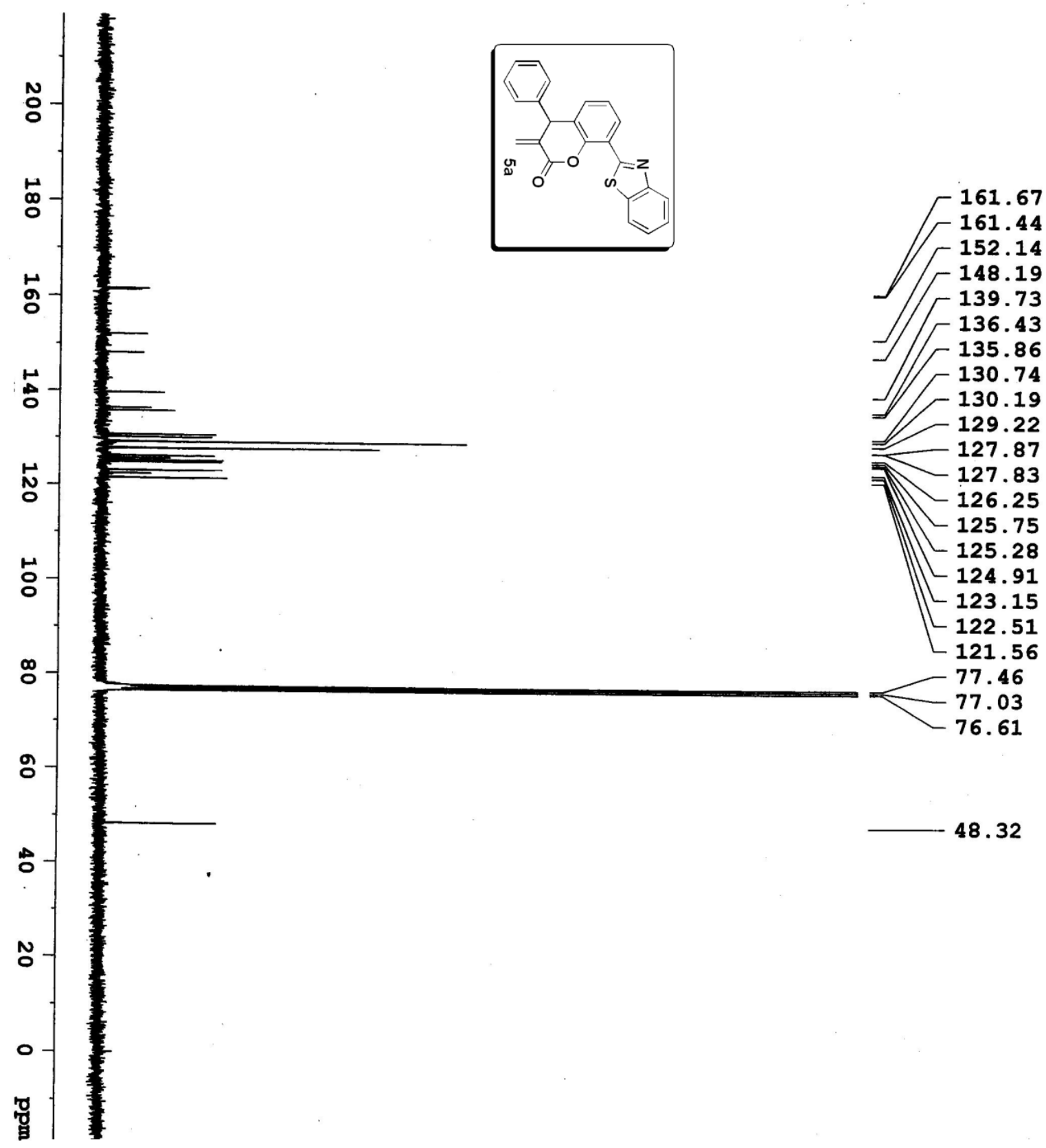




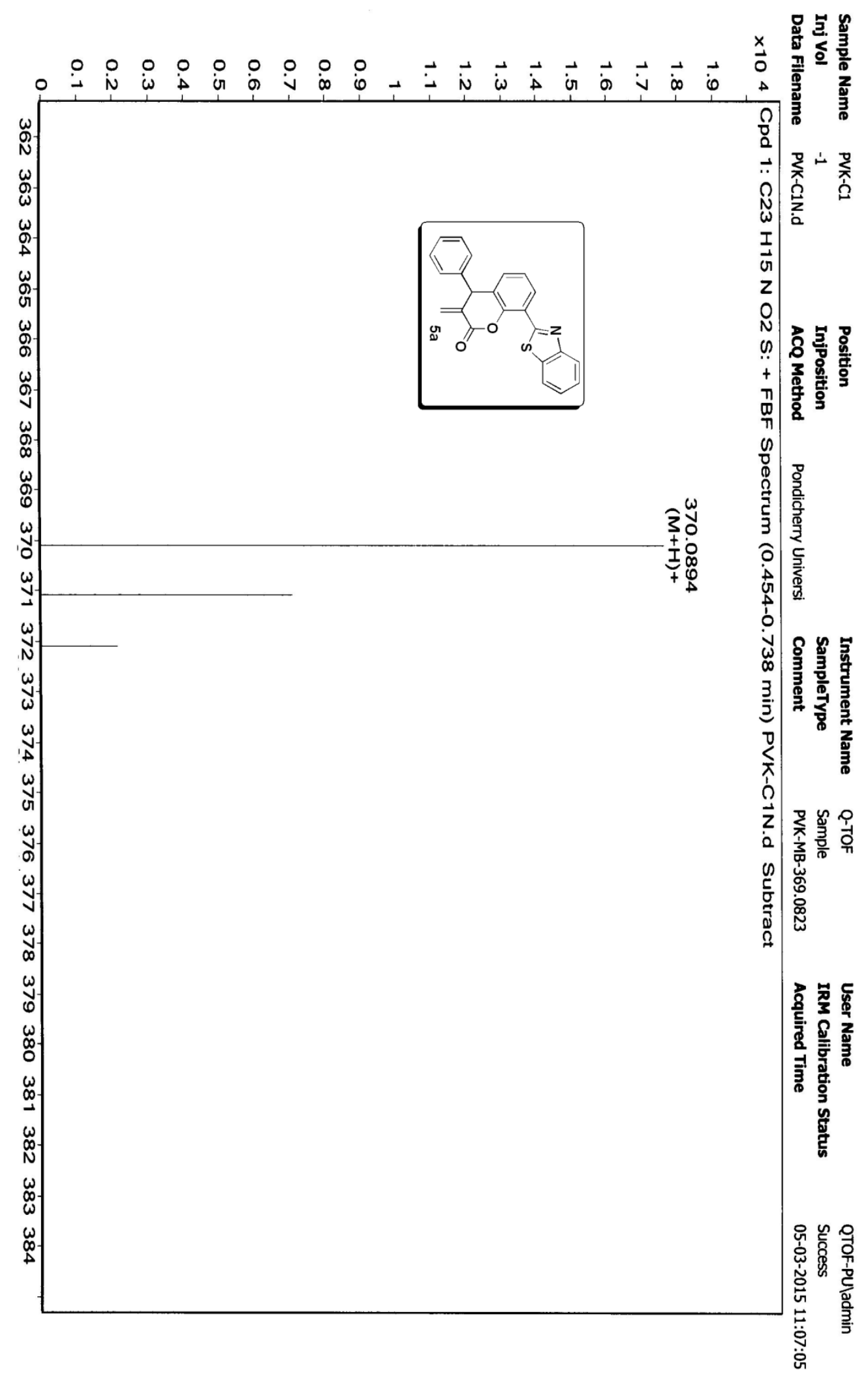




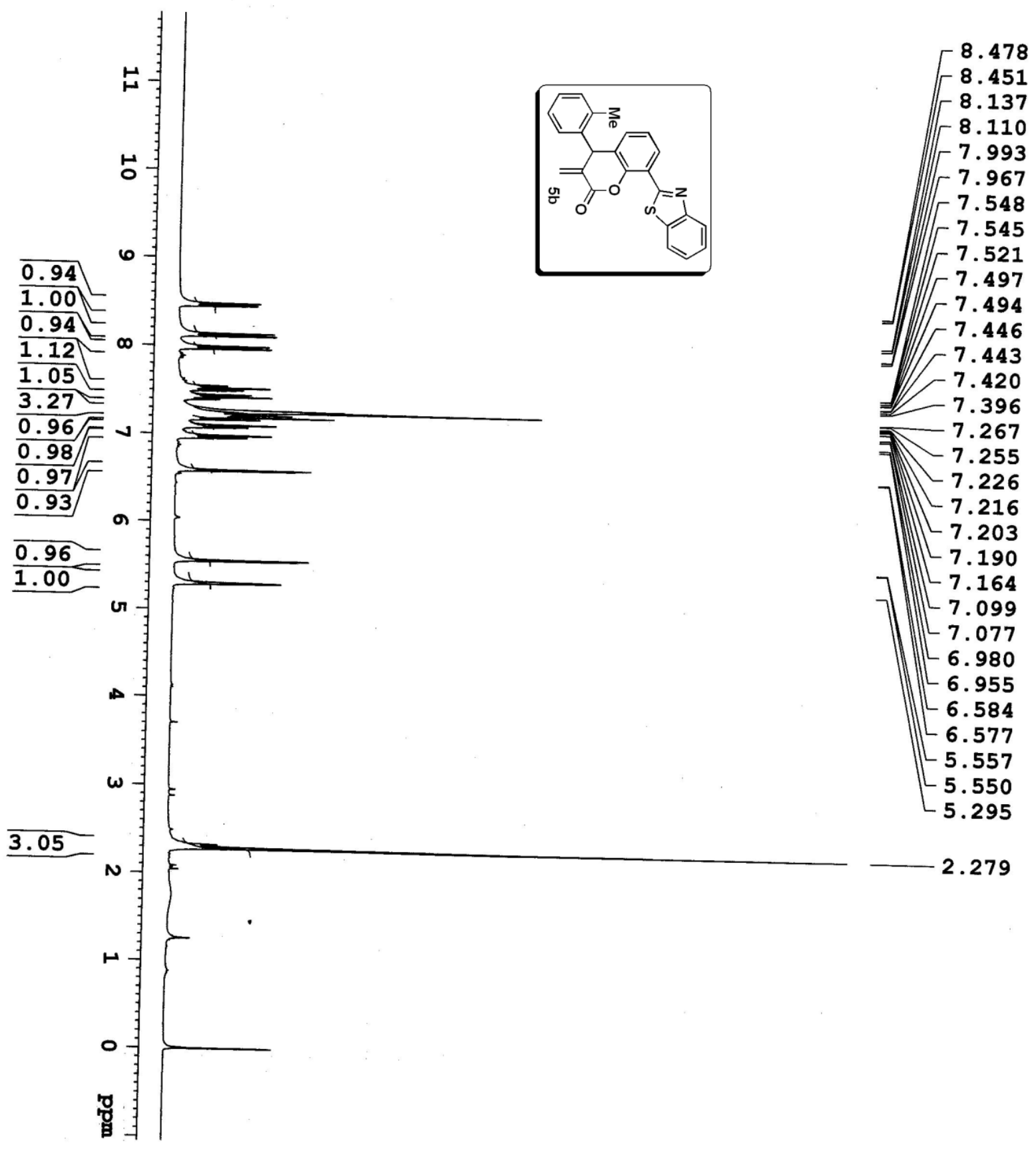



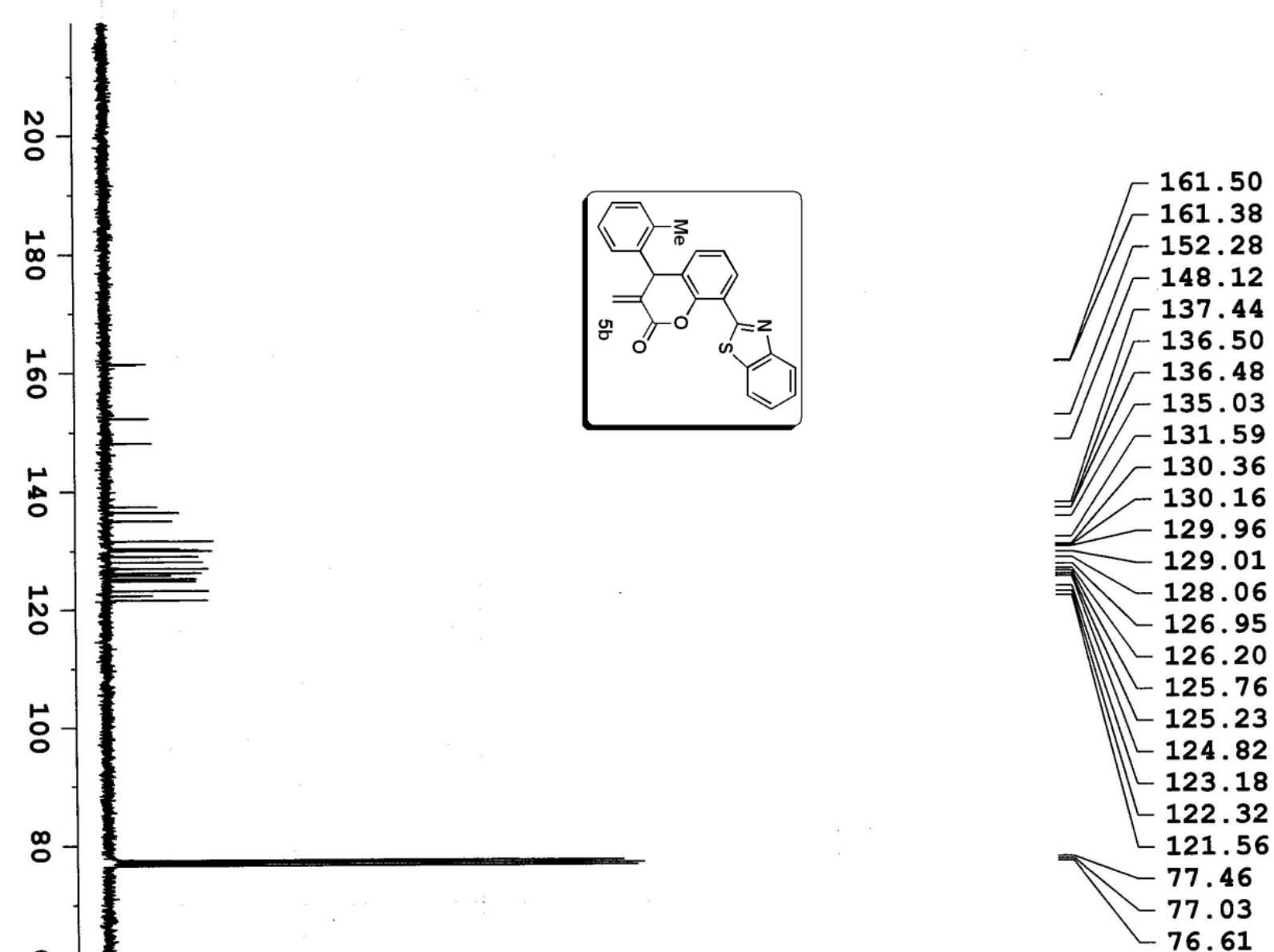

45.11

응

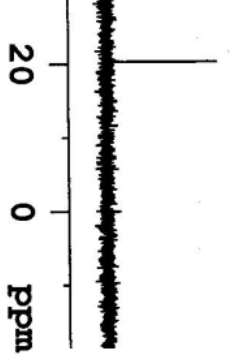

20.31 


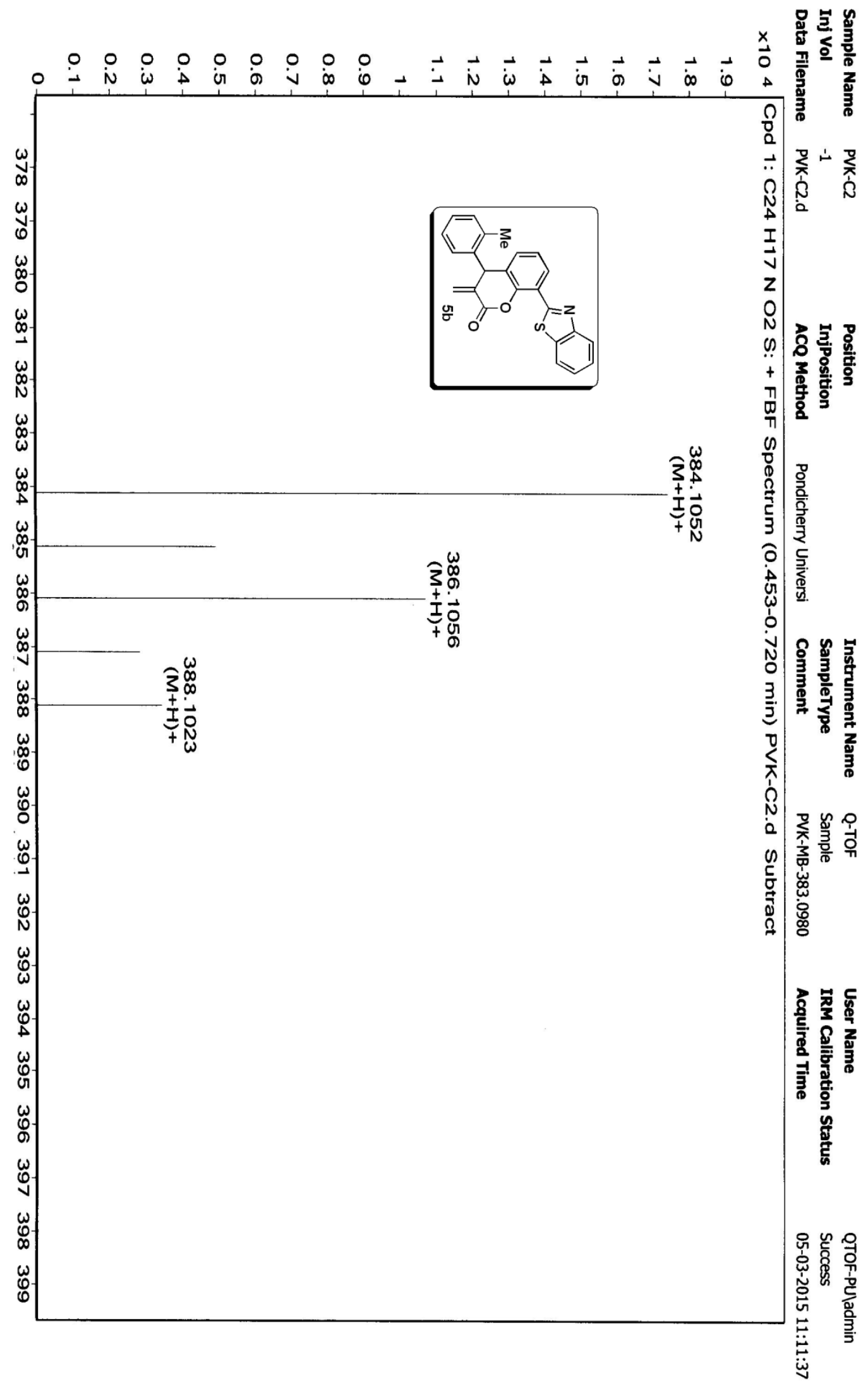



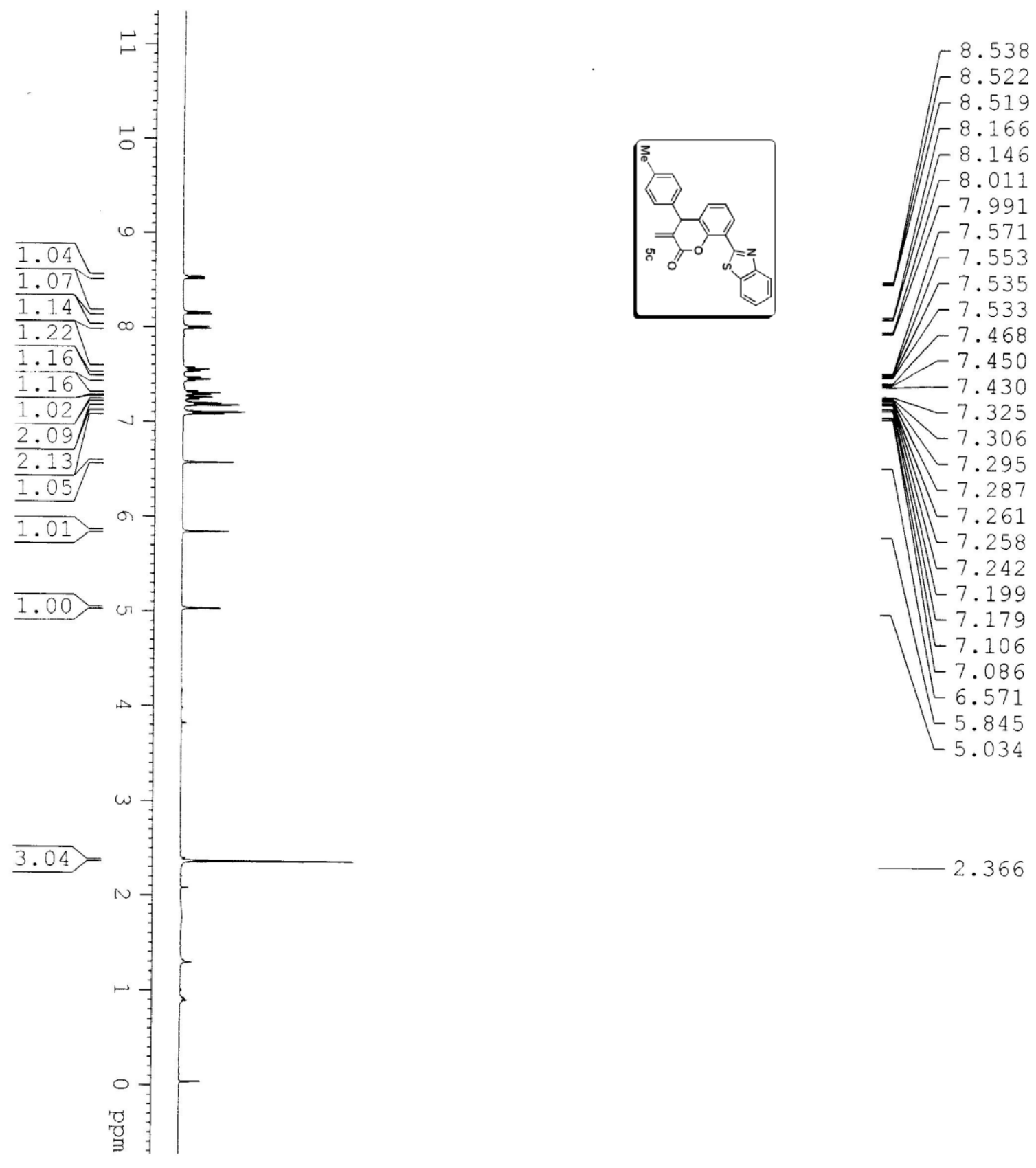

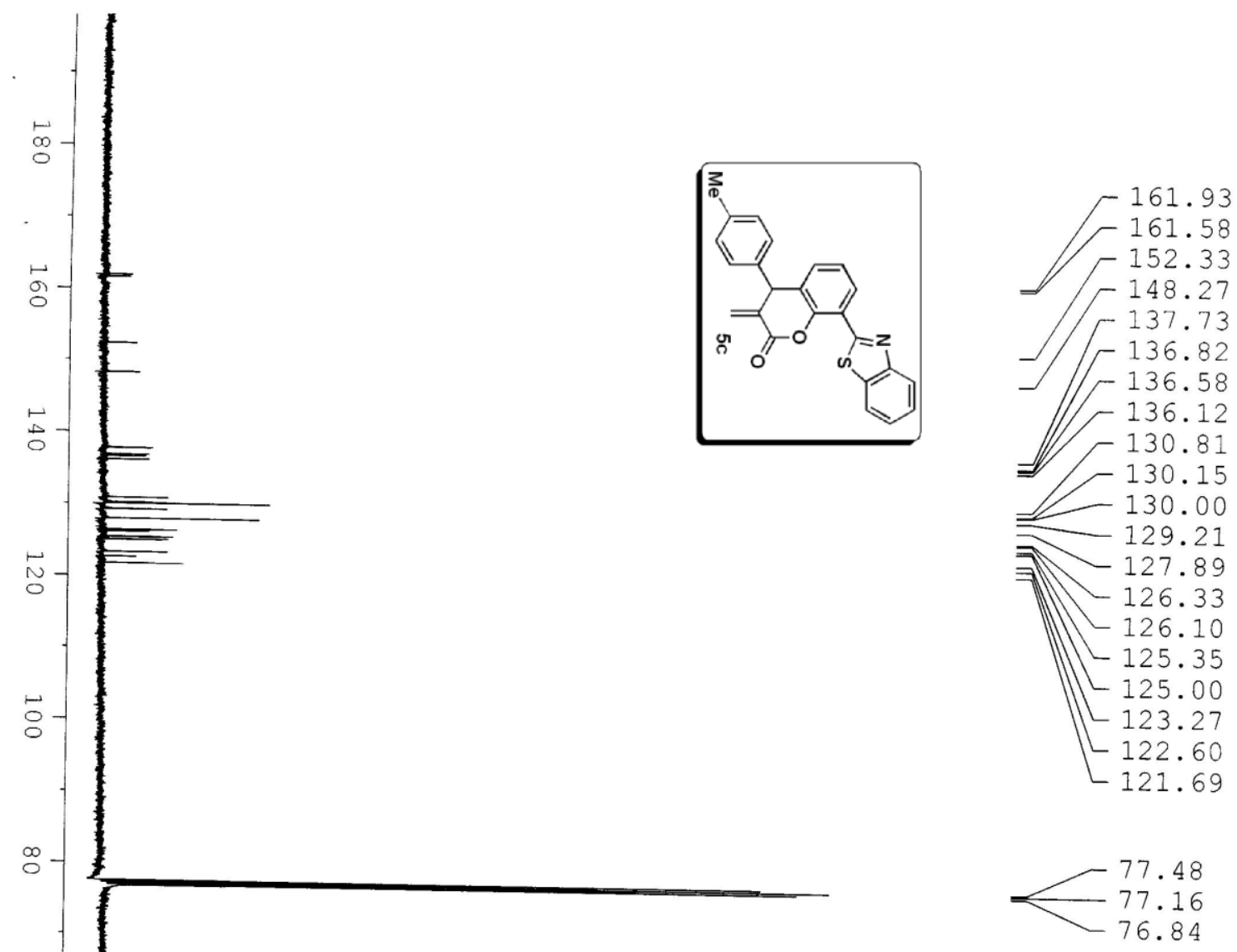

。

$\stackrel{\infty}{\circ}$

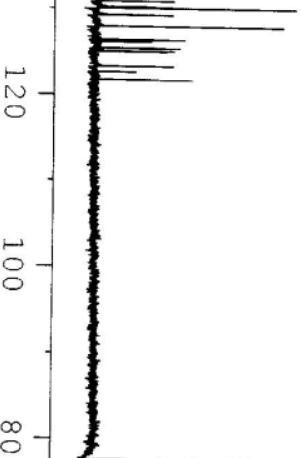




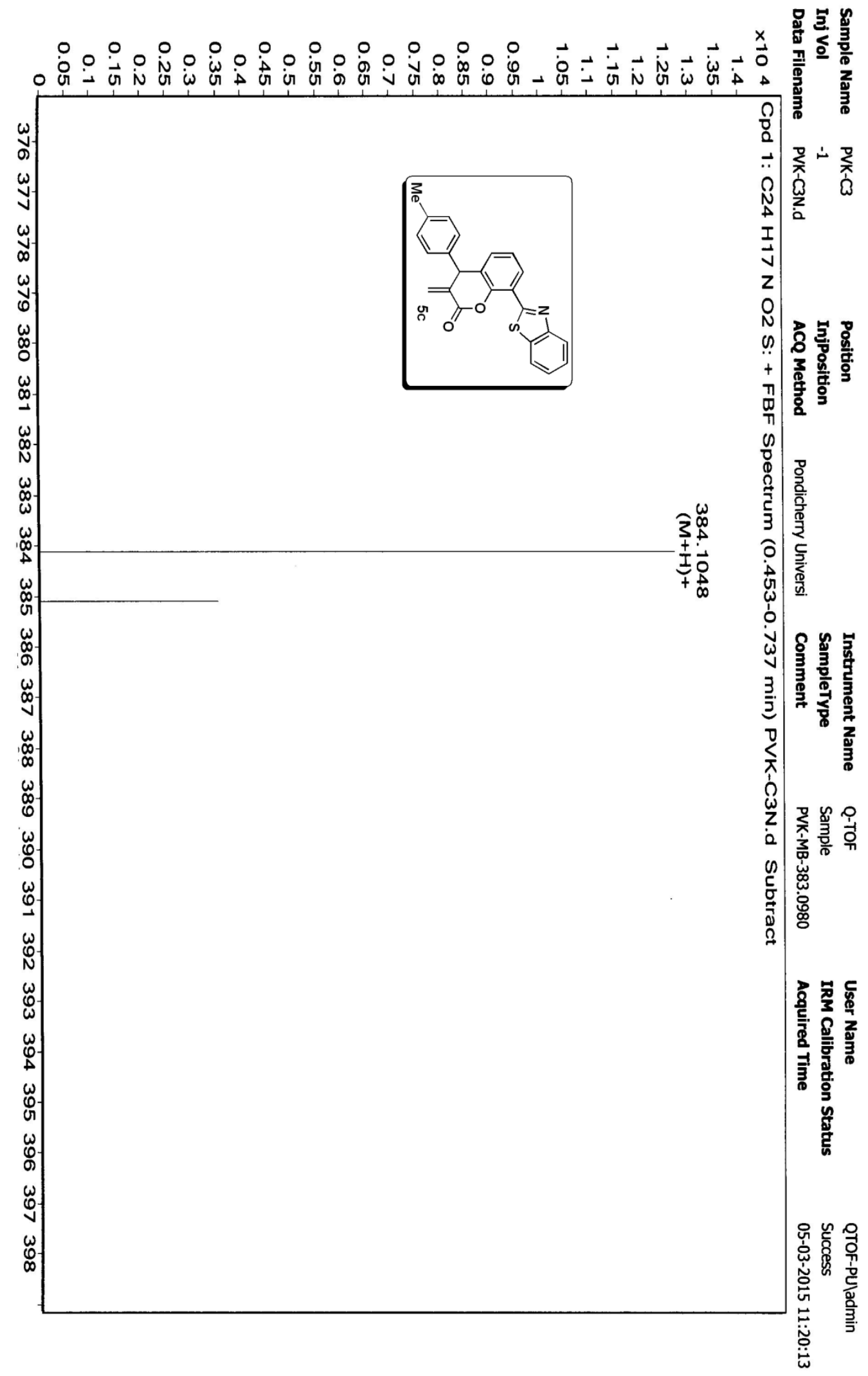



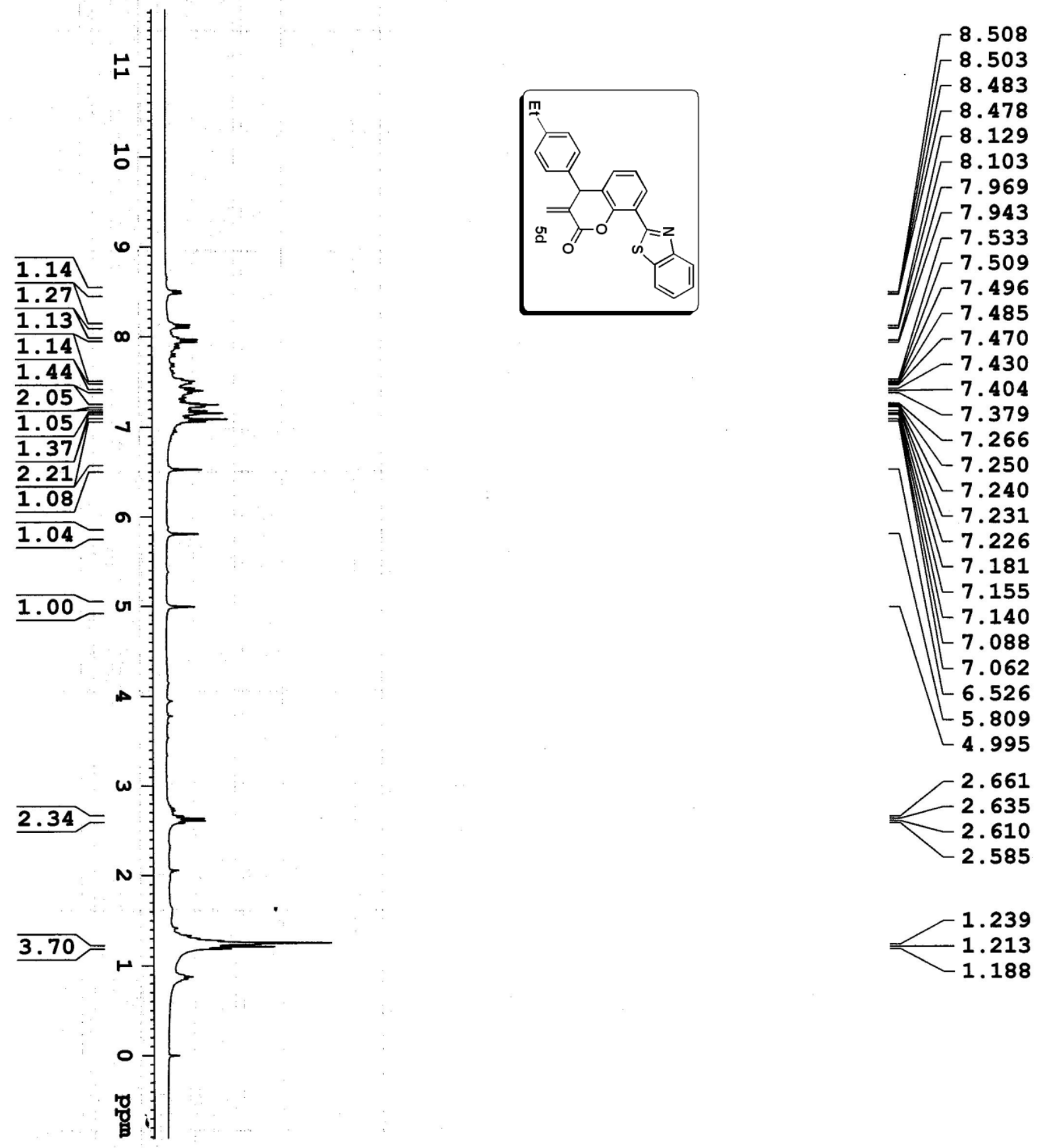


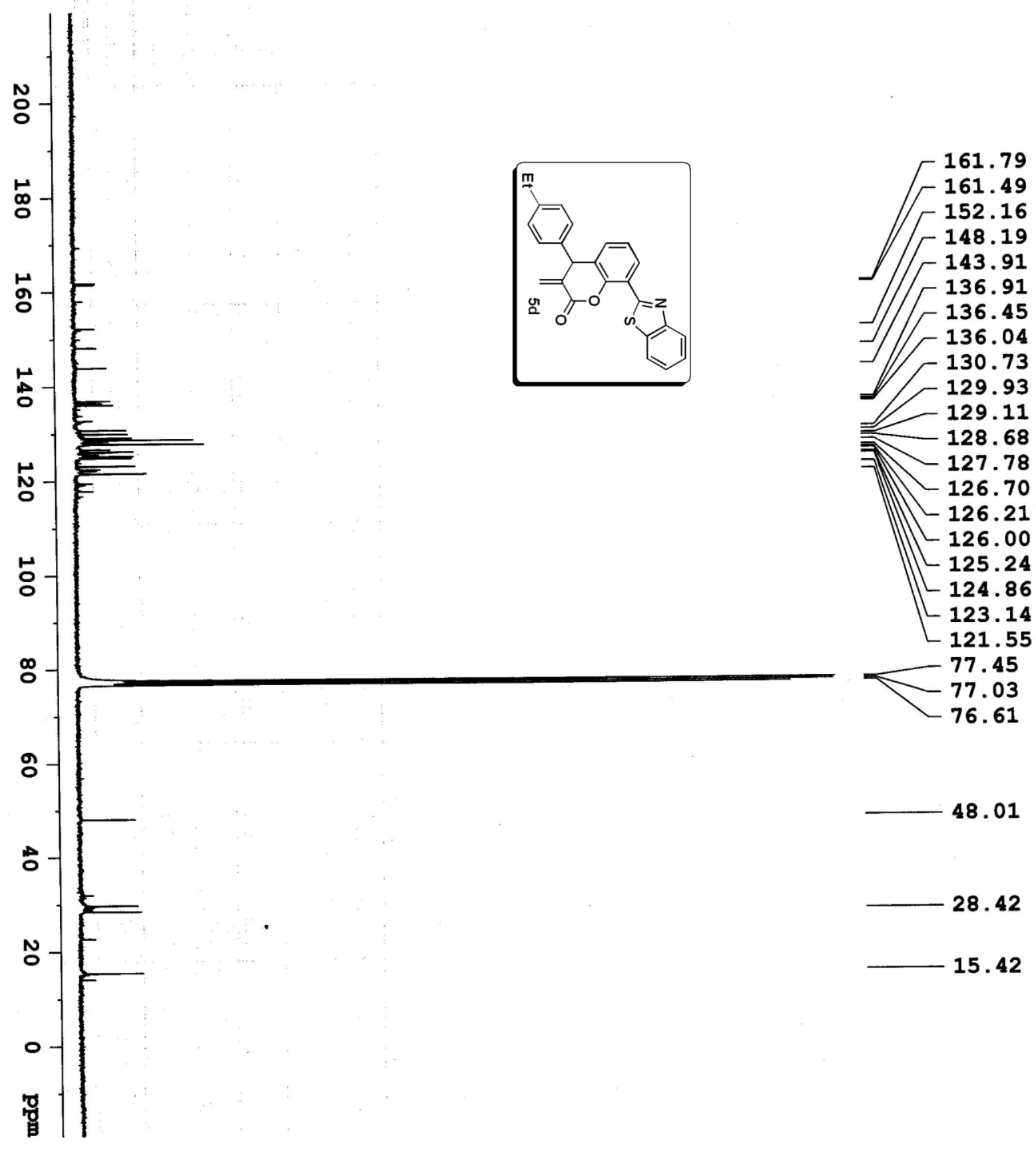




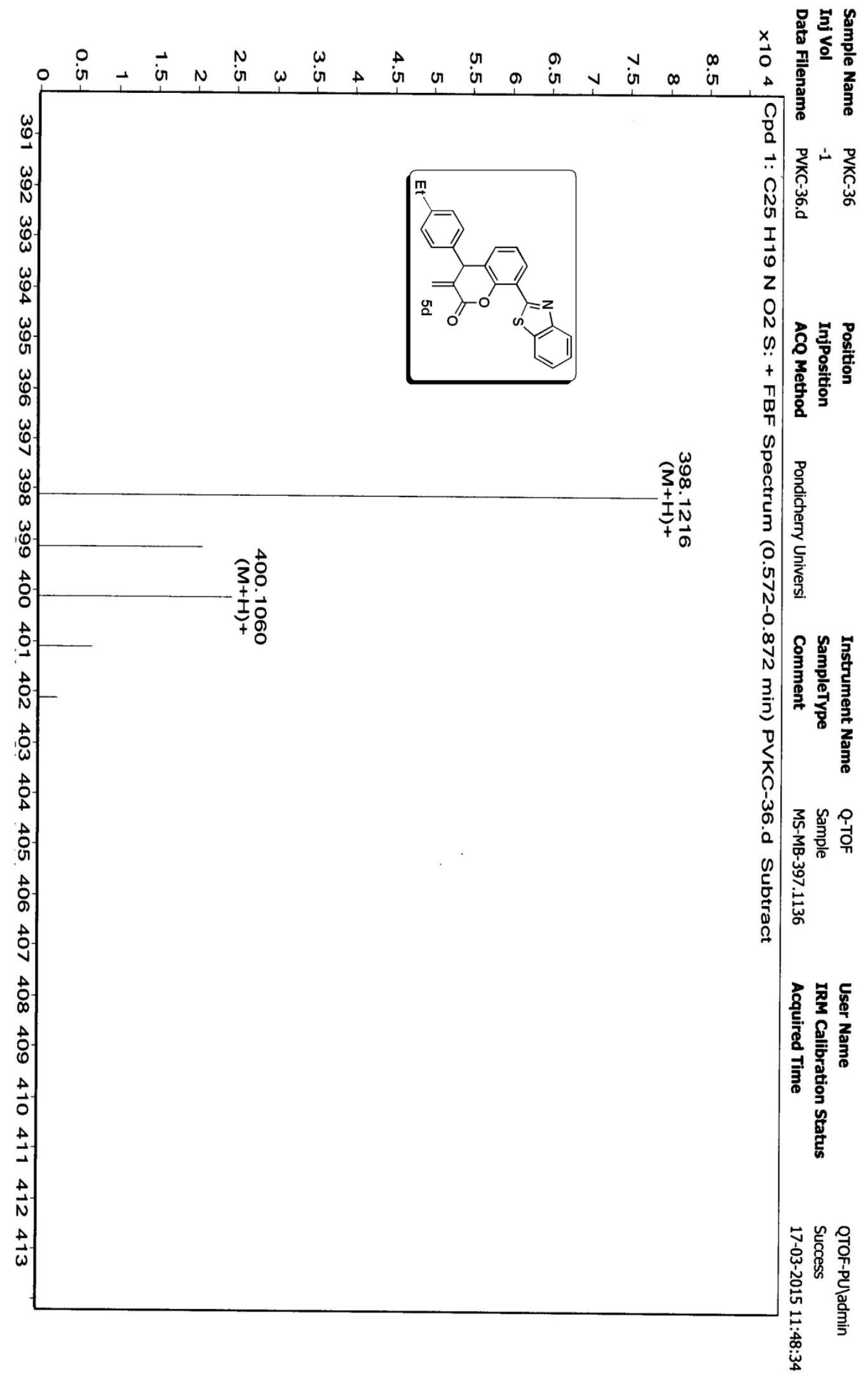



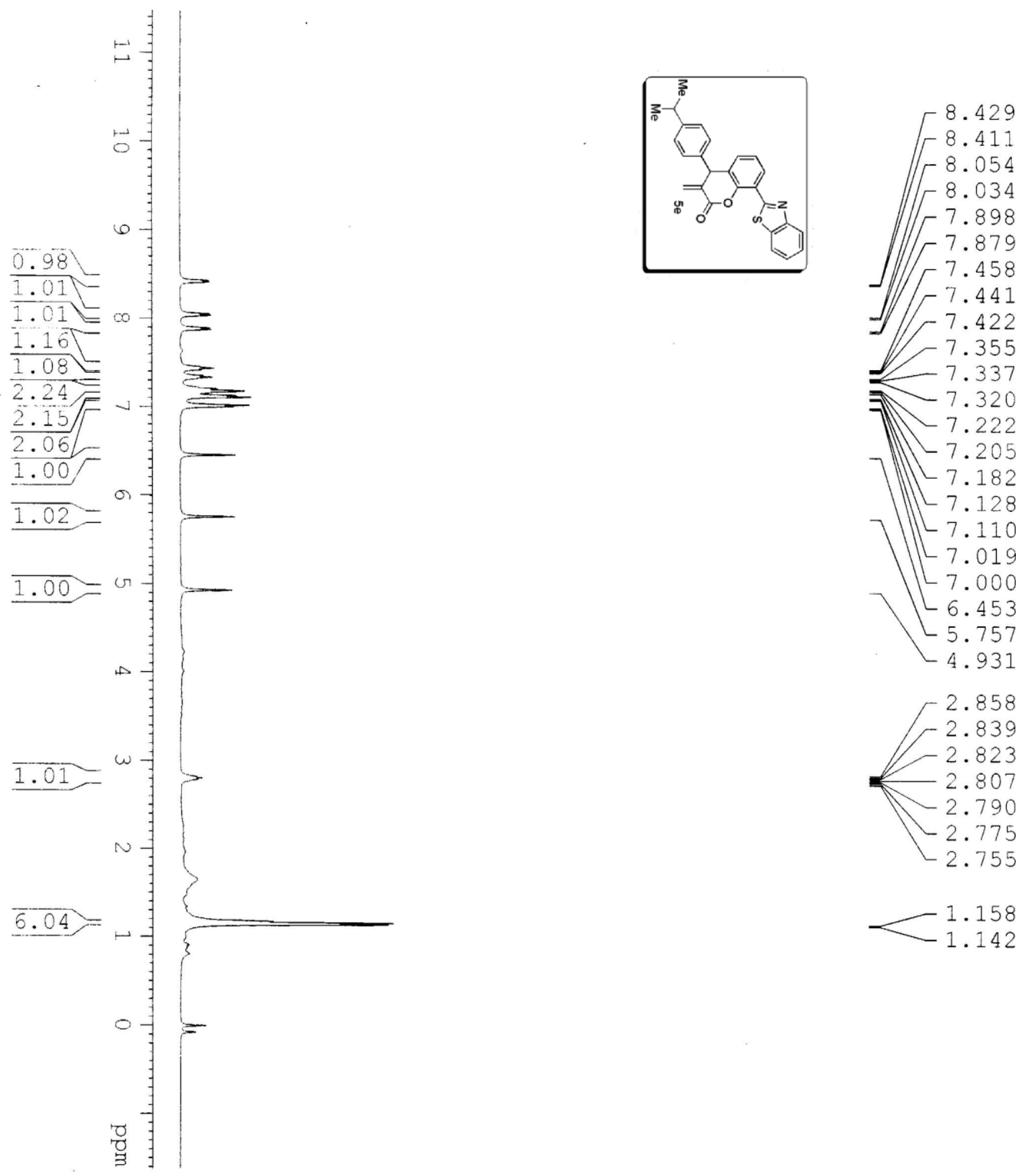

$-7.355$

$-7.337$

$\mathbb{7}-7.320$

$\mathbb{1}-7.222$

$-7.205$

$-7.182$

$-7.128$

$-7.110$

.019

$-7.000$

6.453

$-5.757$

$-4.931$

$-2.858$

$-2.839$

$-2.823$

2.807

$-2.790$

$-2.775$

$-2.755$

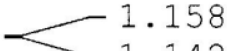

1.142 


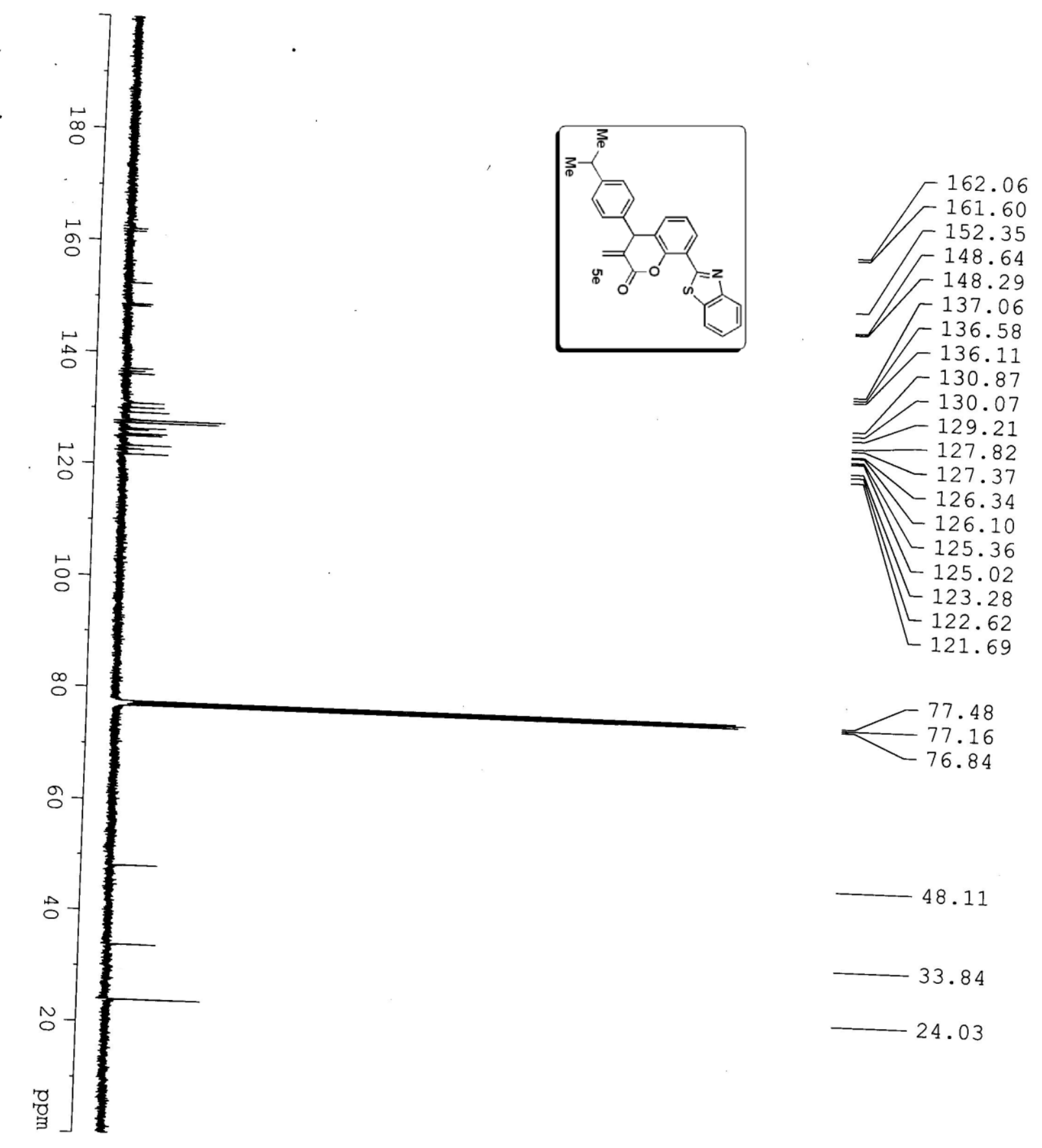




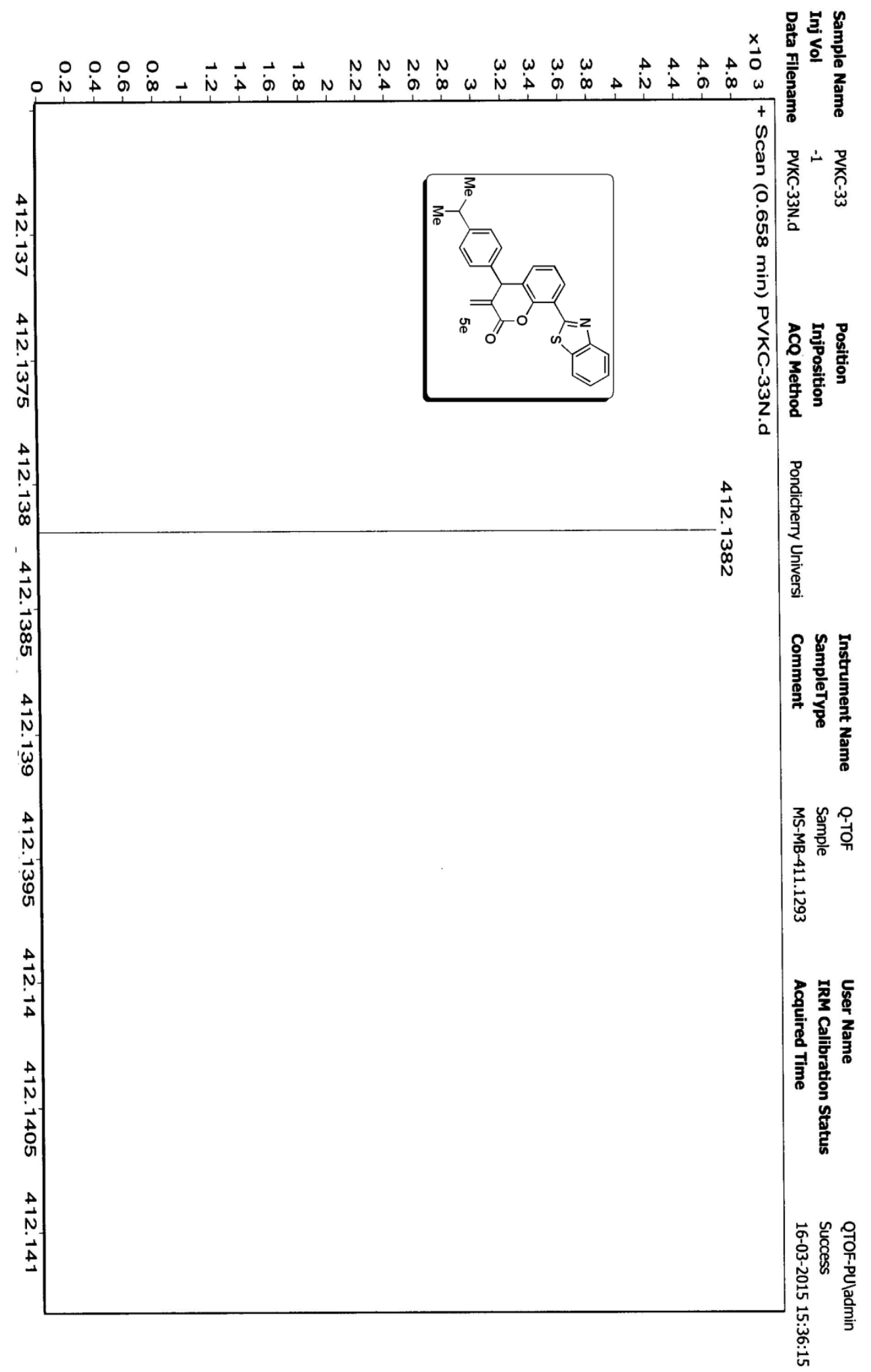




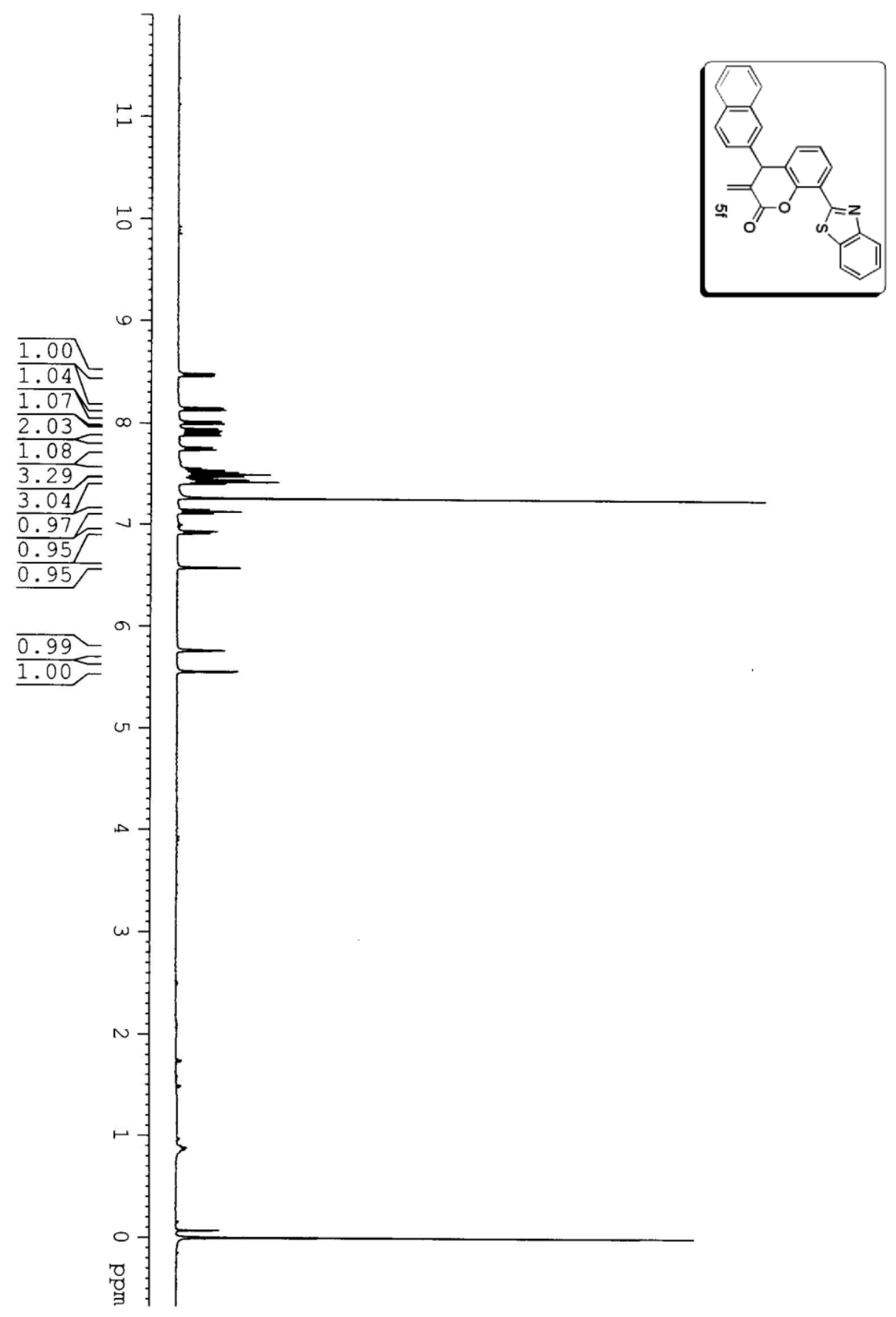




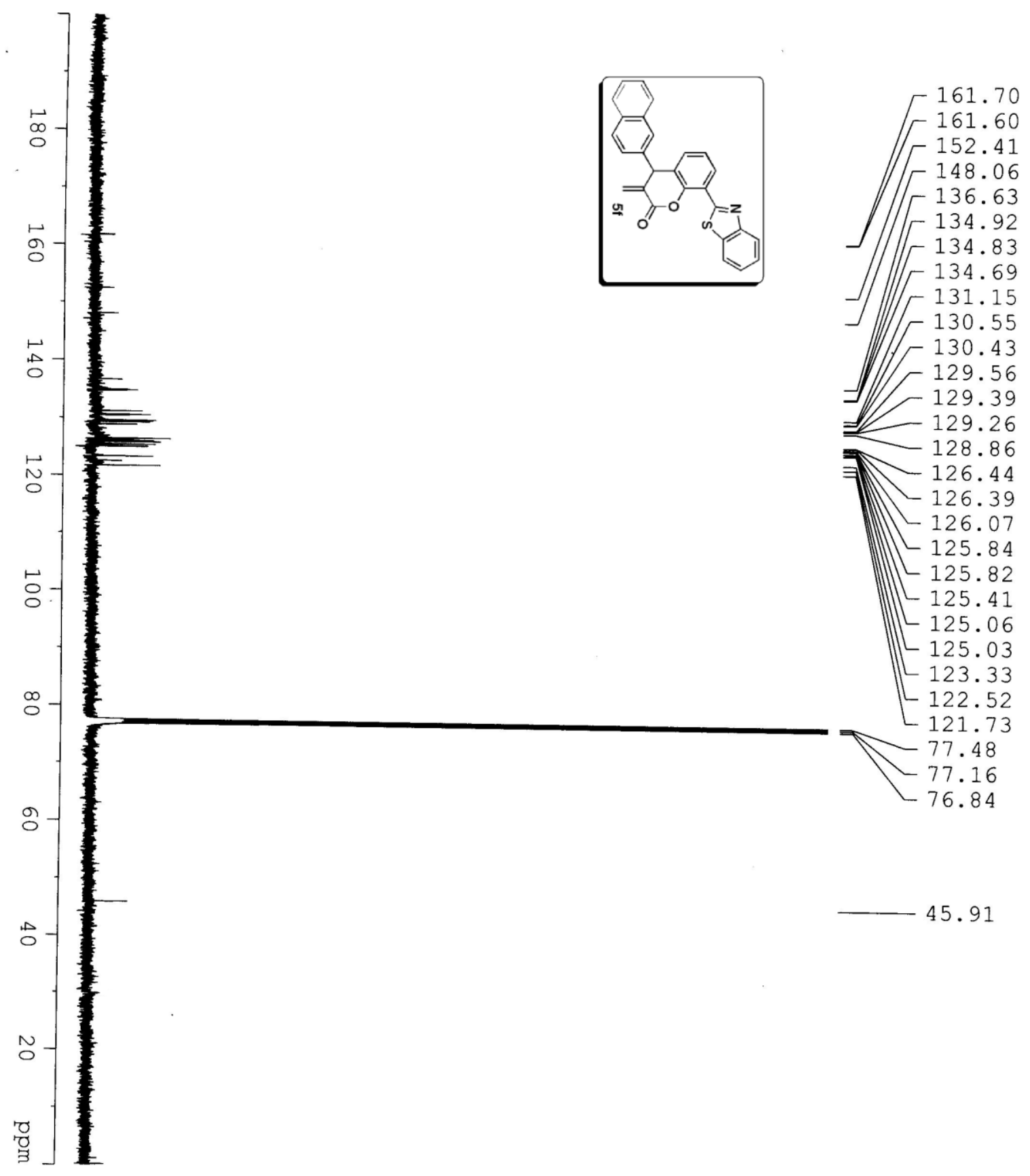




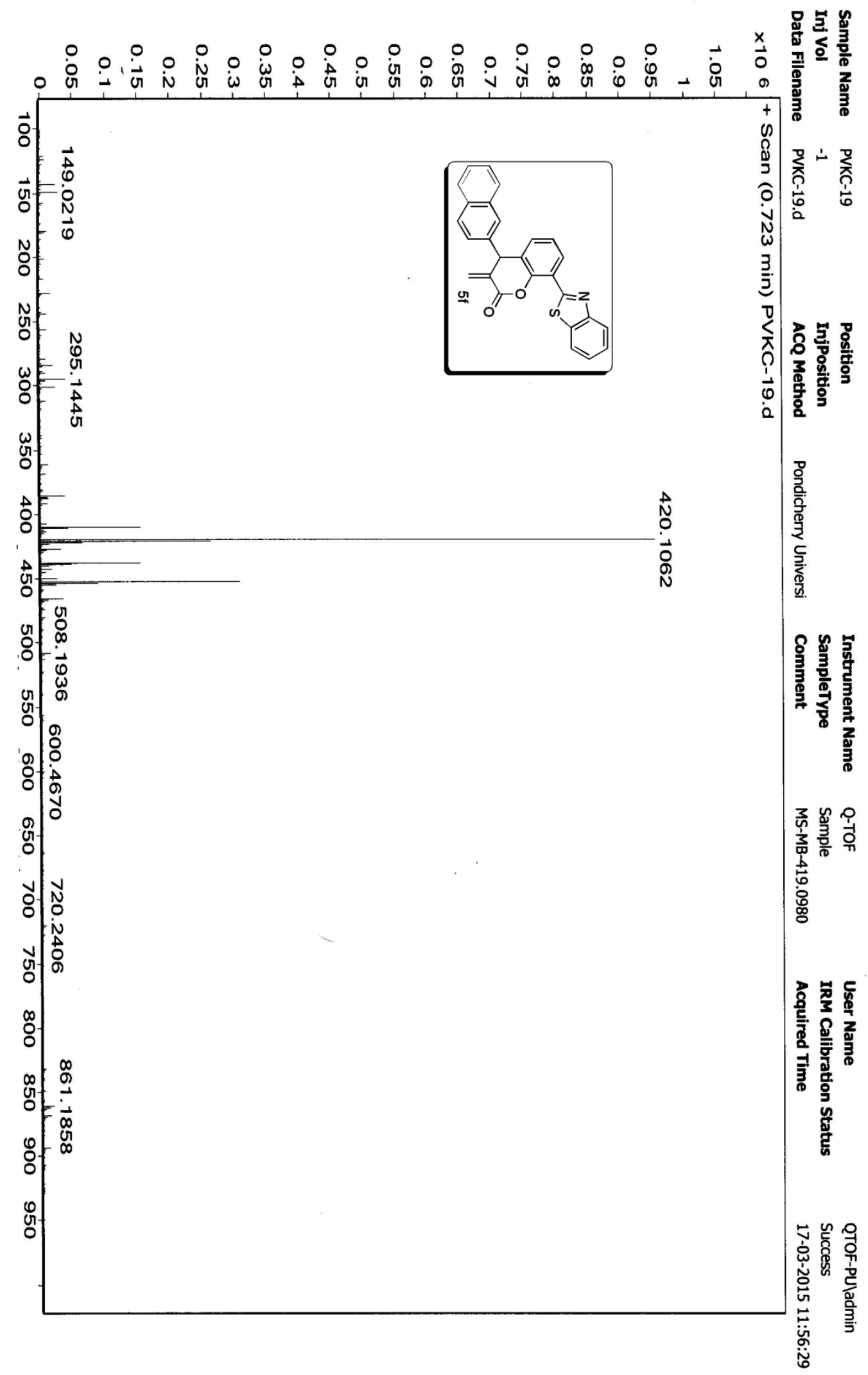



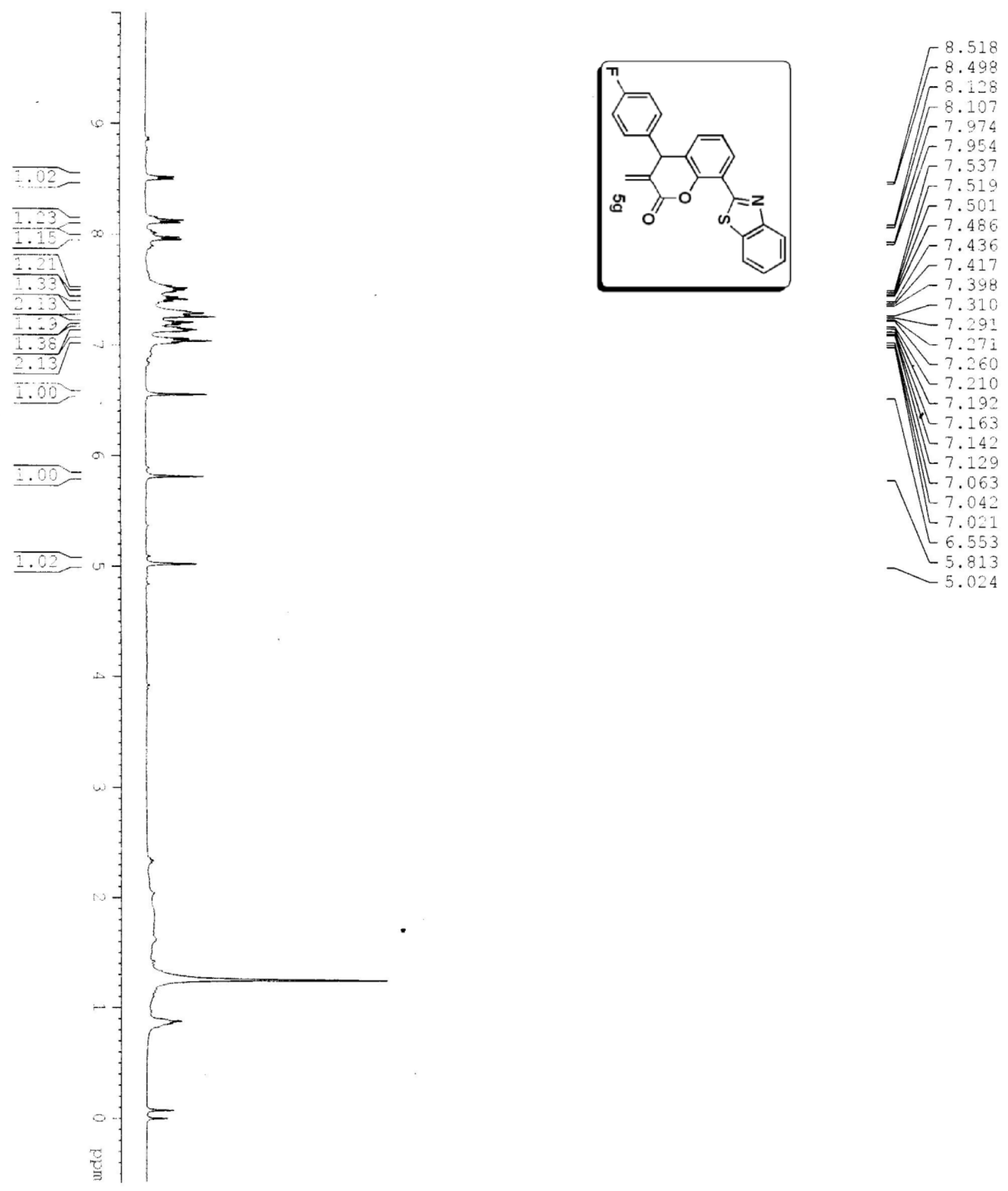


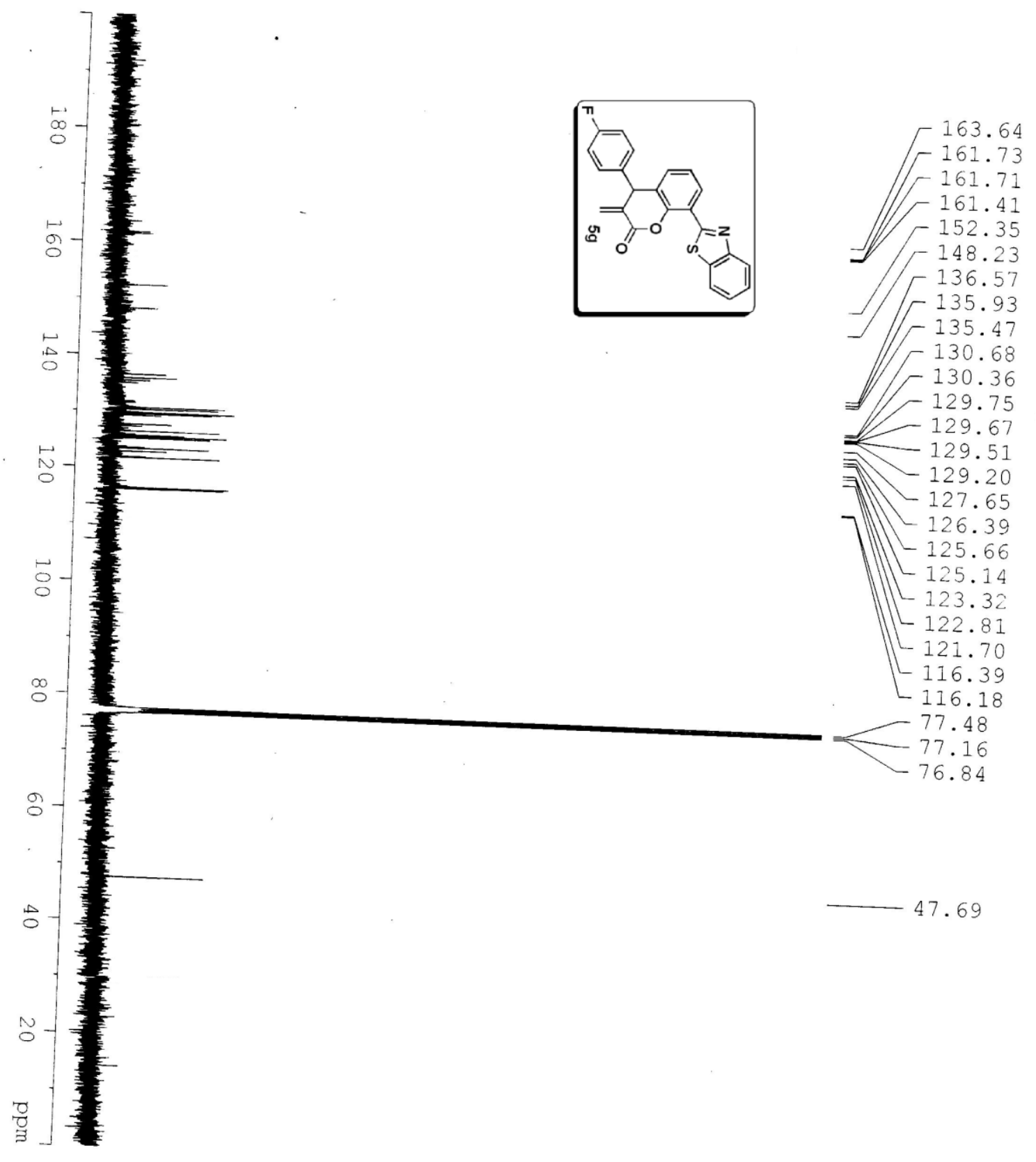




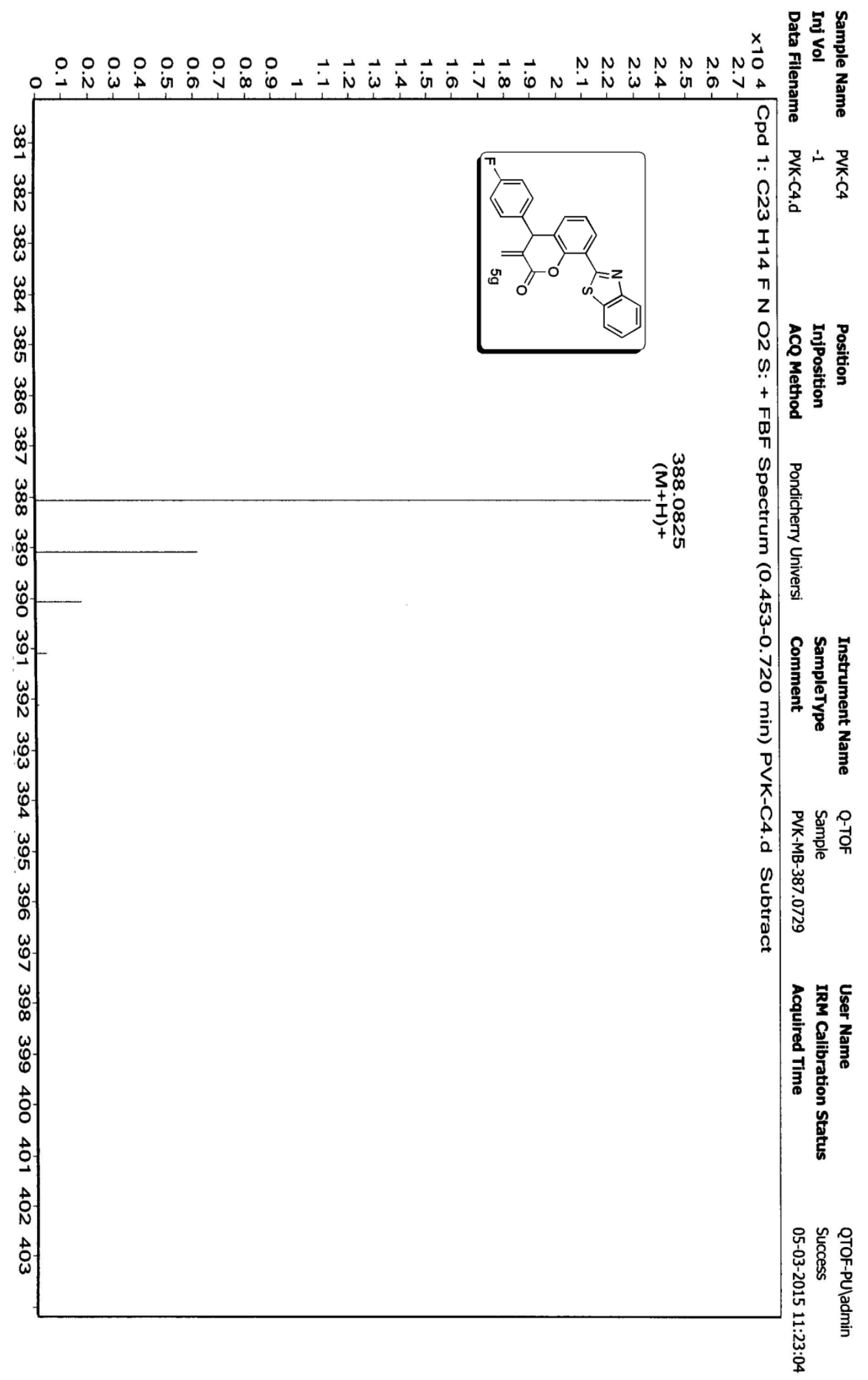



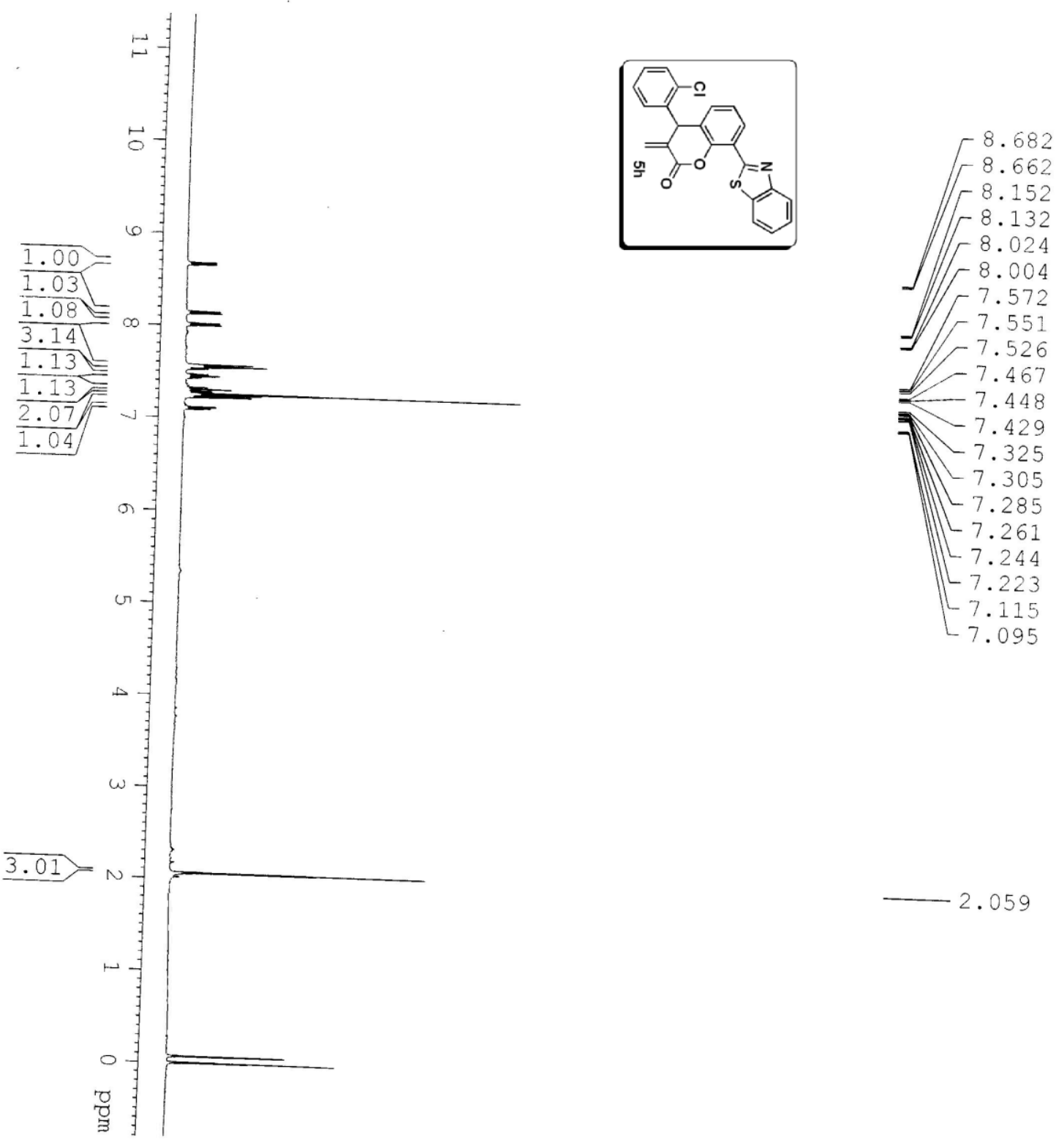


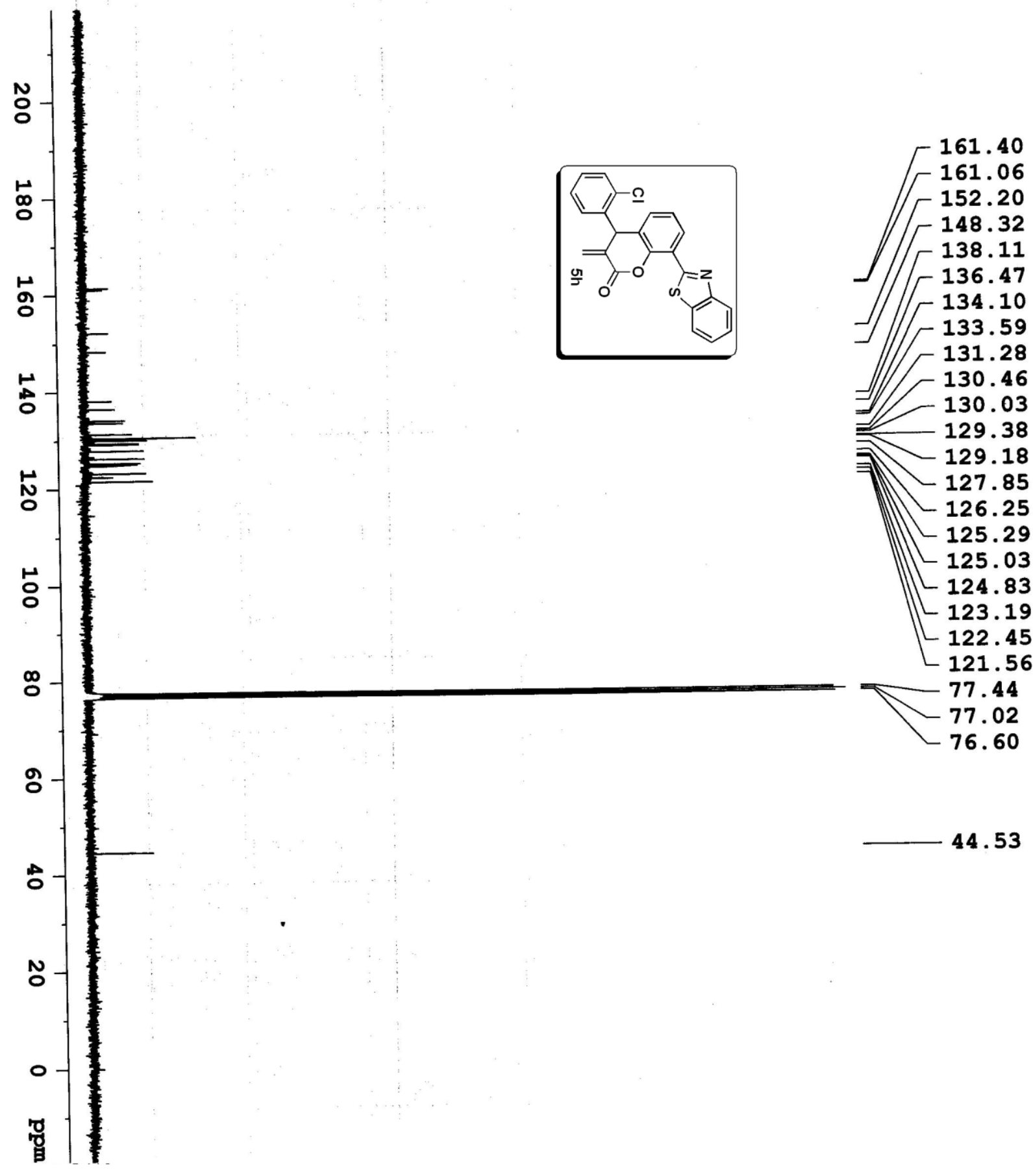




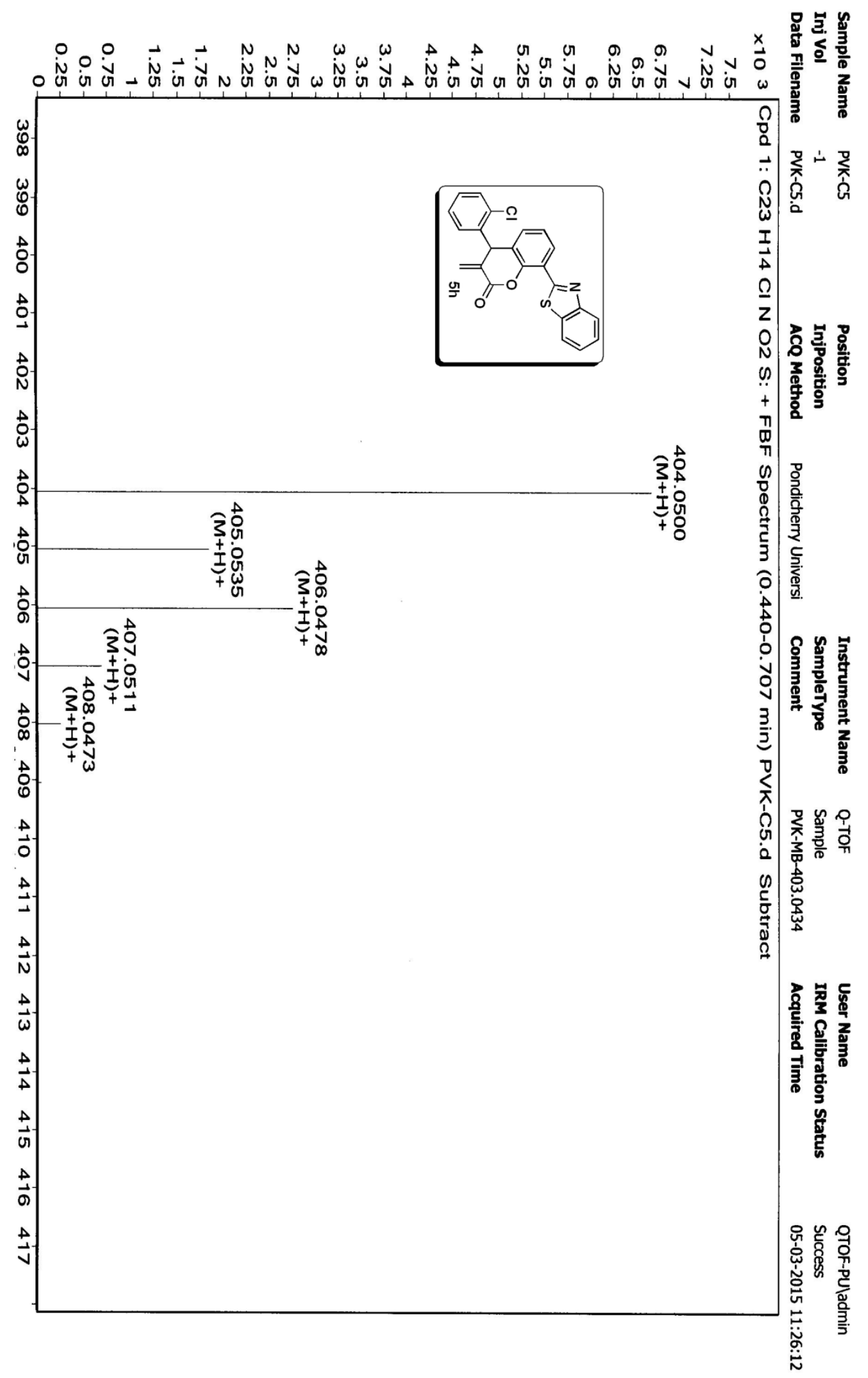



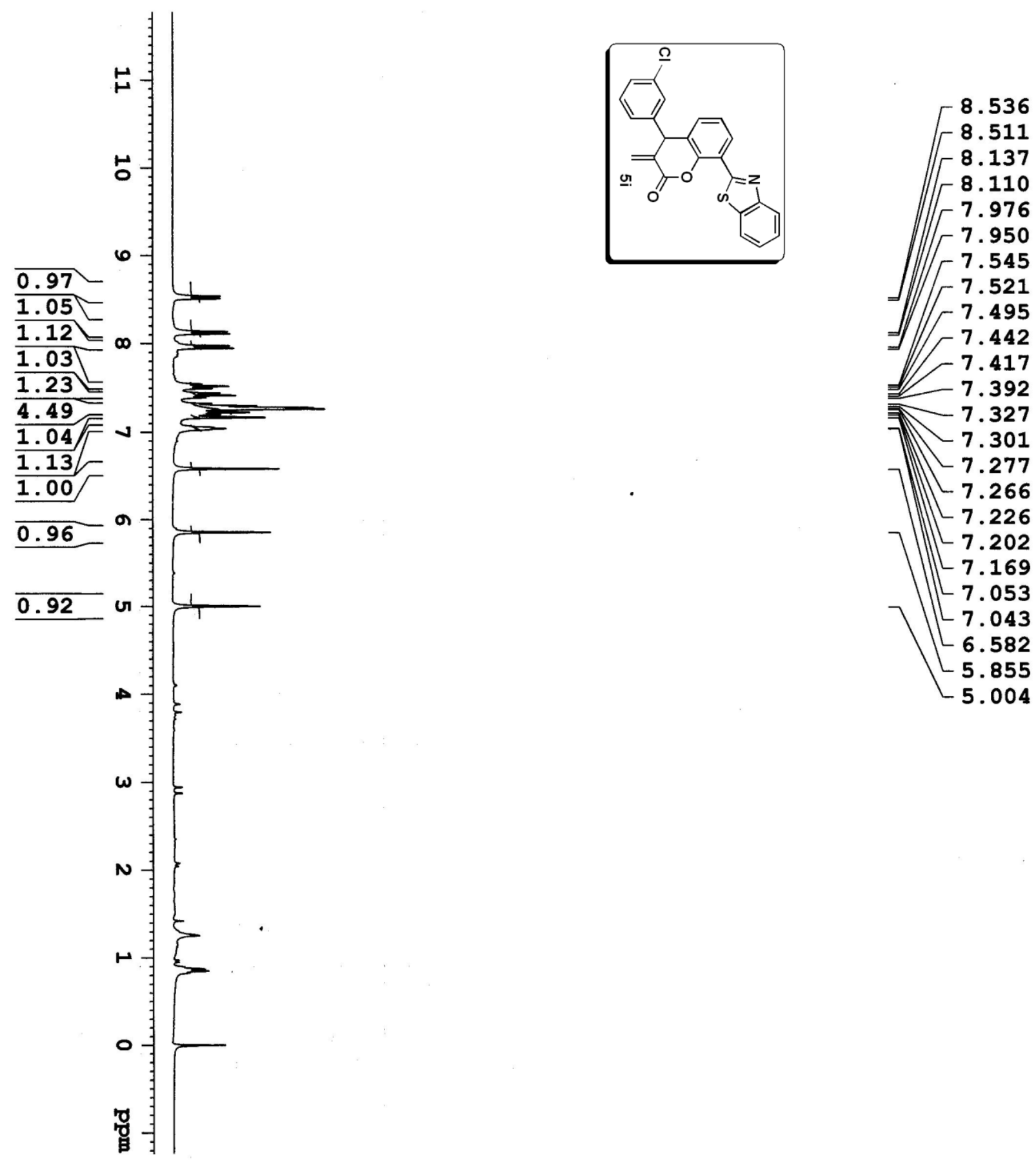


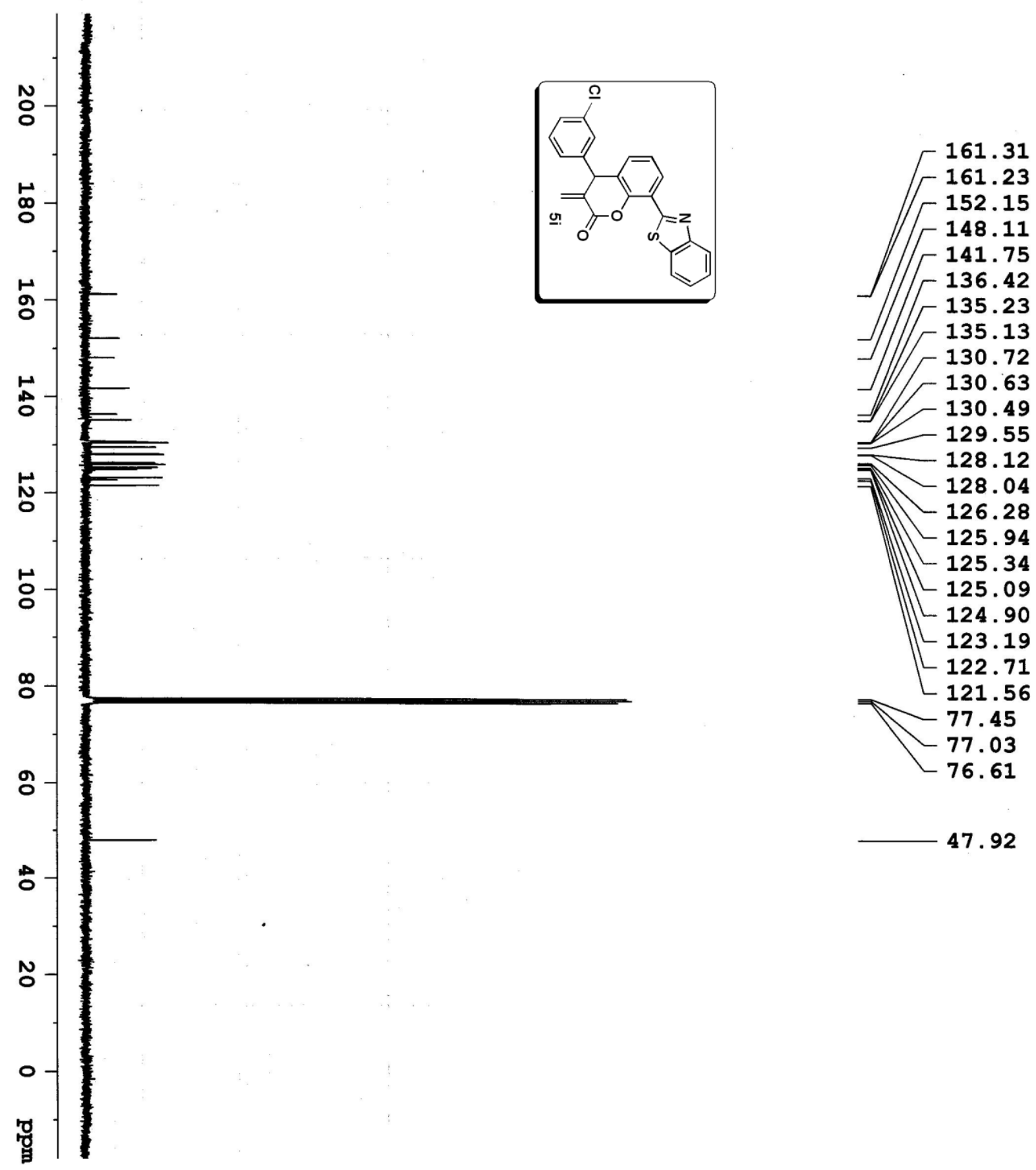




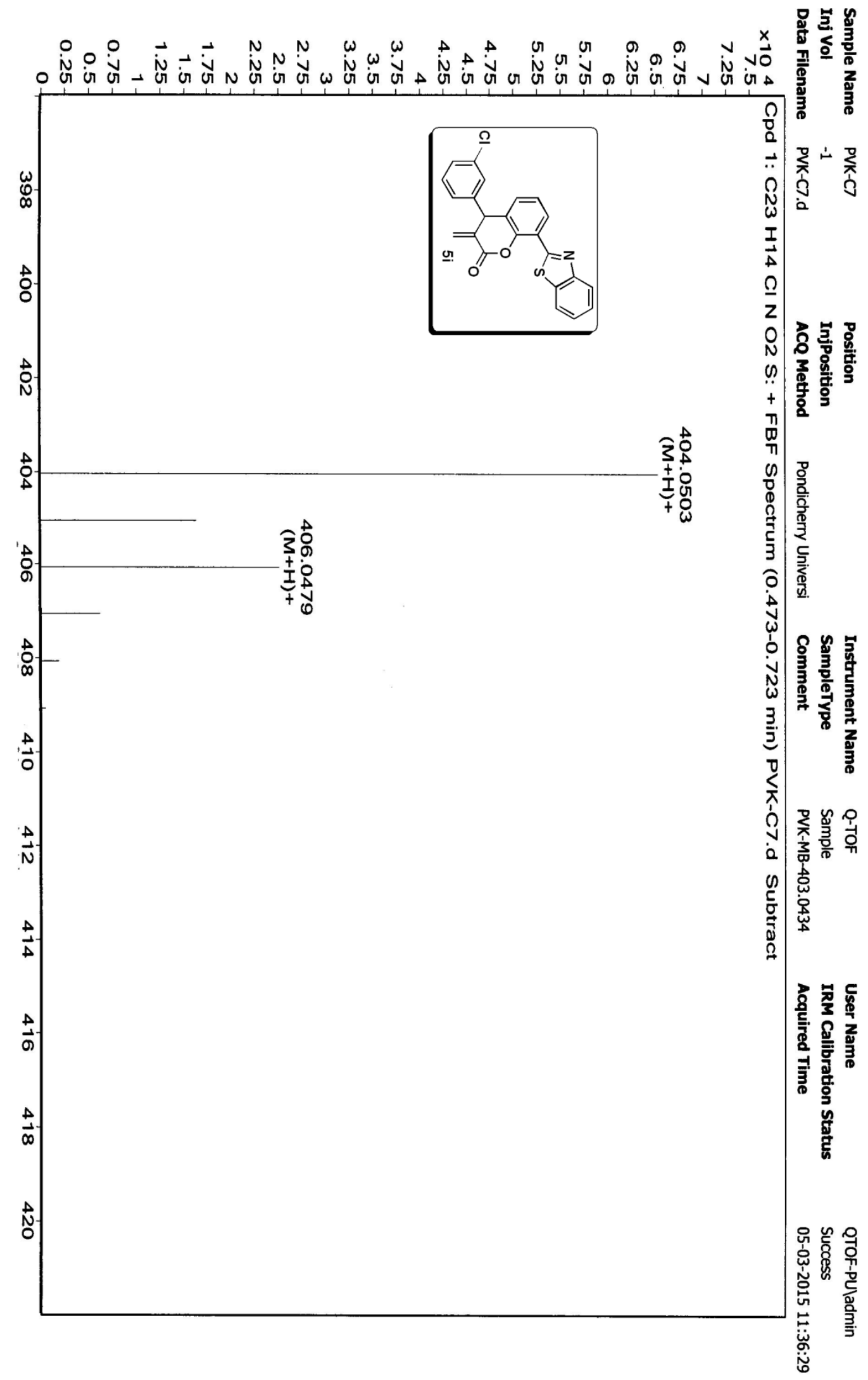



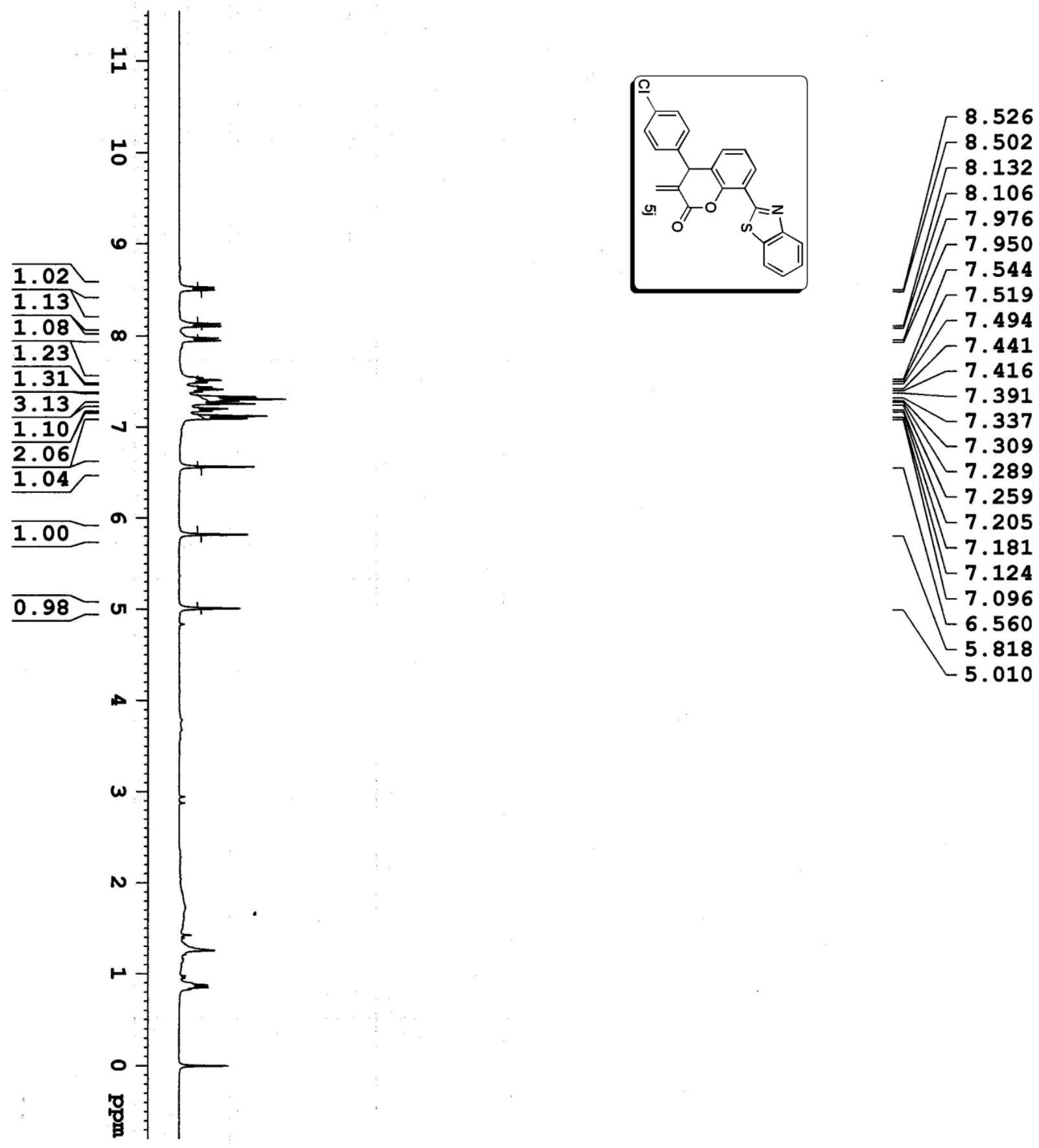

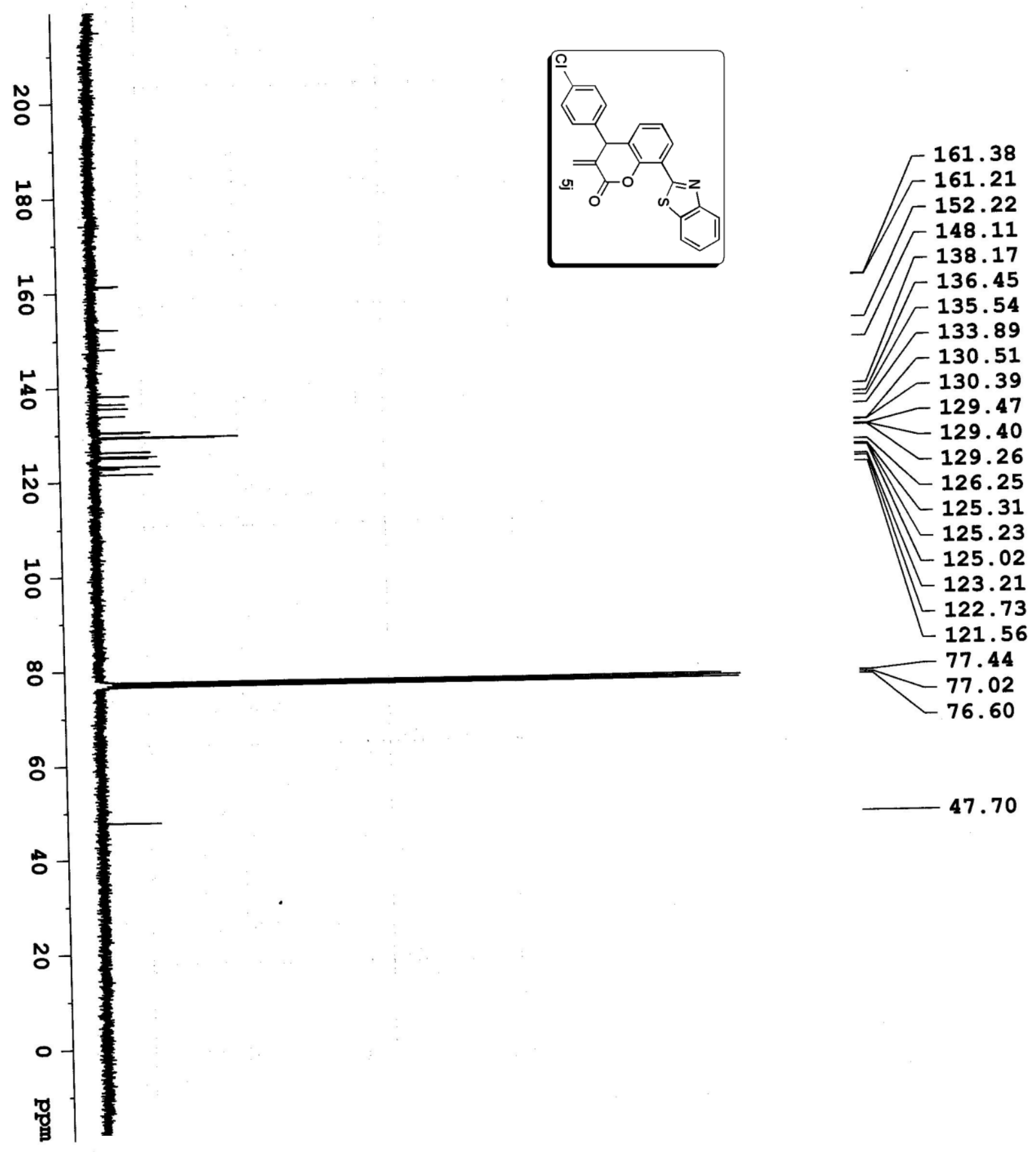


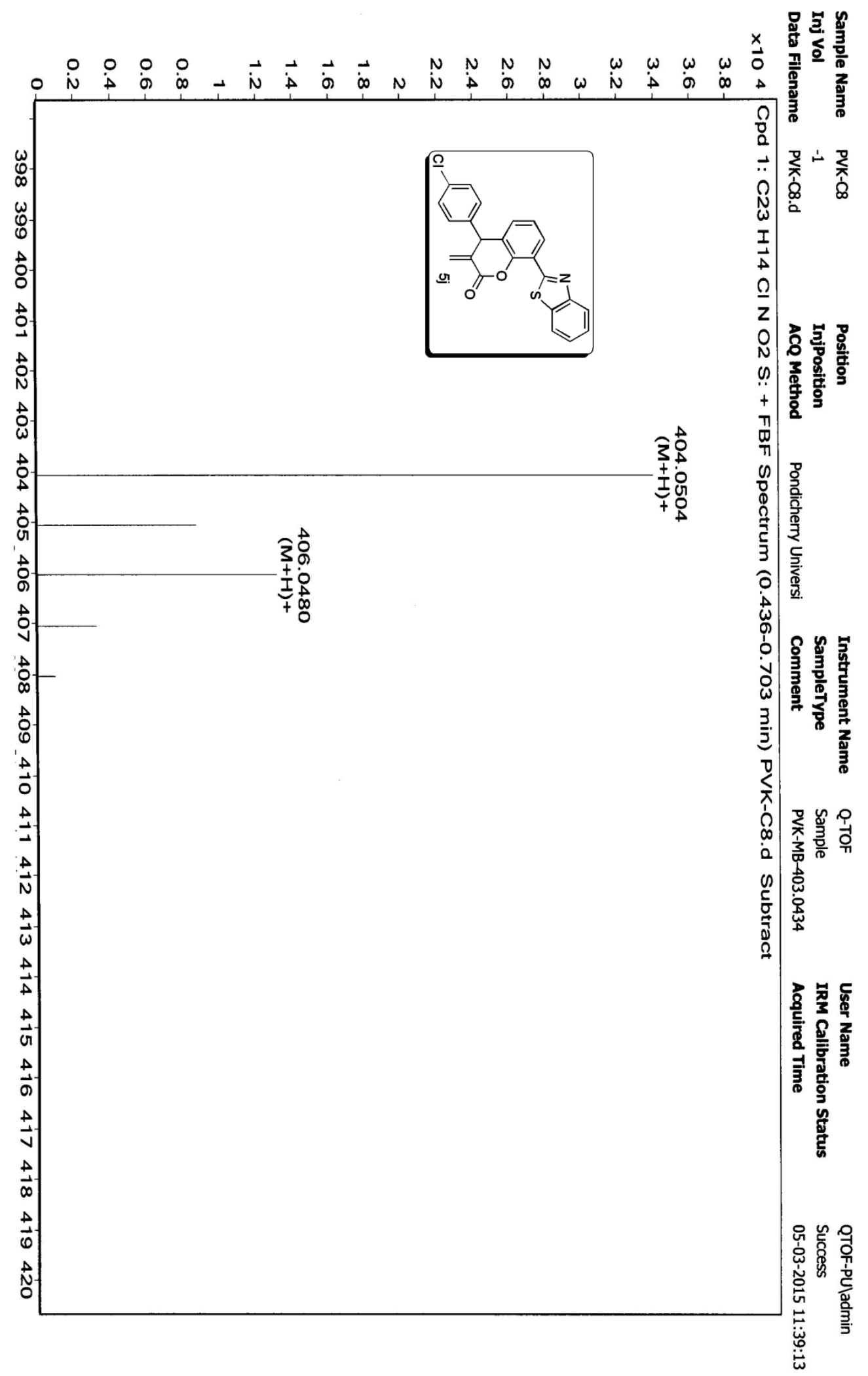



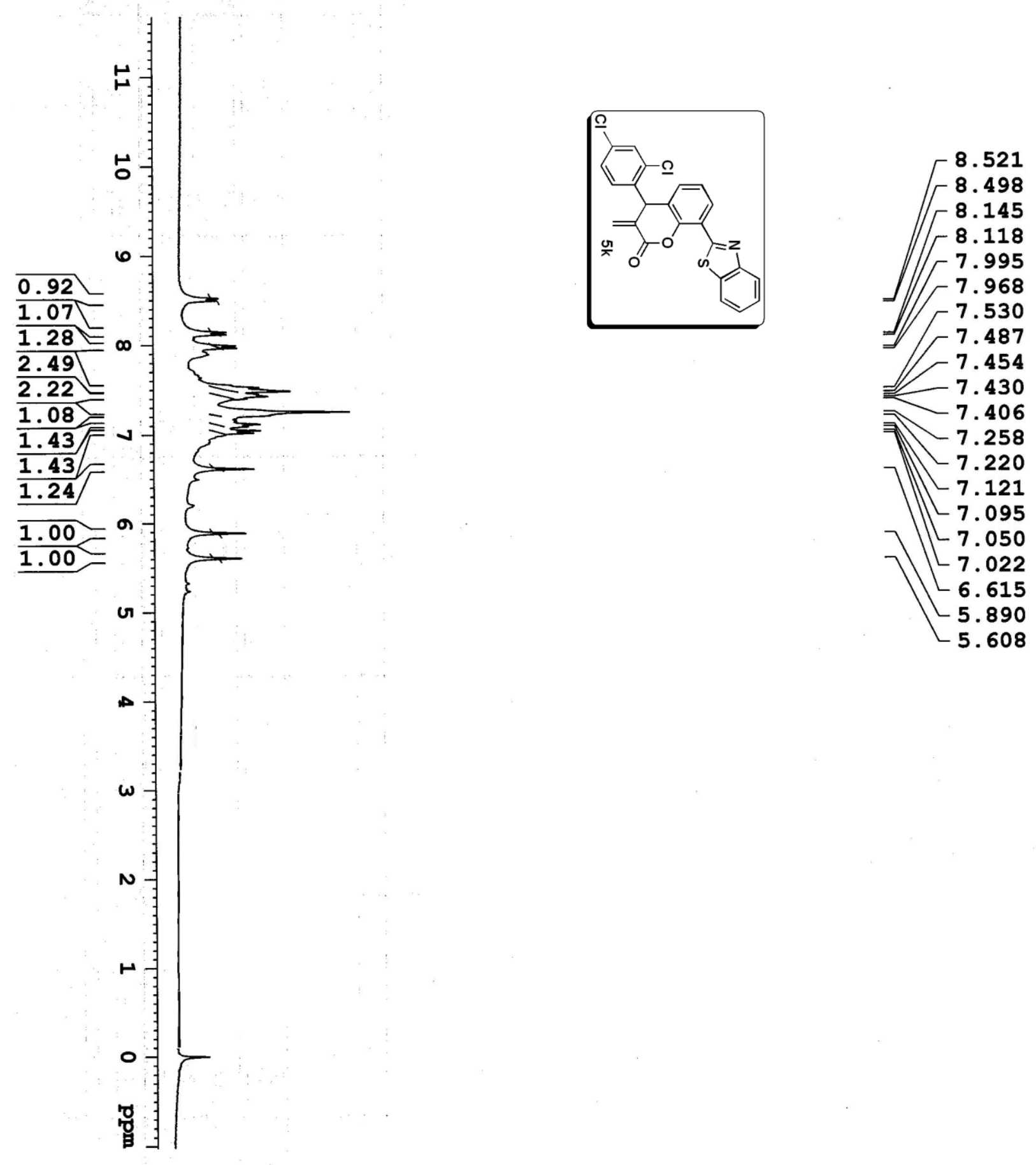


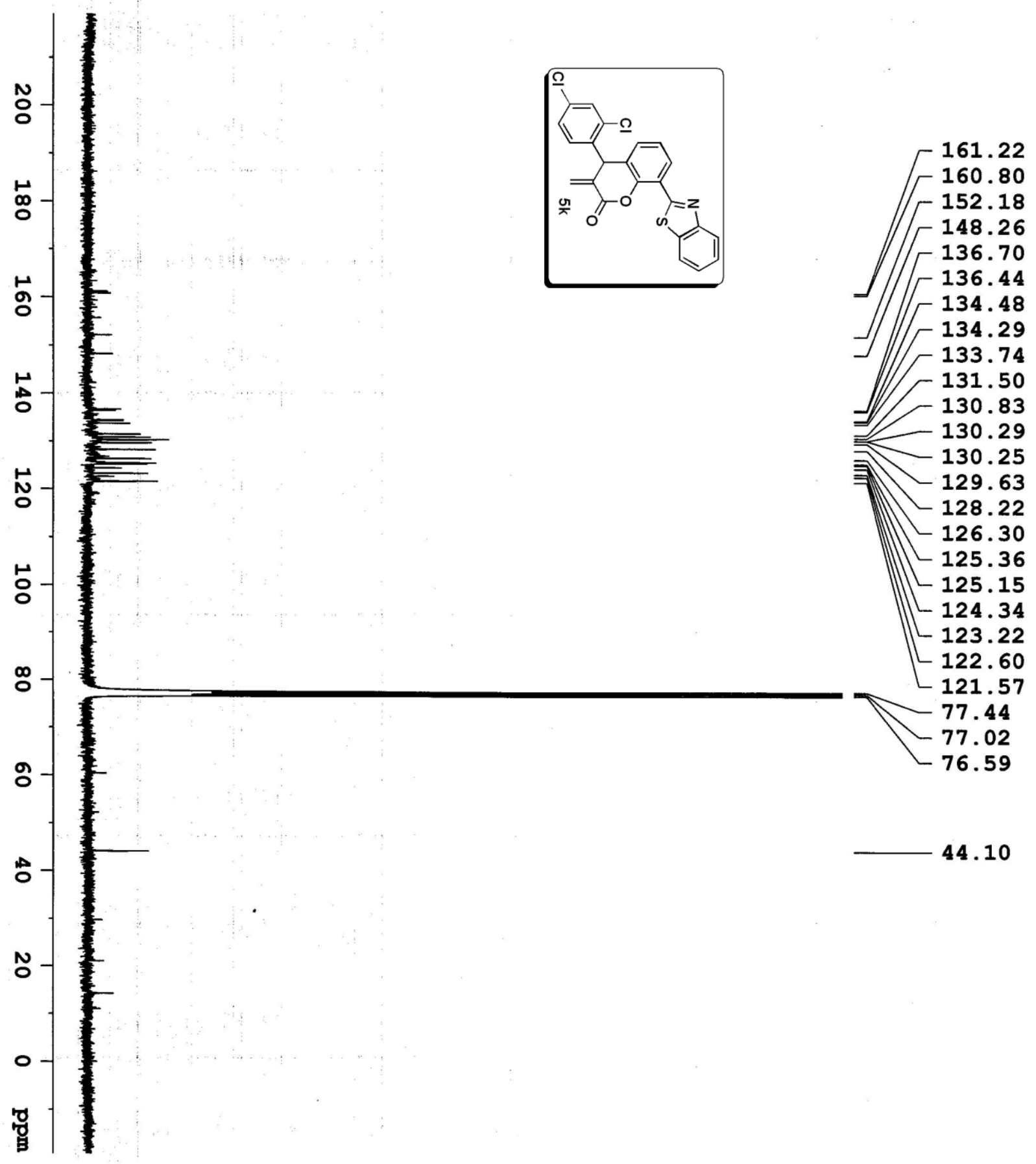




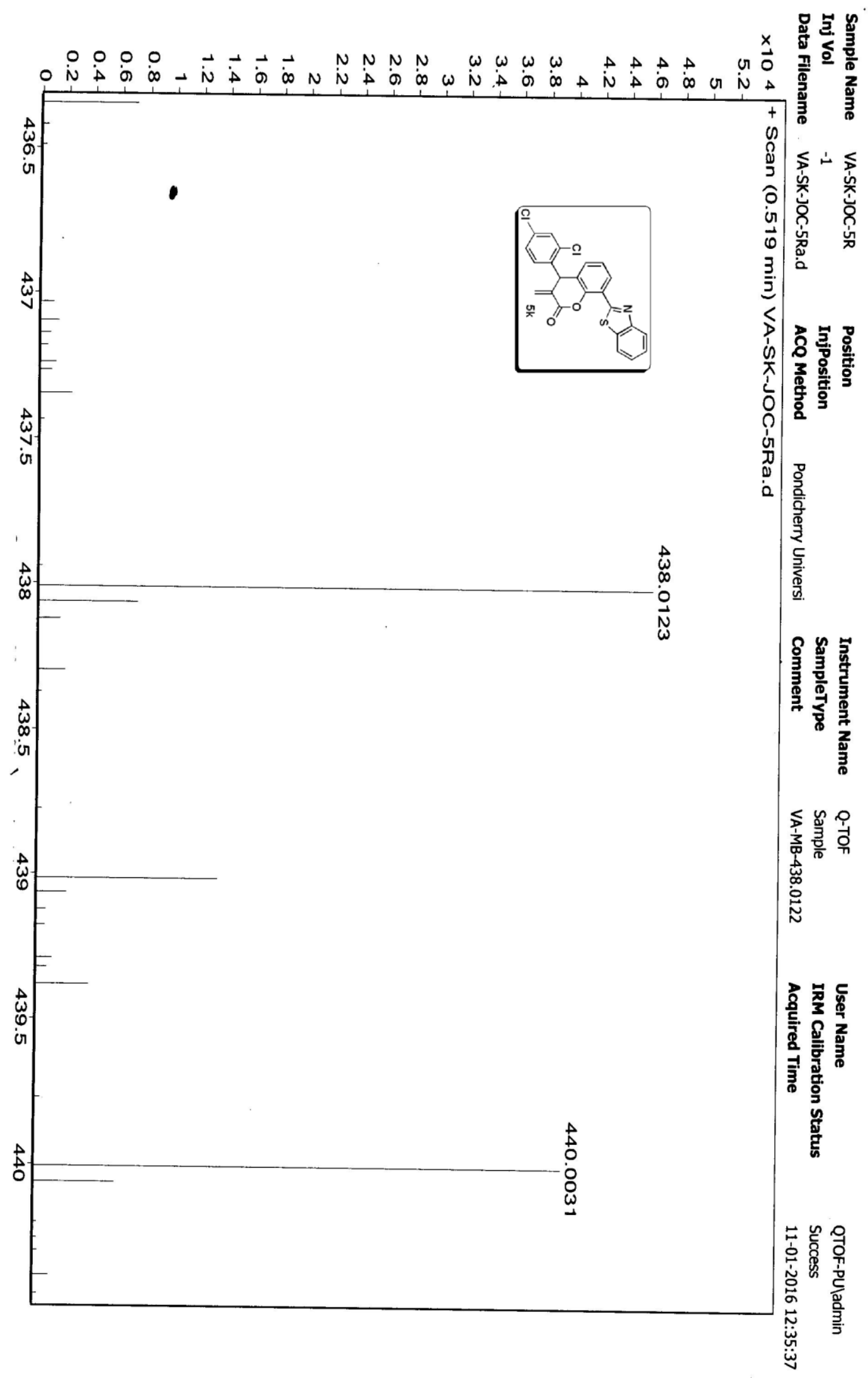



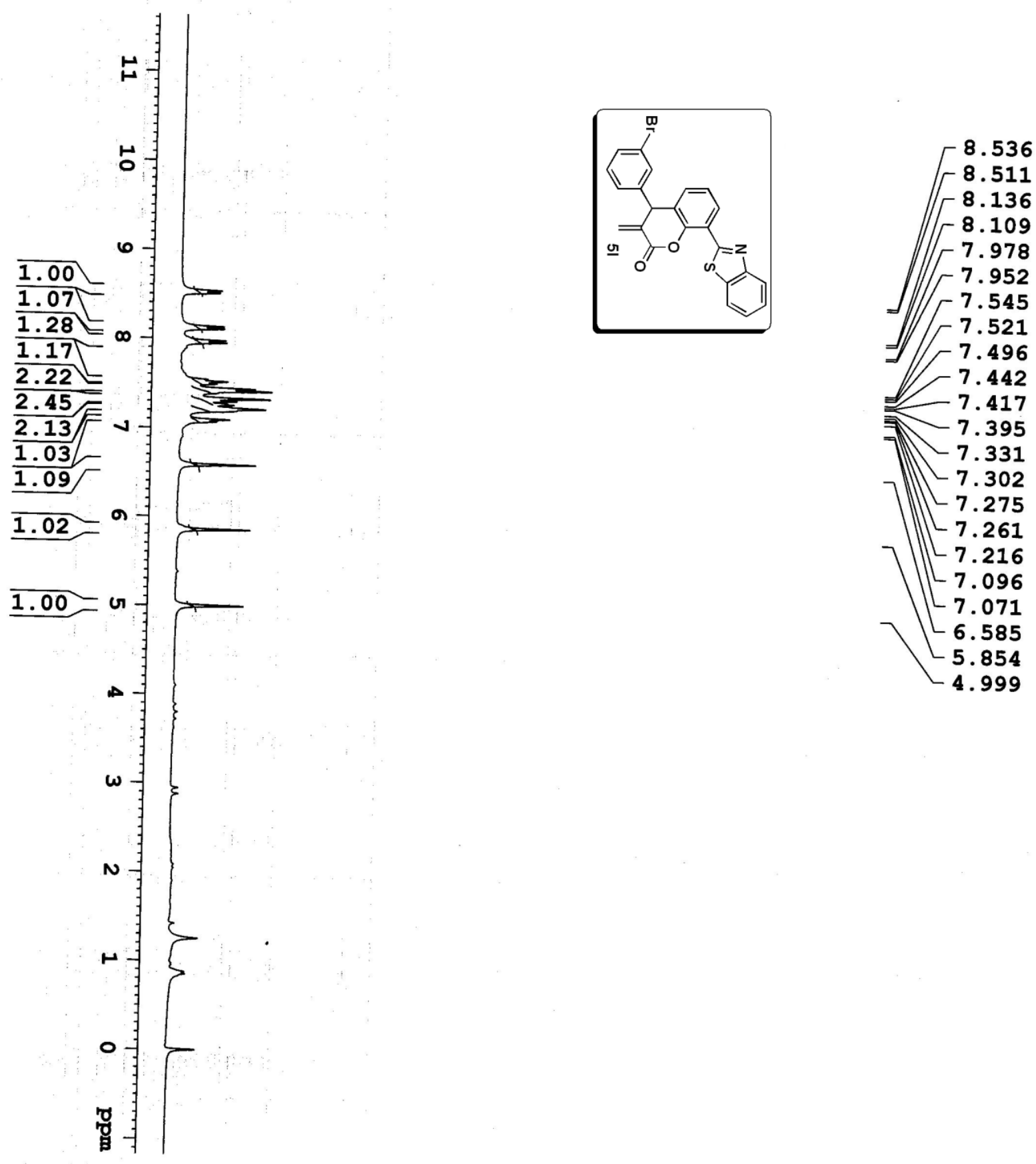

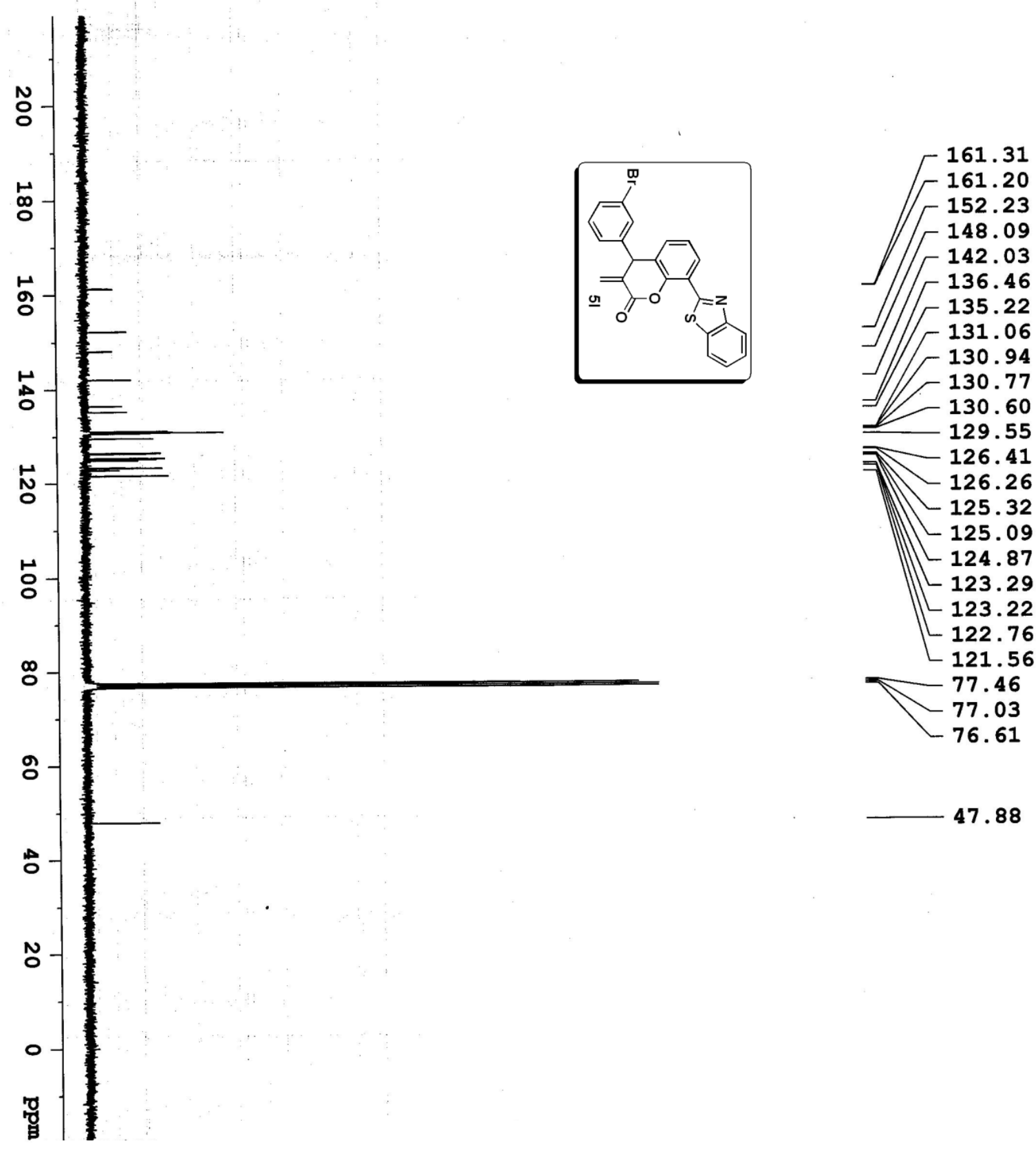


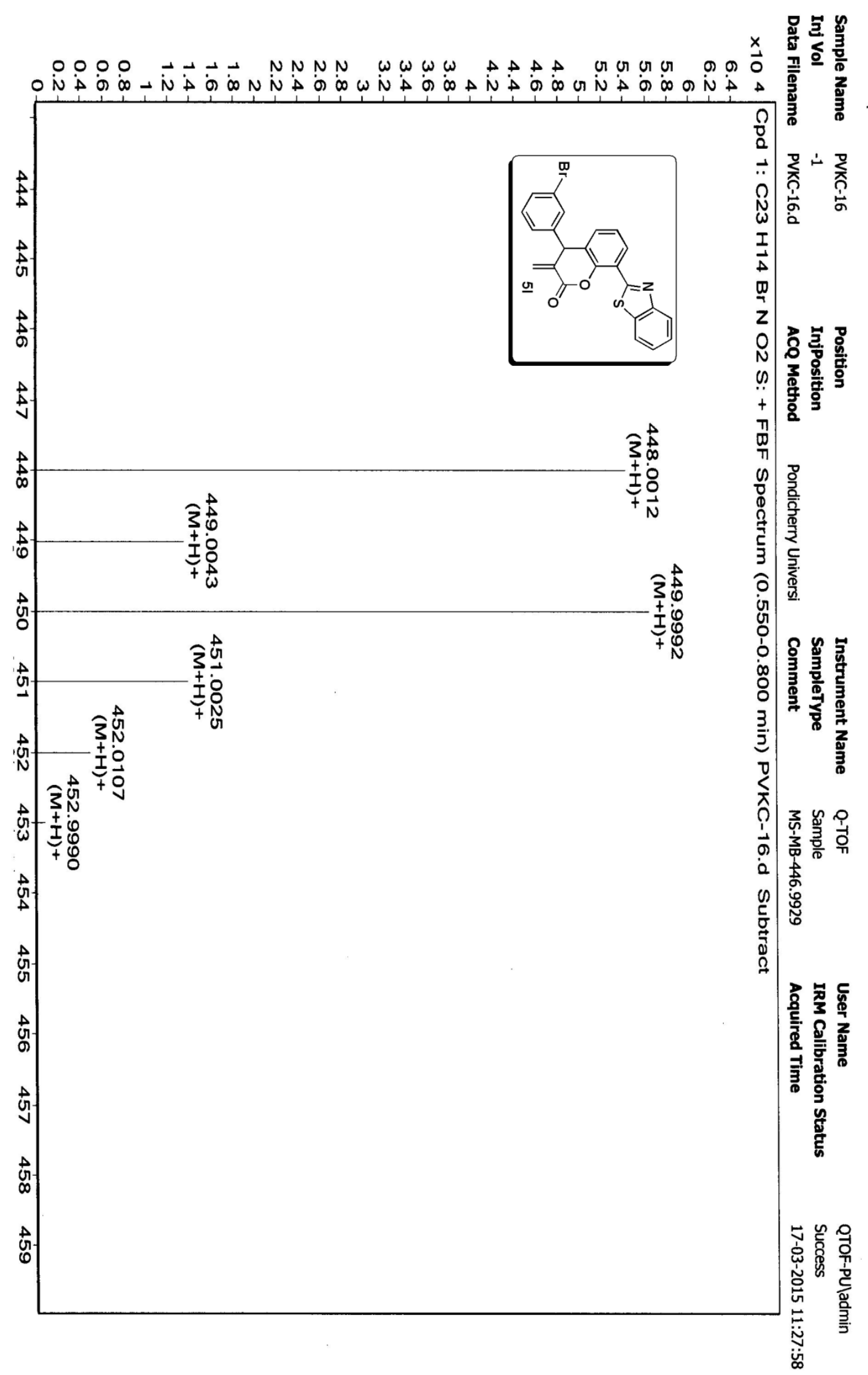



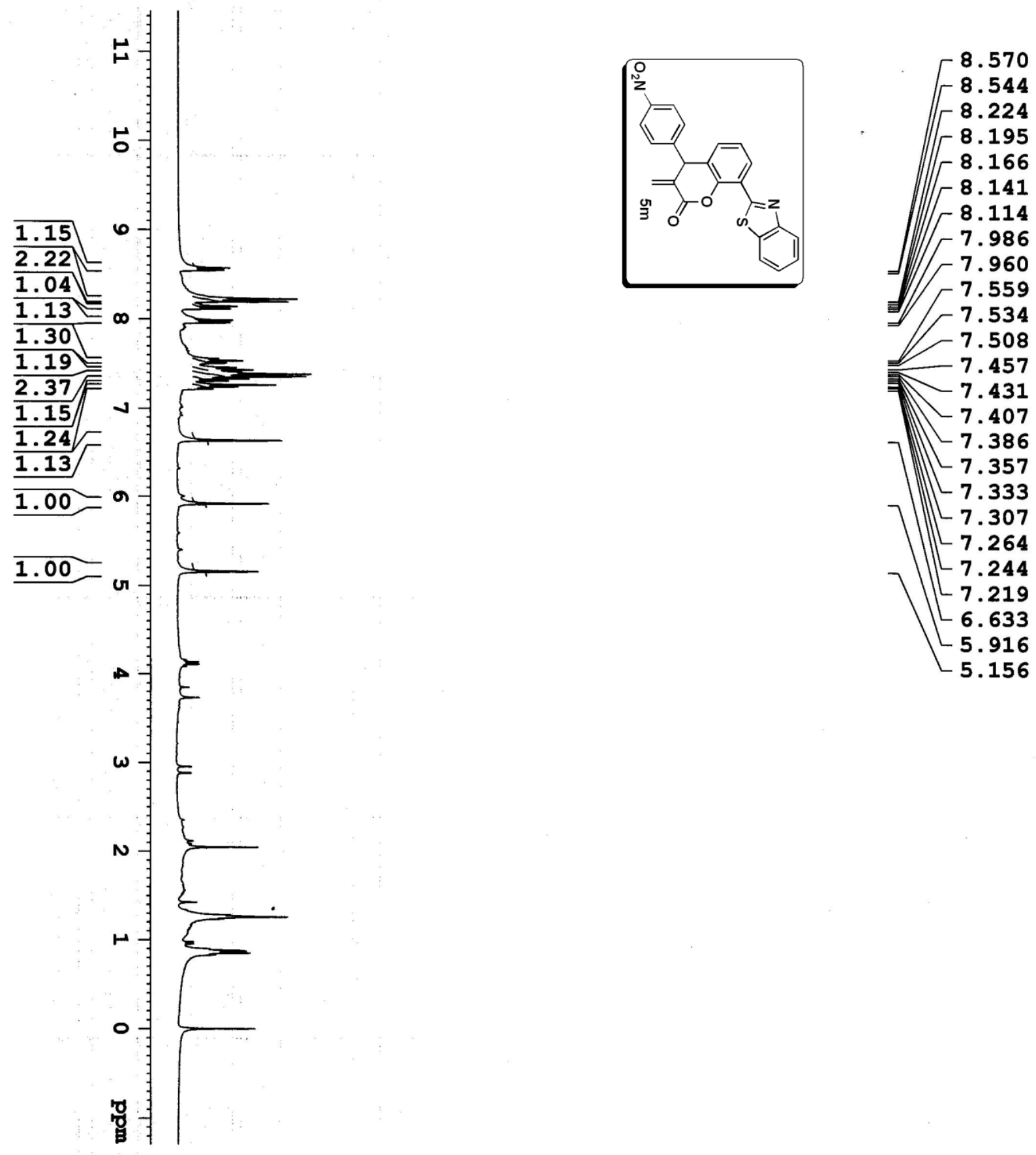

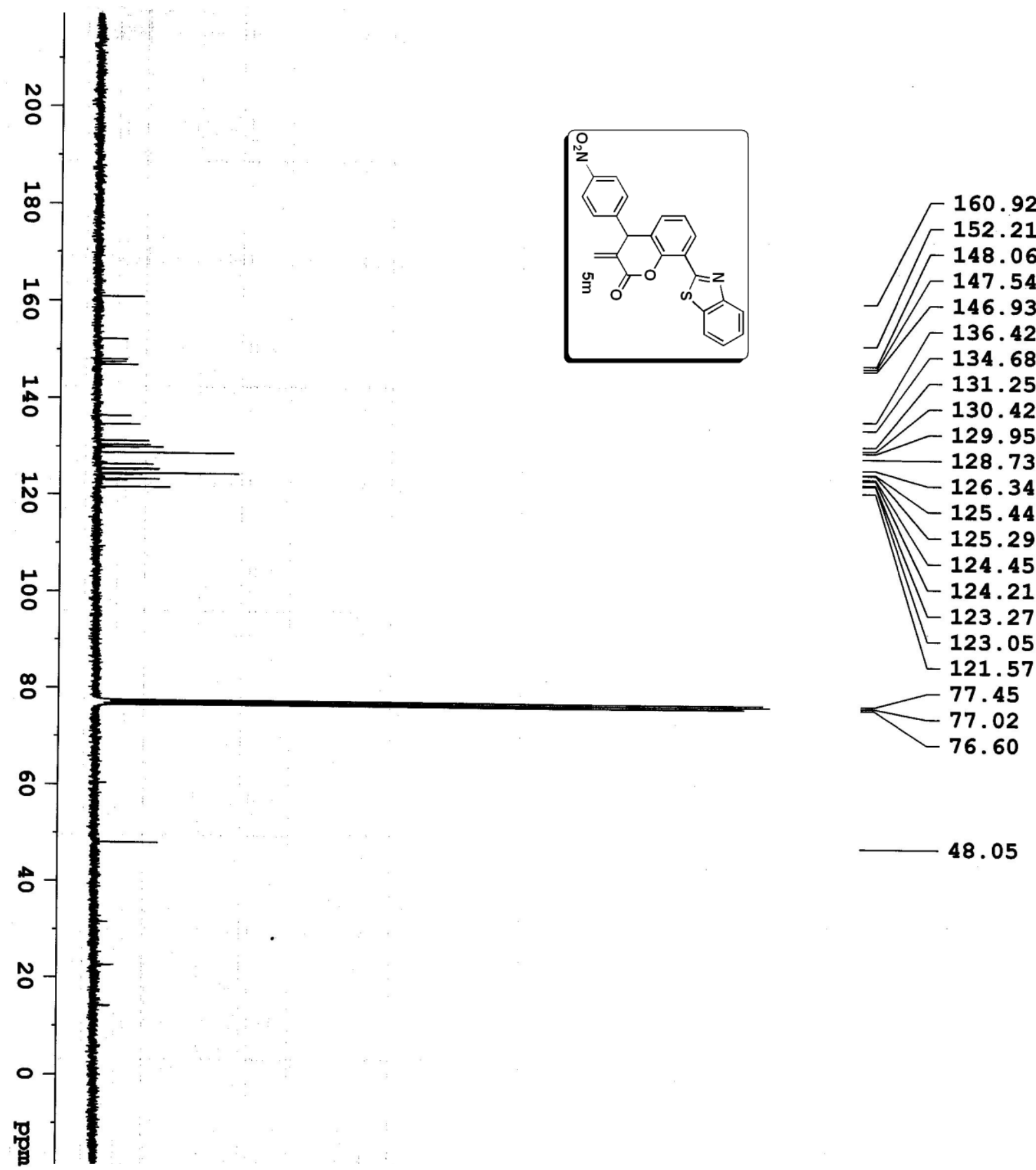

48.05 


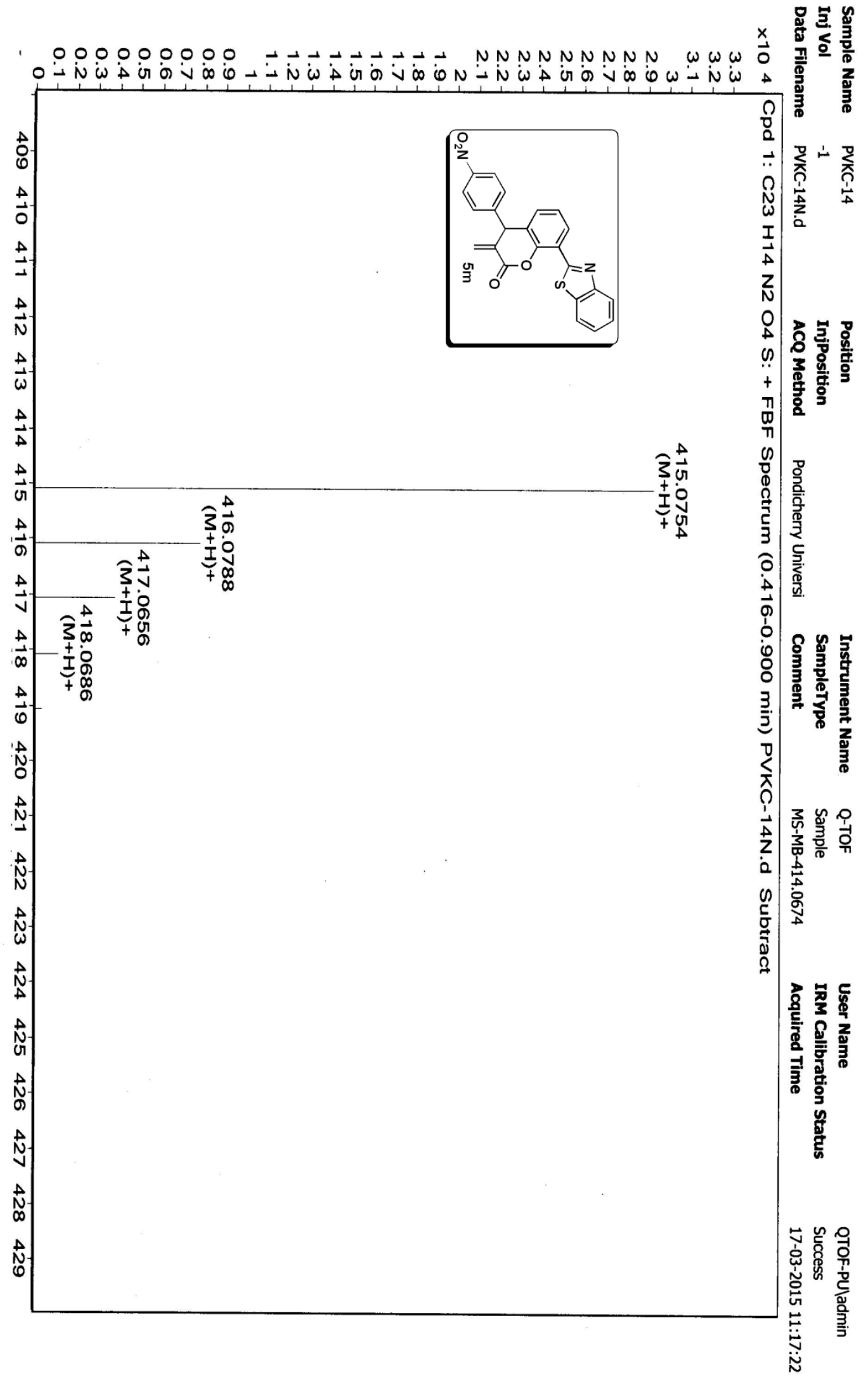




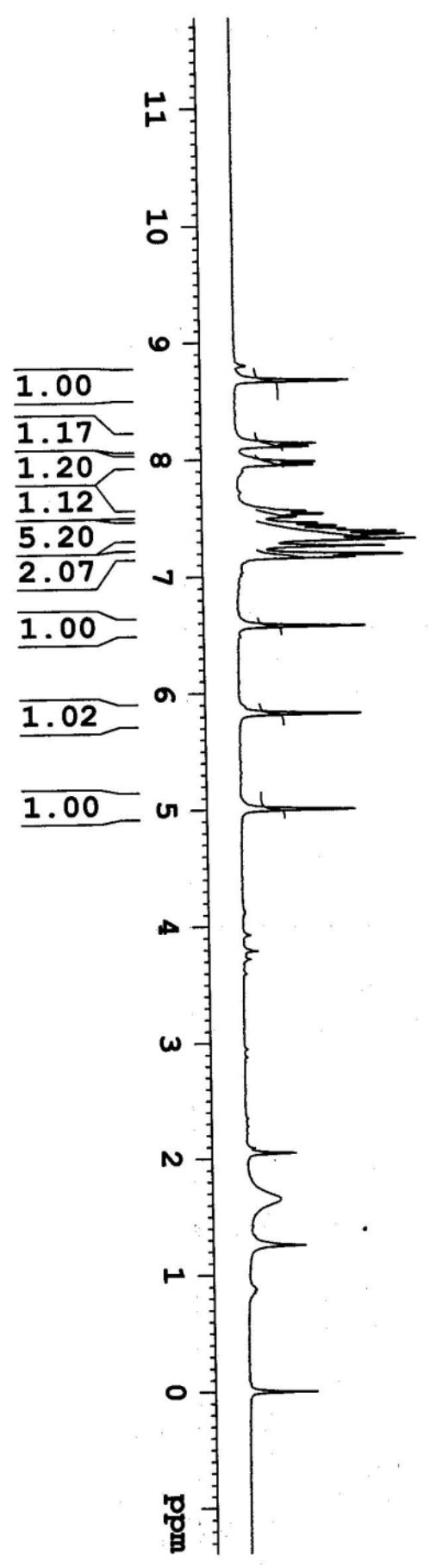

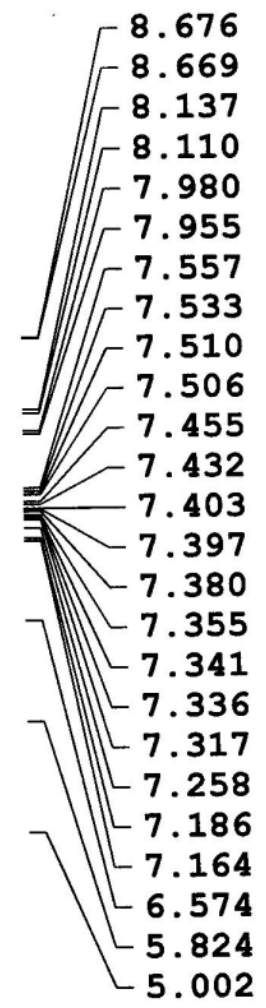



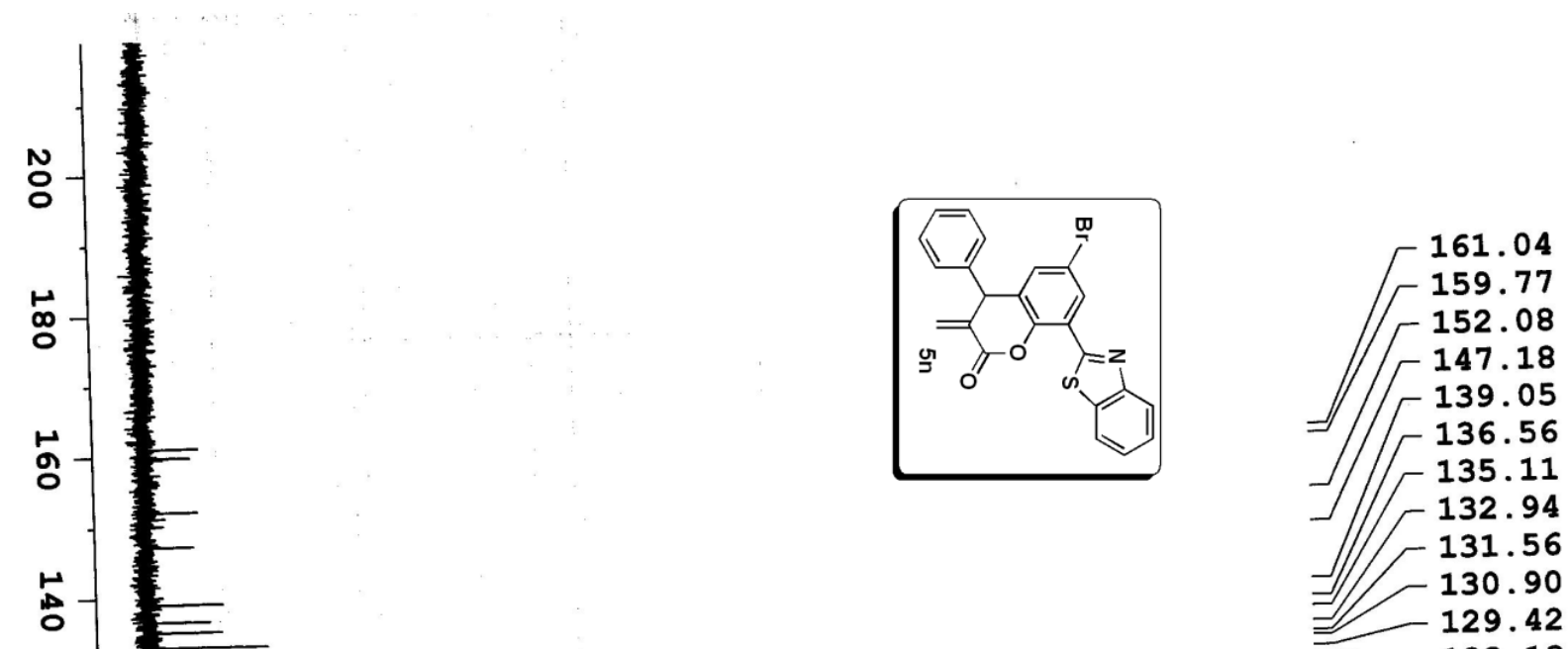

$-129.42$

品

능

흥

\&

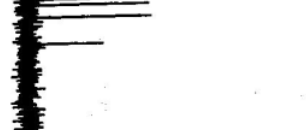

$-127.79$

$-126.44$

$-125.59$

124.20

$-123.37$

$\leftarrow 121.60$

117.85

77.44

77.02

76.60

옹

48.15

응

N

$\circ$

" 


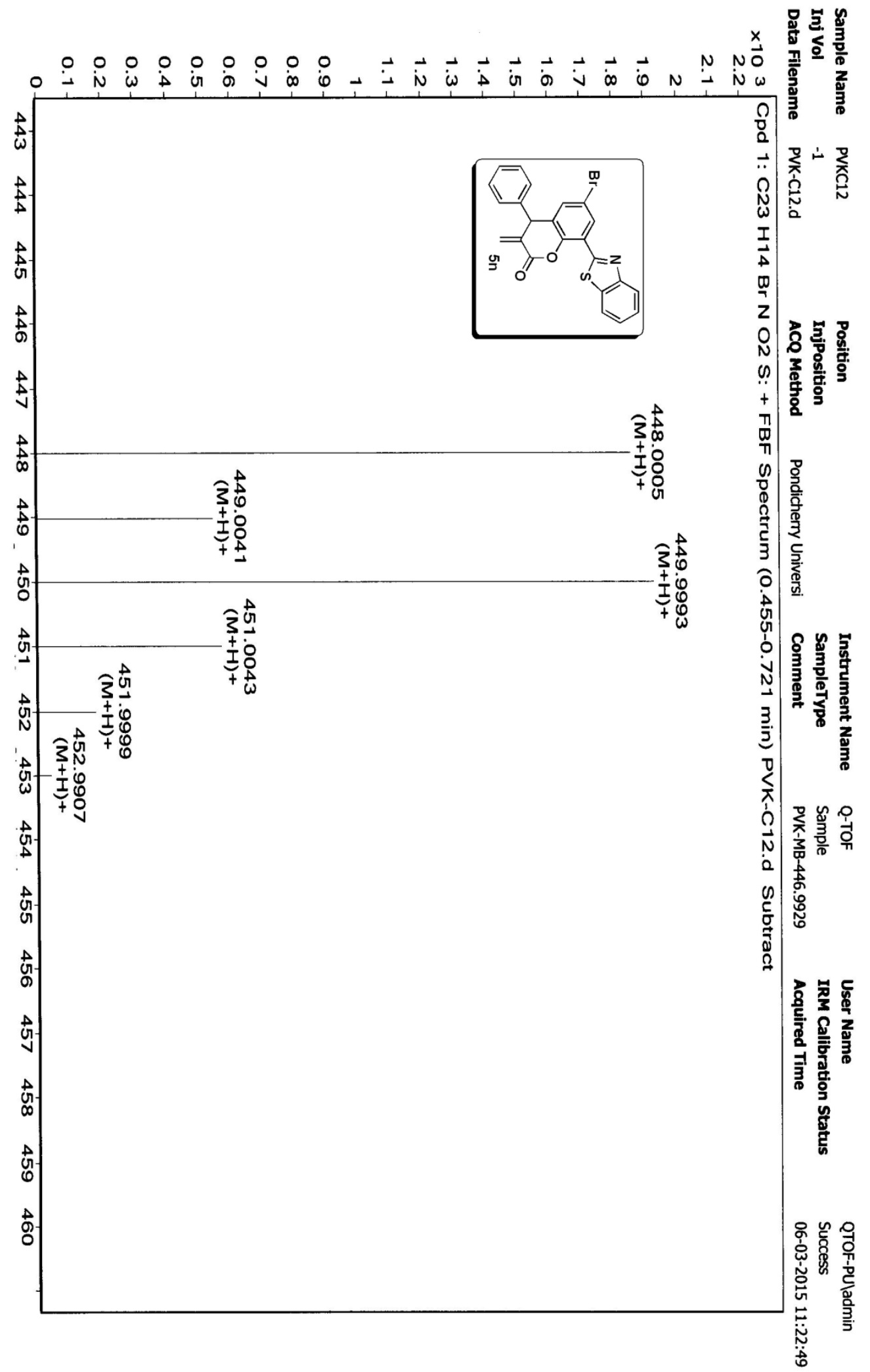



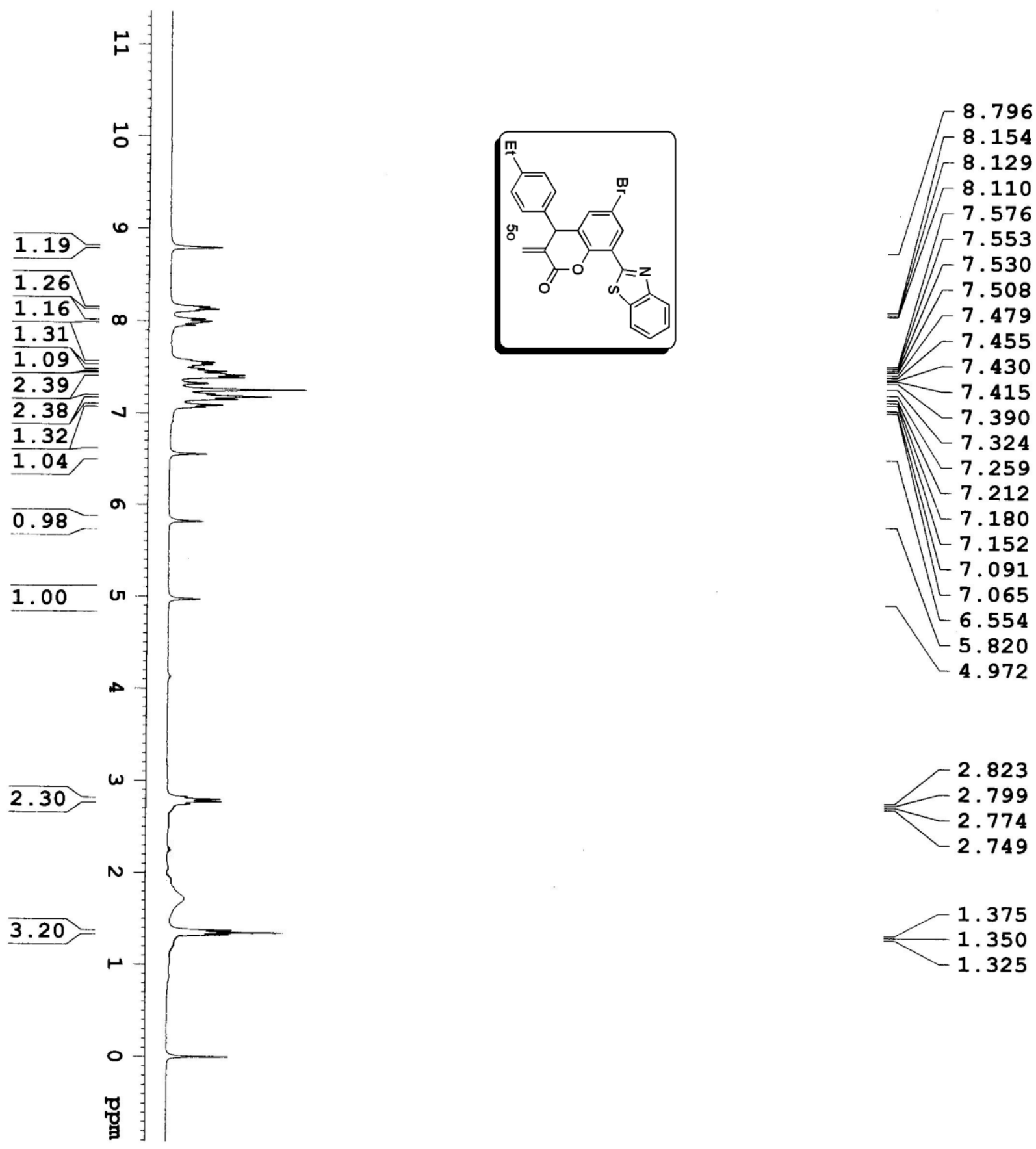


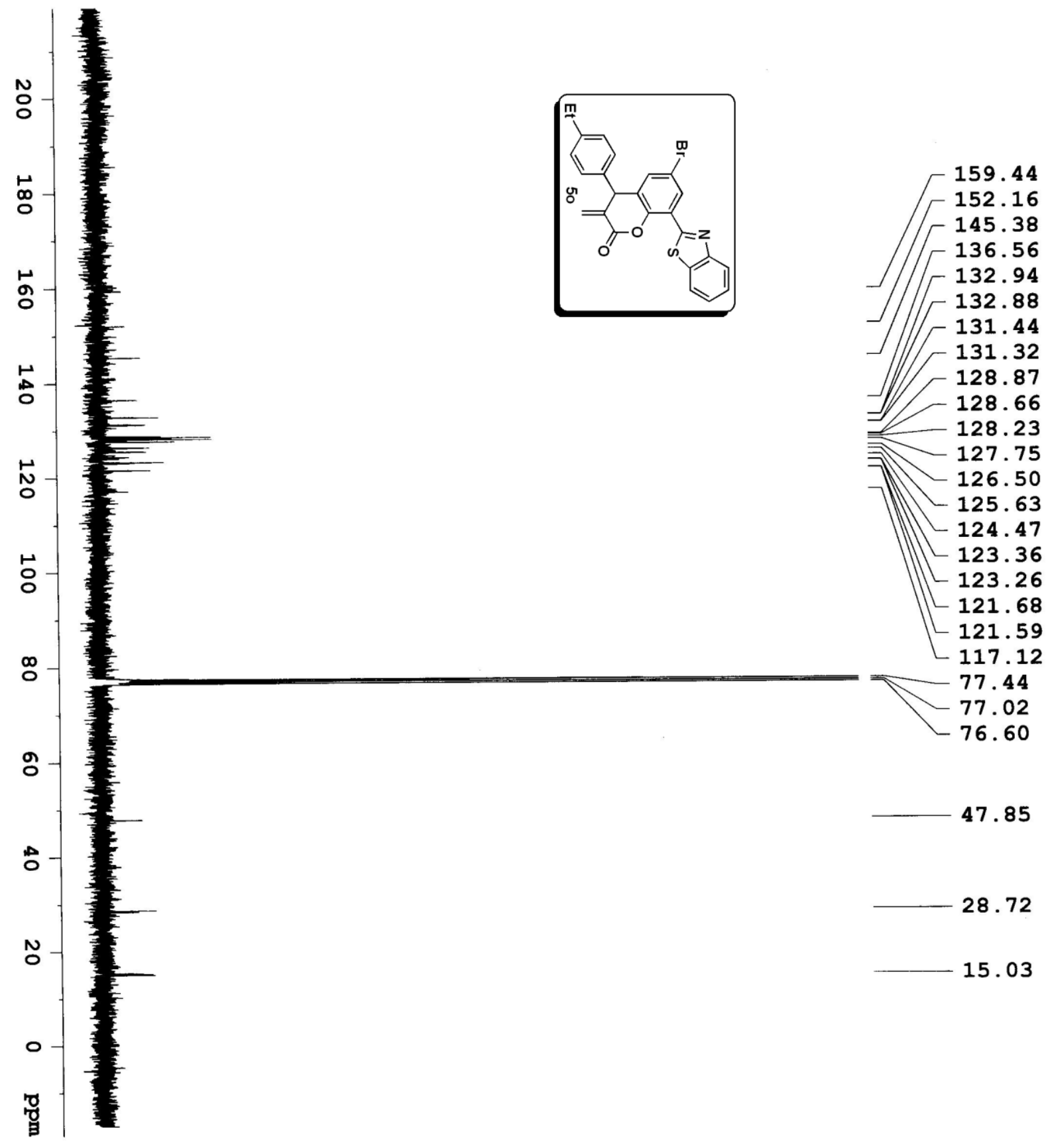




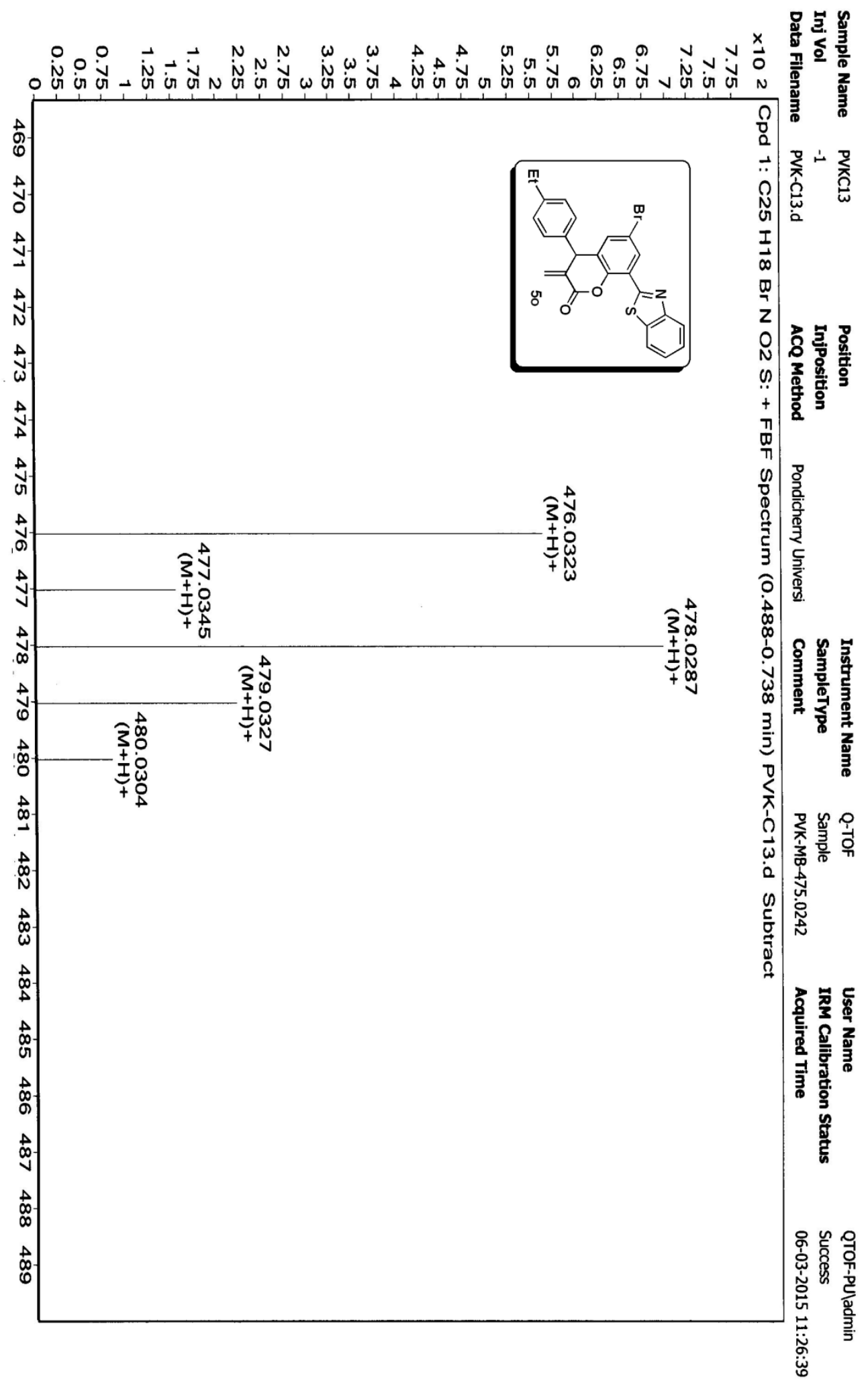



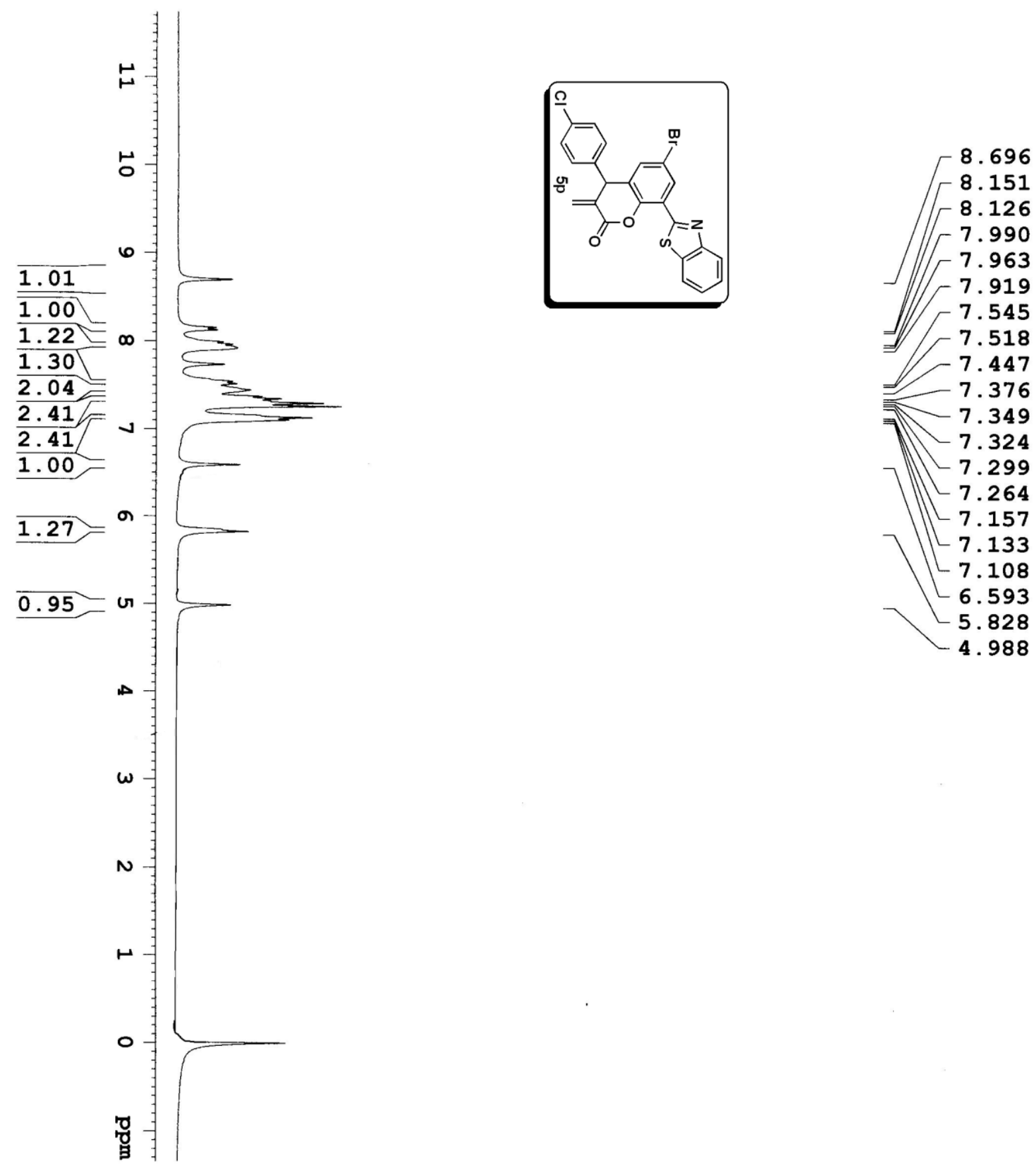

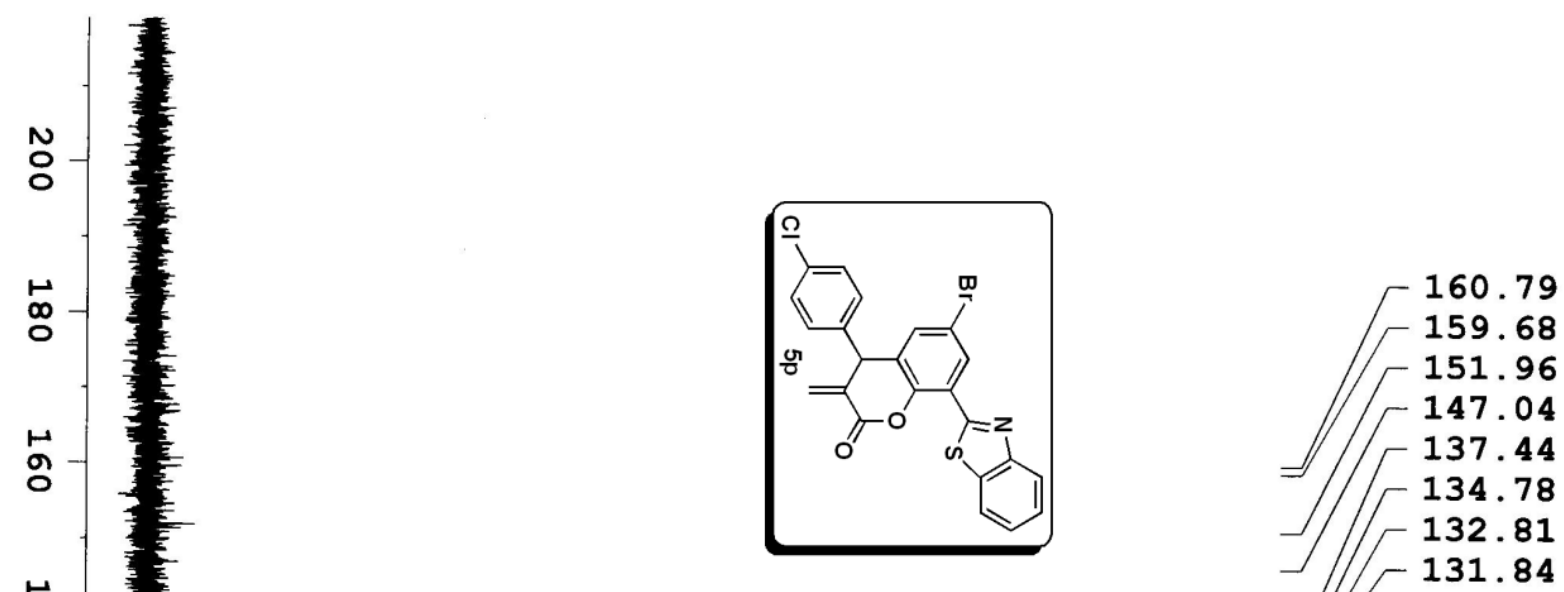

is

㟔

N

$$
\begin{aligned}
& \text { N. } \\
& \text { 능 }
\end{aligned}
$$

$\infty$

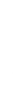

。-

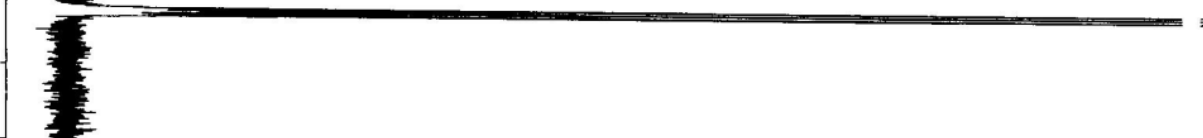

131.84
-130.42

$-129.62$

$-129.24$

$-128.83$

$-127.01$

126.52

126.00

125.69

$-123.37$

$-122.26$

$-121.61$

$-117.98$

77.43

77.00

76.58

47. 51

음

N

0

漗

$\left\{\begin{array}{l}\frac{1}{4} \\ 0\end{array}\right.$




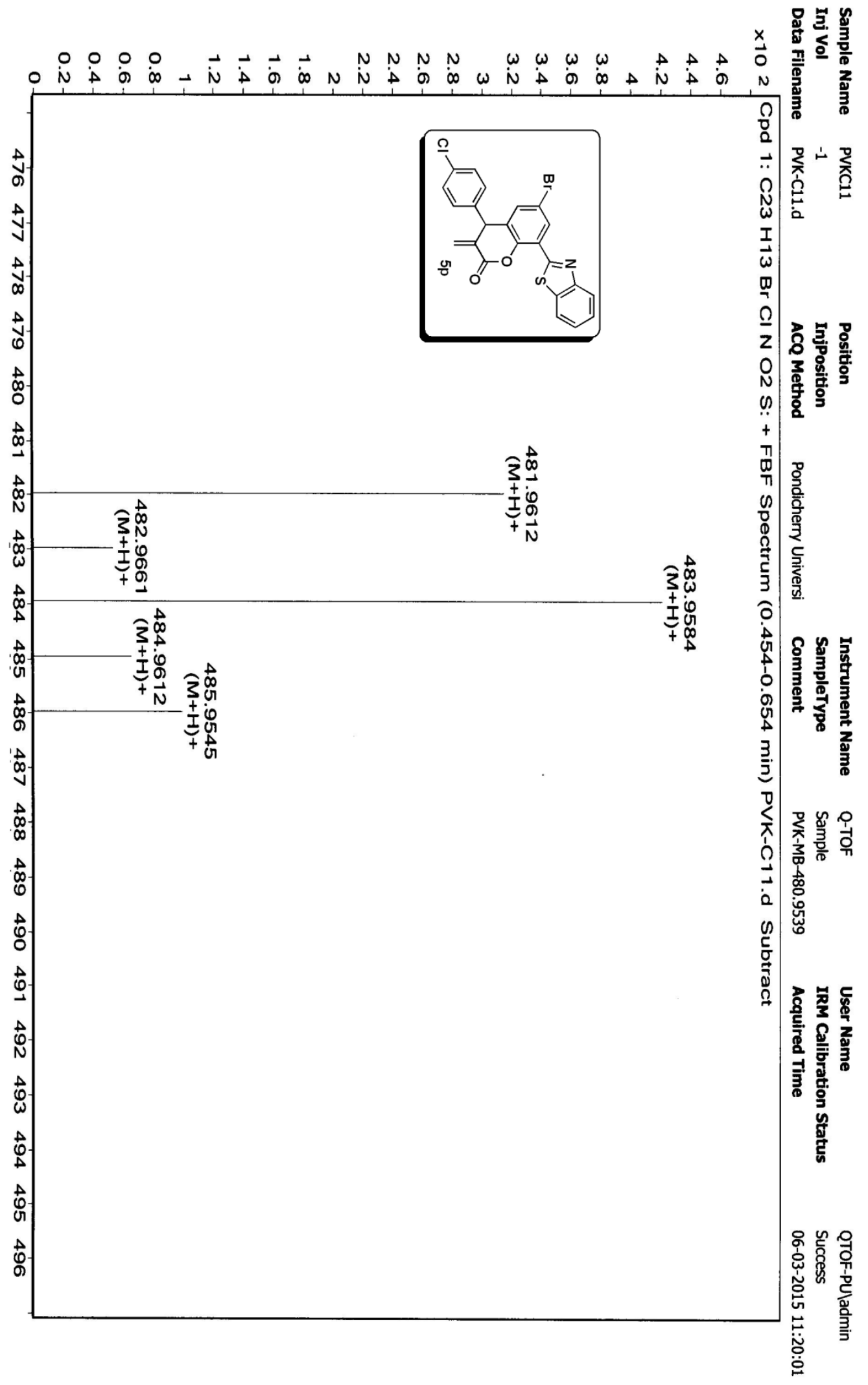



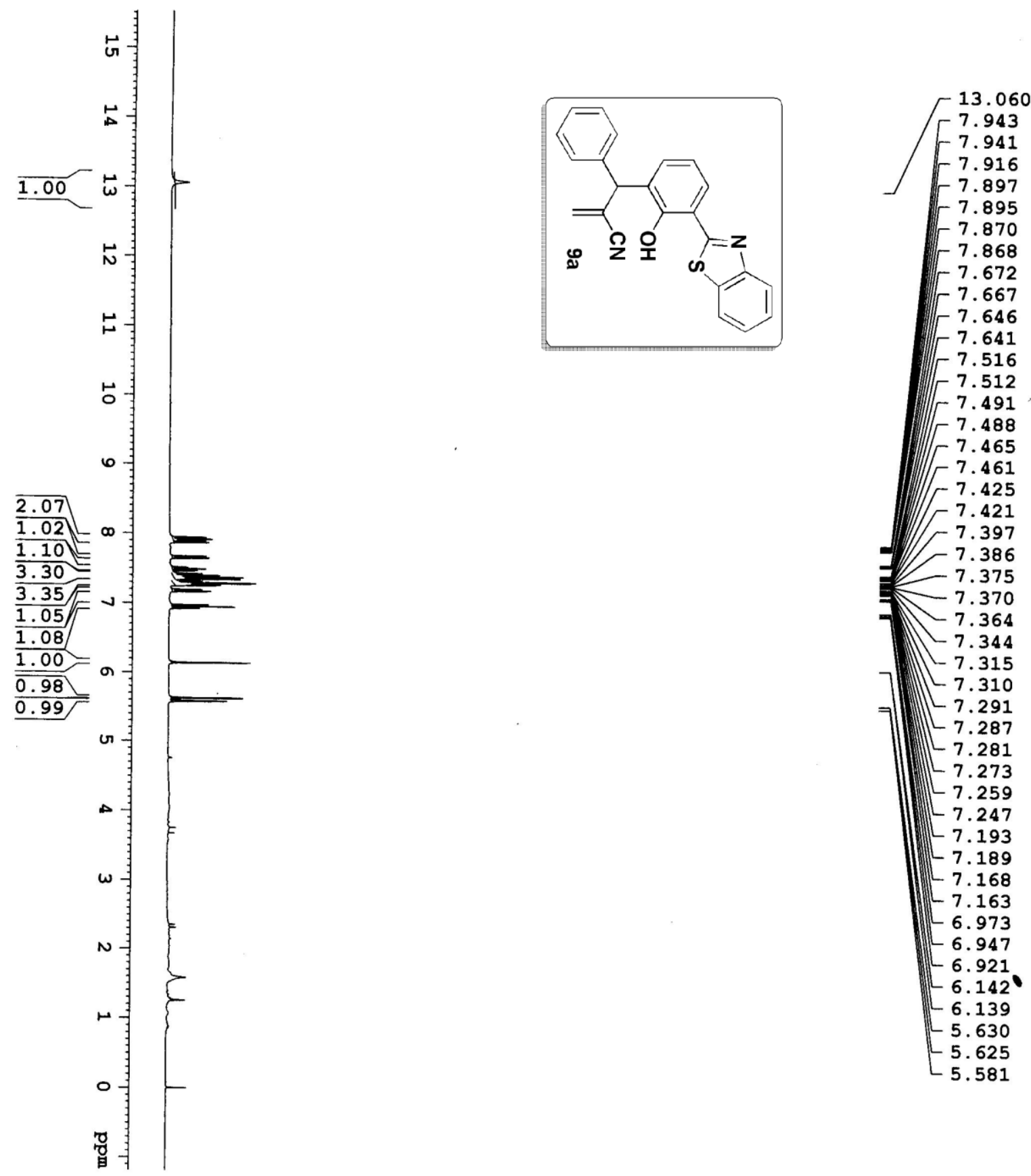


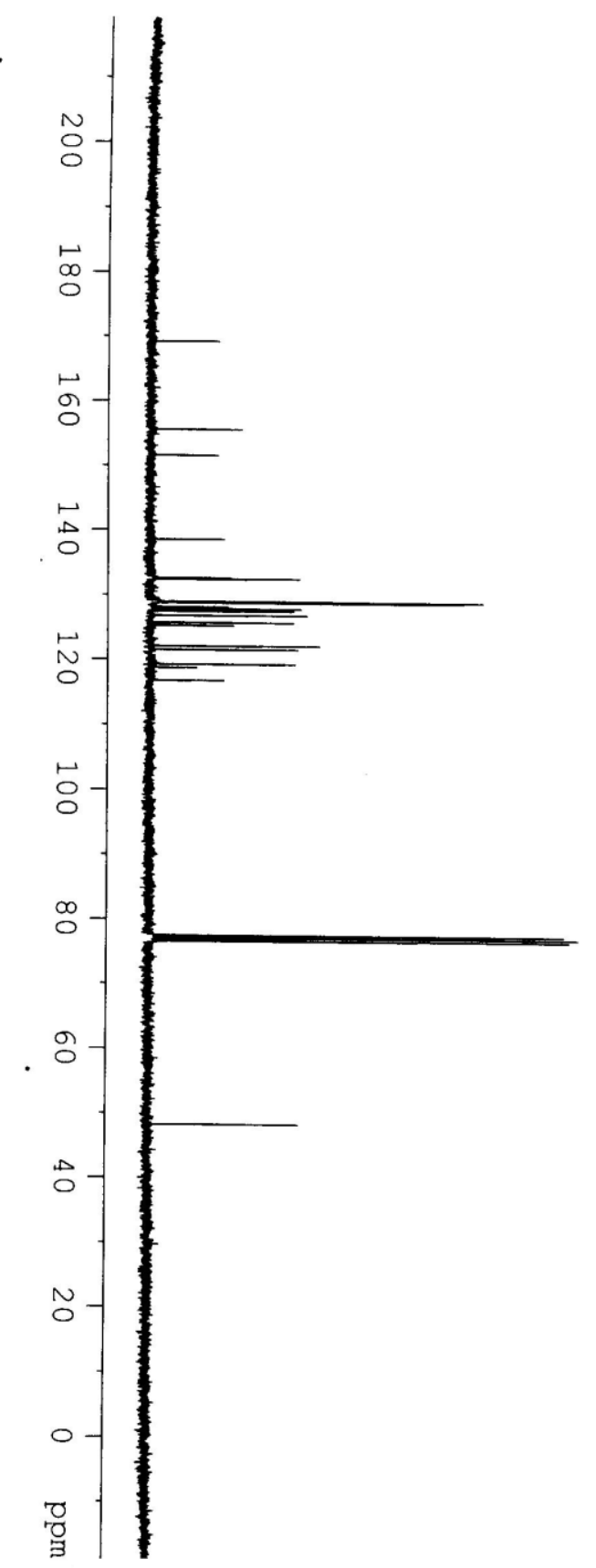

$\left\lceil=\begin{array}{l}169.27 \\ 155.63 \\ 151.60\end{array}\right.$

$-138.59$

$-132.65$

/ 132.49

$\mp 132.42$

$\mp 128.98$

$-128.81$

$-128.17$

$-127.49$

$7-126.82$

$\longrightarrow 125.71$

- -125.27

$-122.12$

$-121.56$

$-119.30$

$-118.80$

L 116.81

77.47

$-77.05$

76.62

48.20 


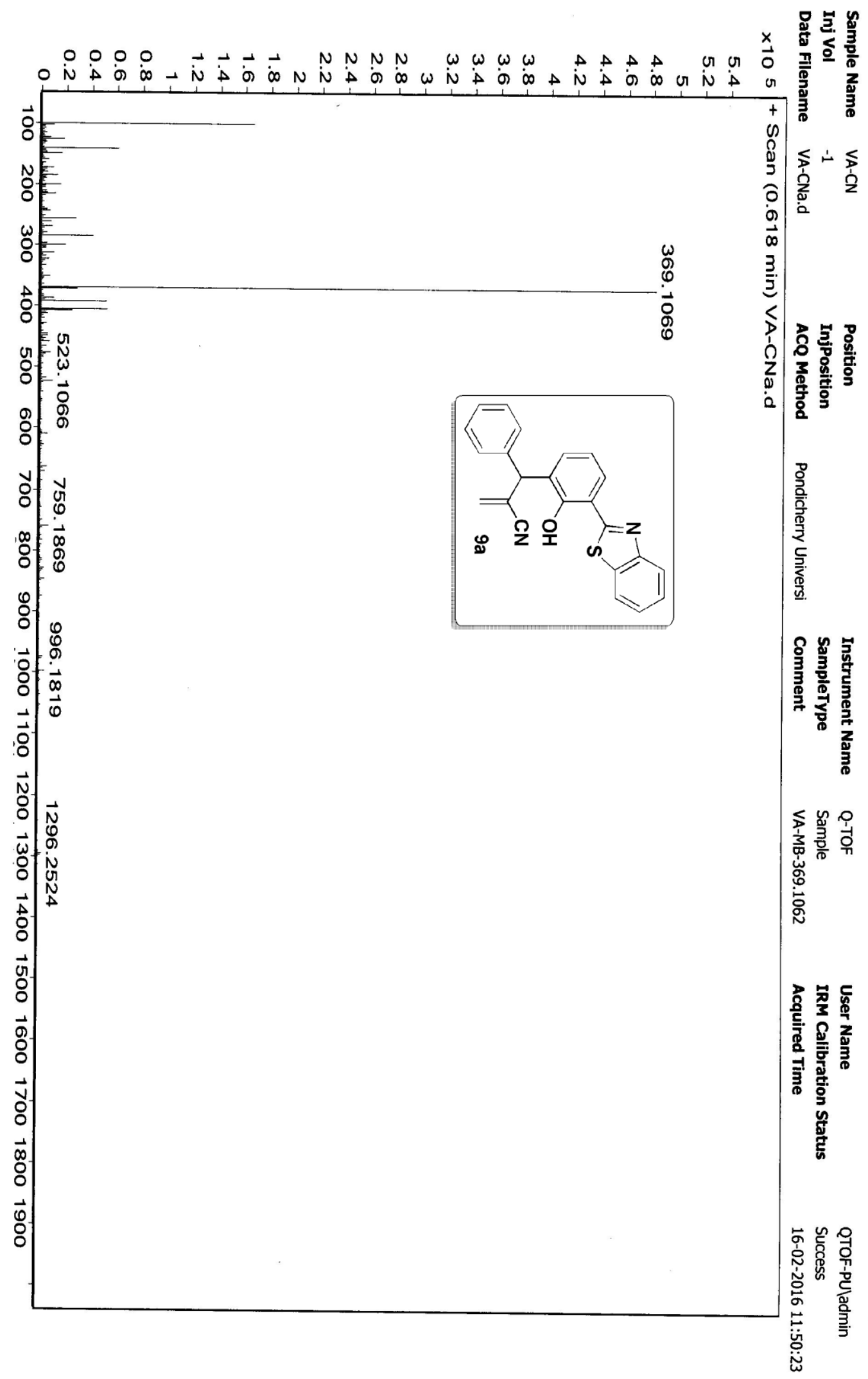



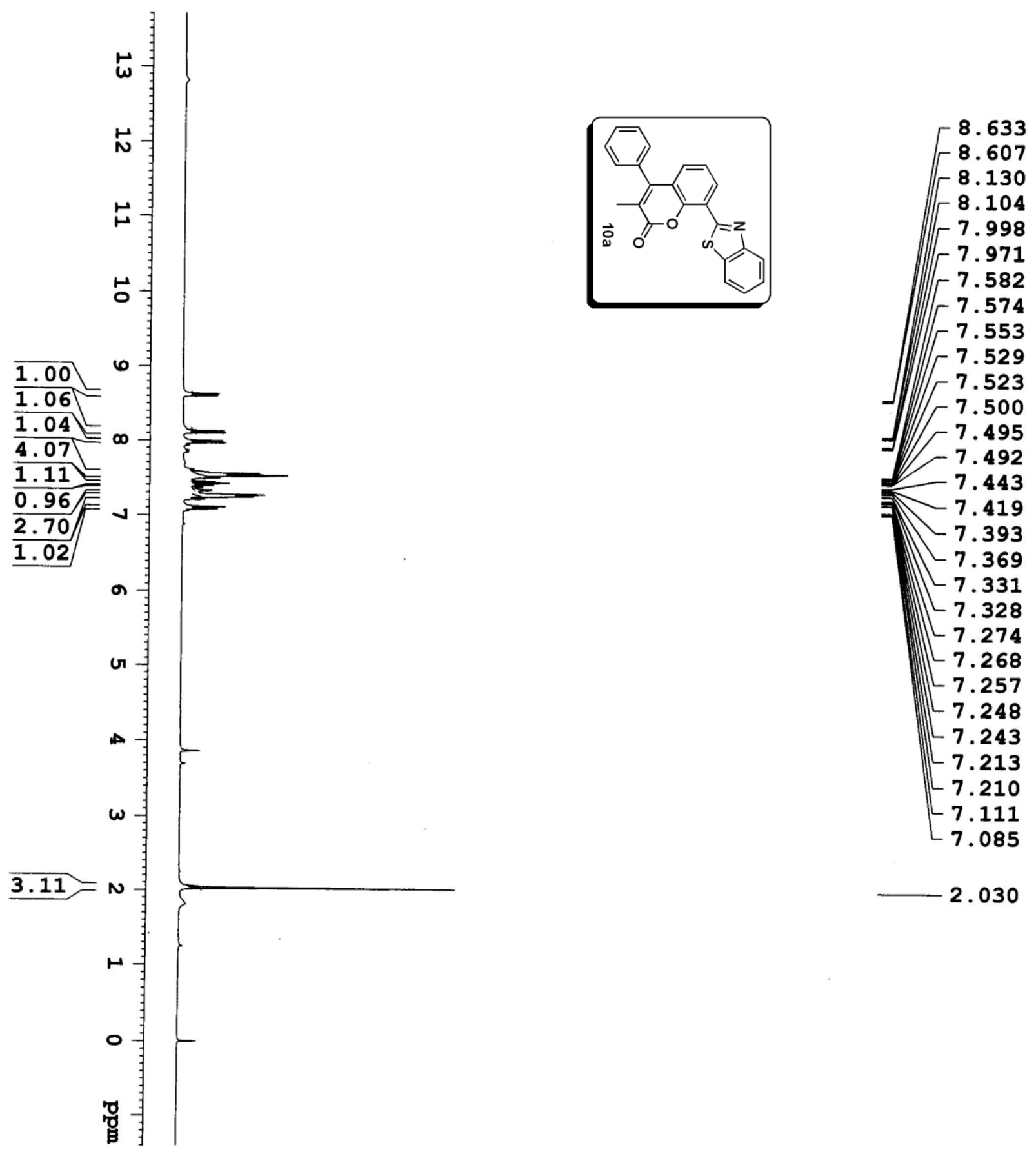

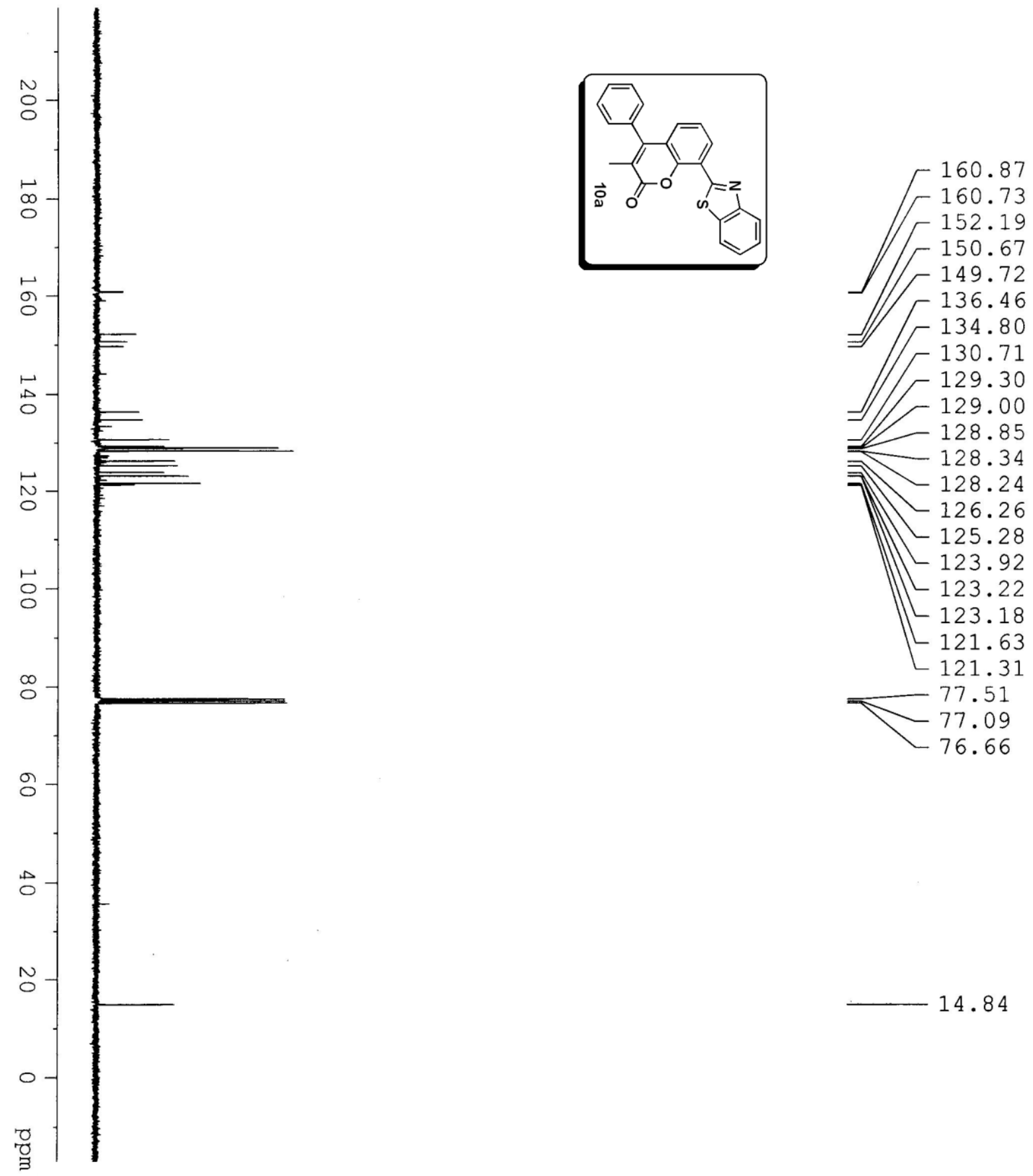

$-130.71$

$-129.30$

$-129.00$

128.85

$-128.34$

$7-128.24$

$\longrightarrow 126.26$

$\longrightarrow 125.28$

$[123.92$

$-123.22$

123.18

121.63

$-121.31$

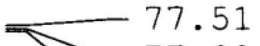

77.09

76.66

14.84 


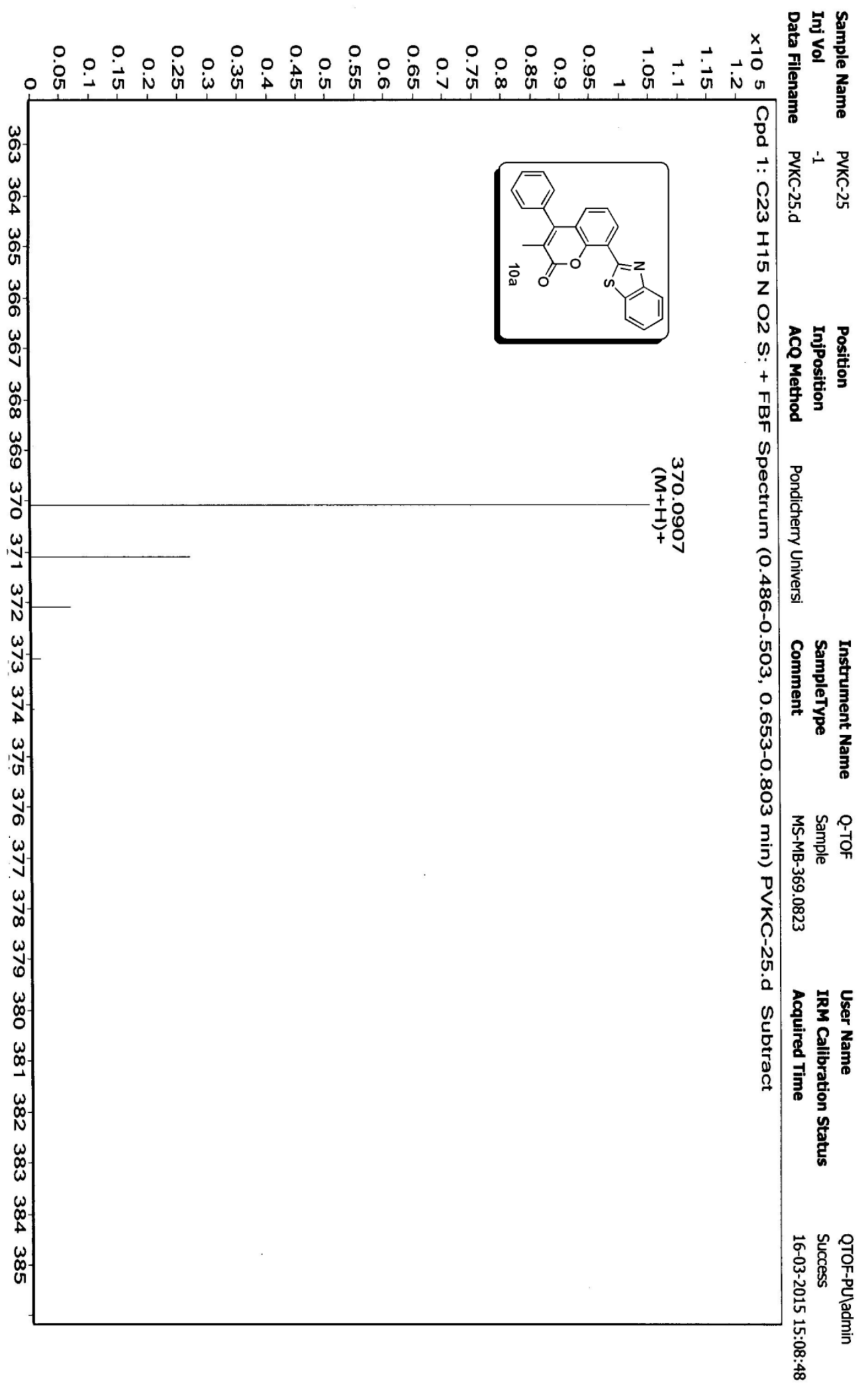



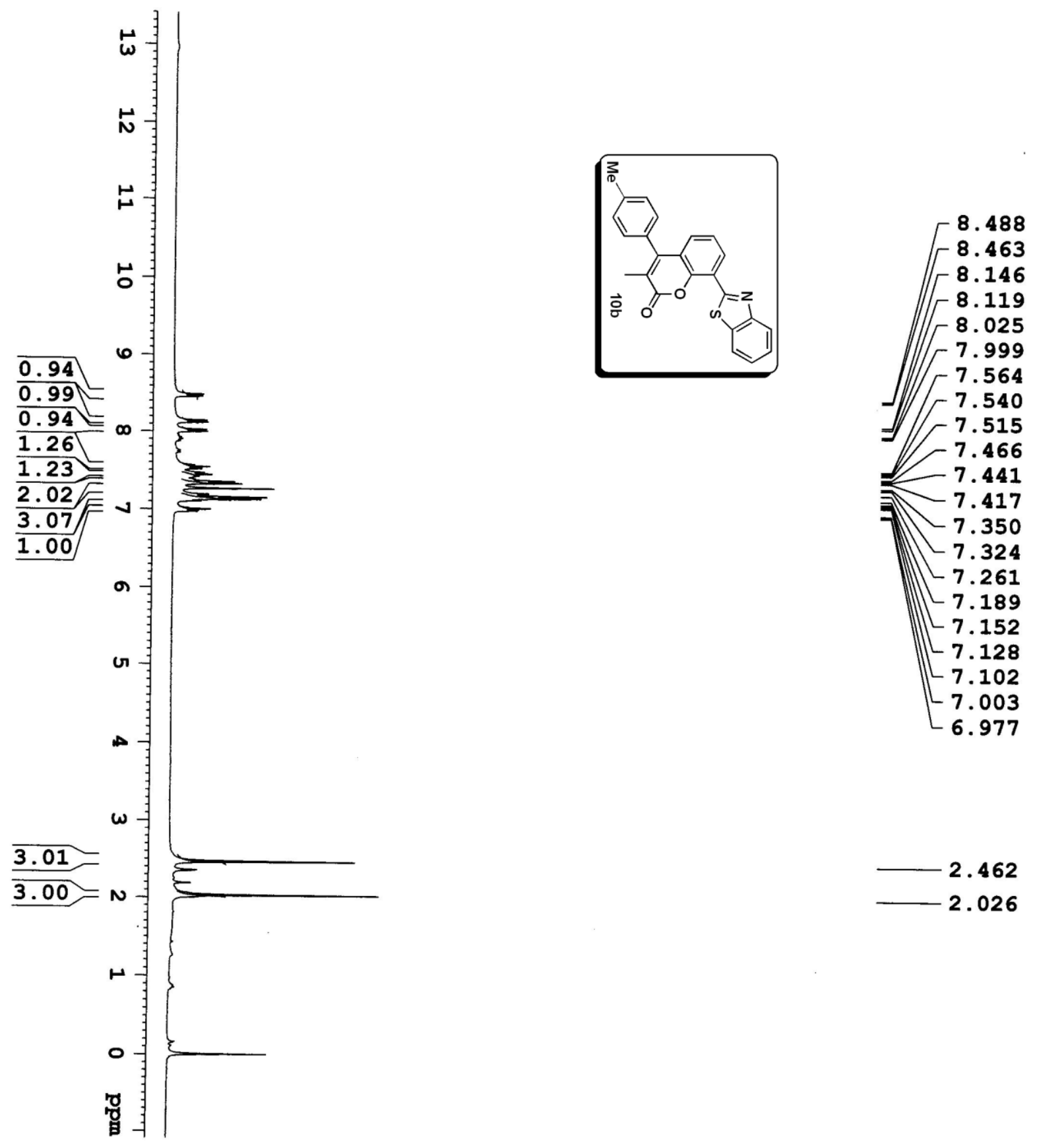

2.462

2.026 


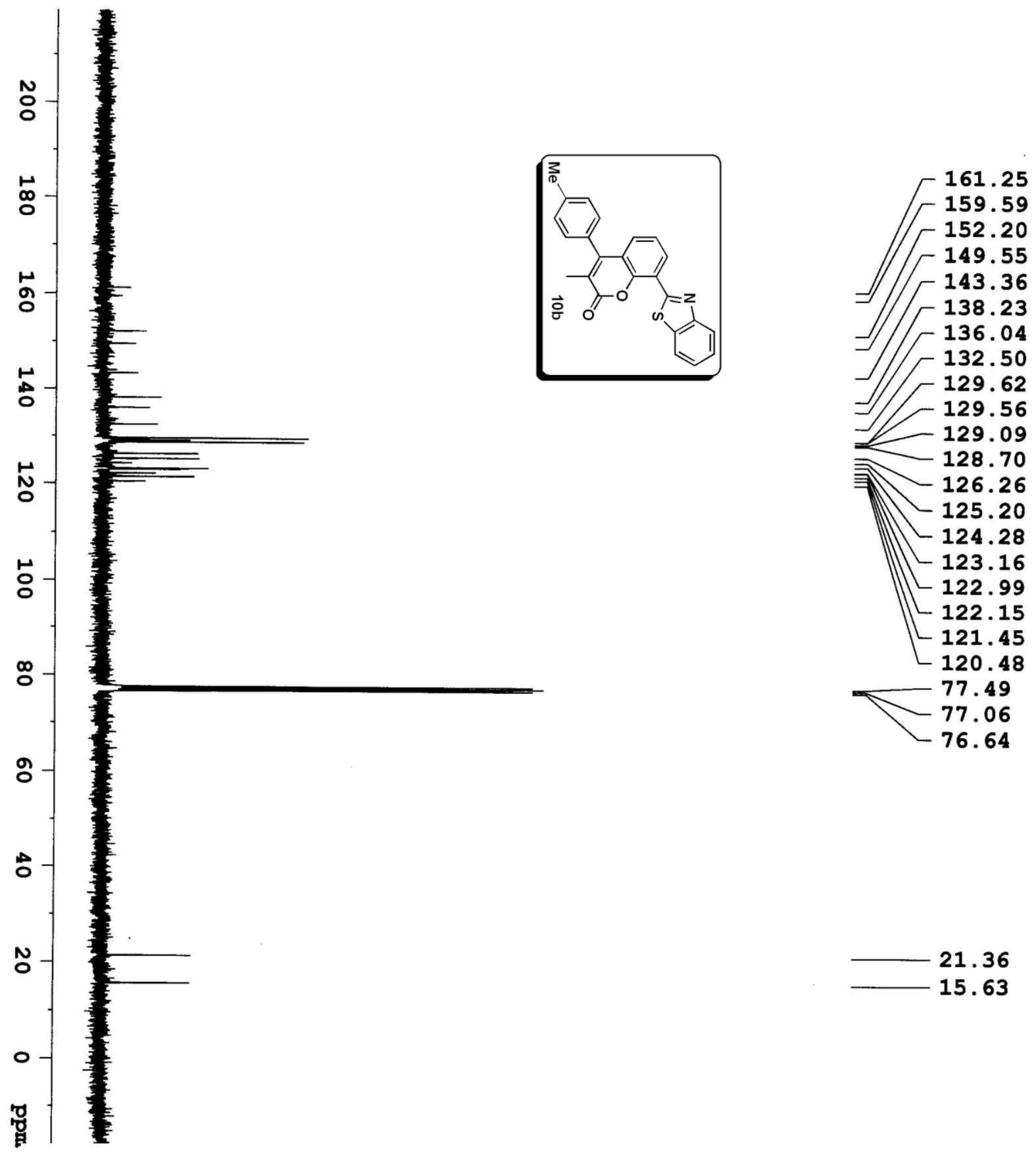




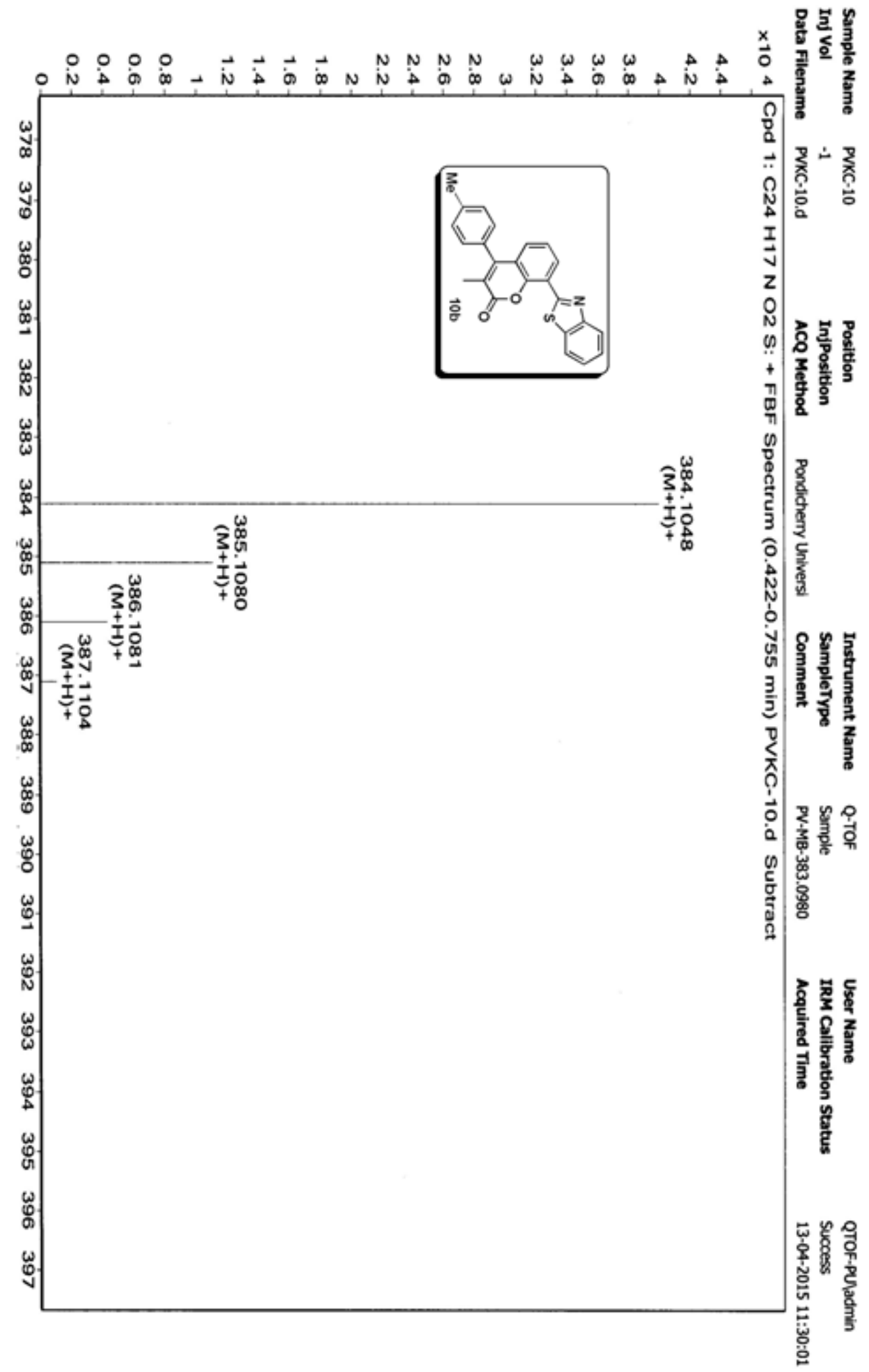




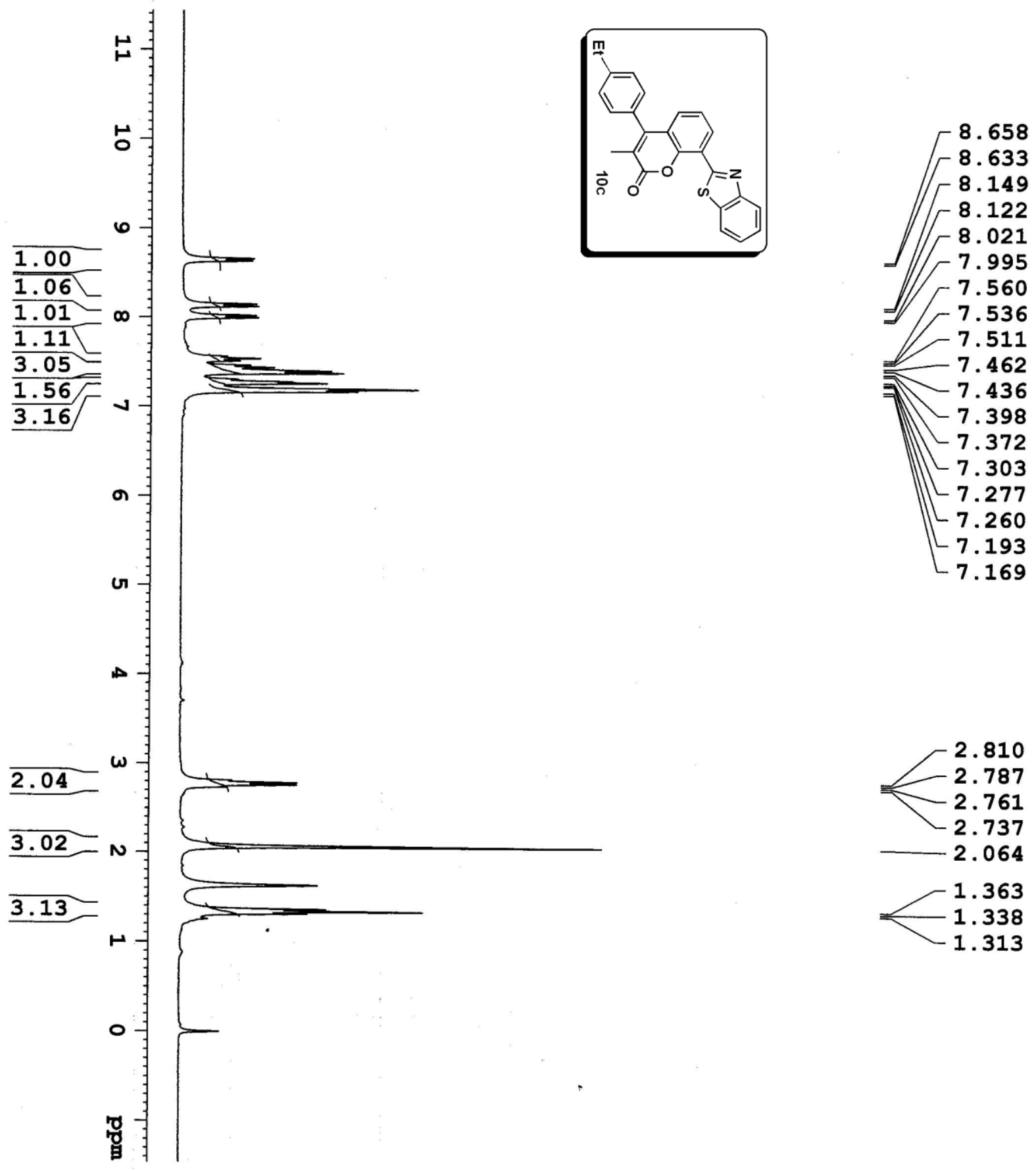




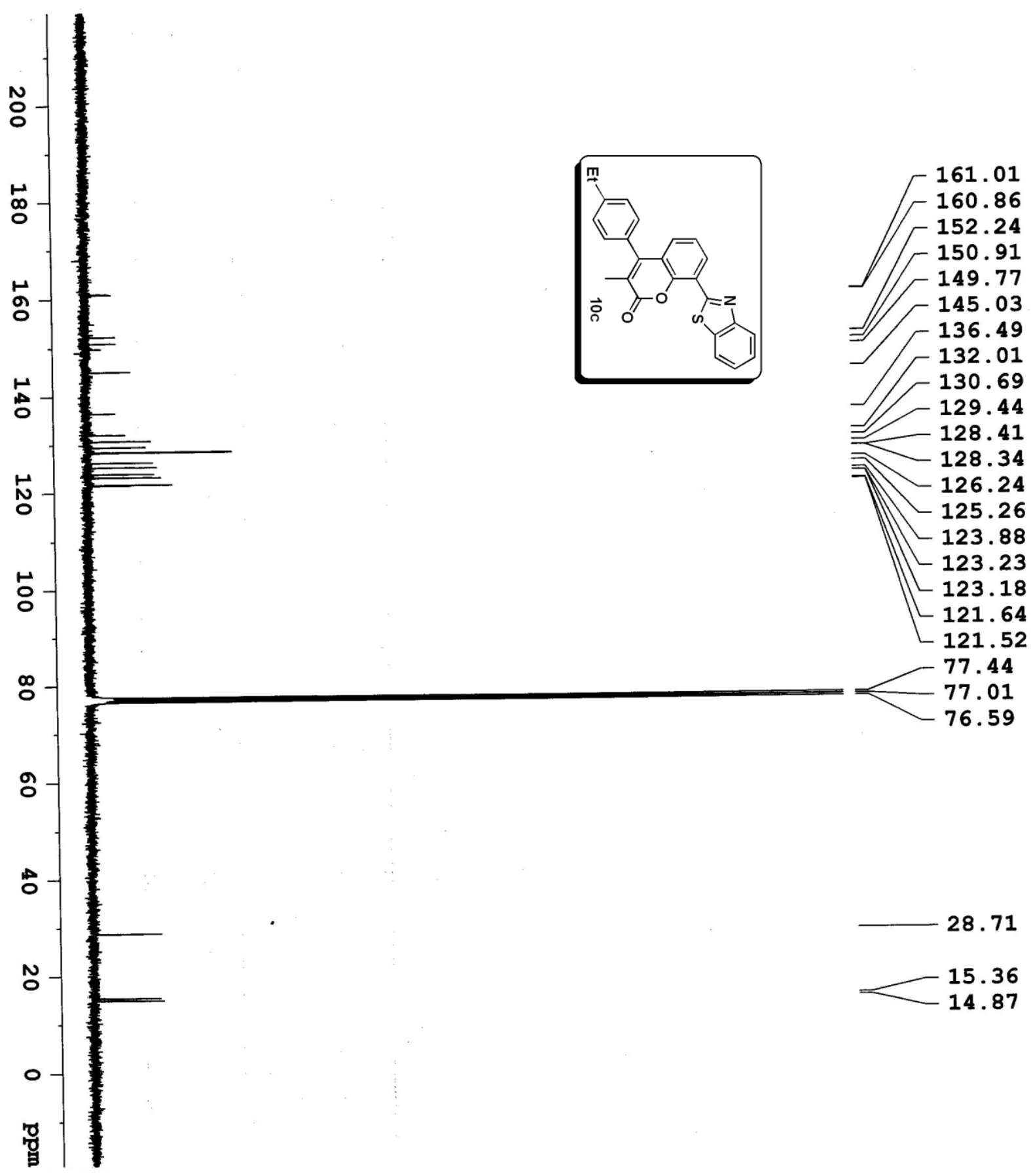




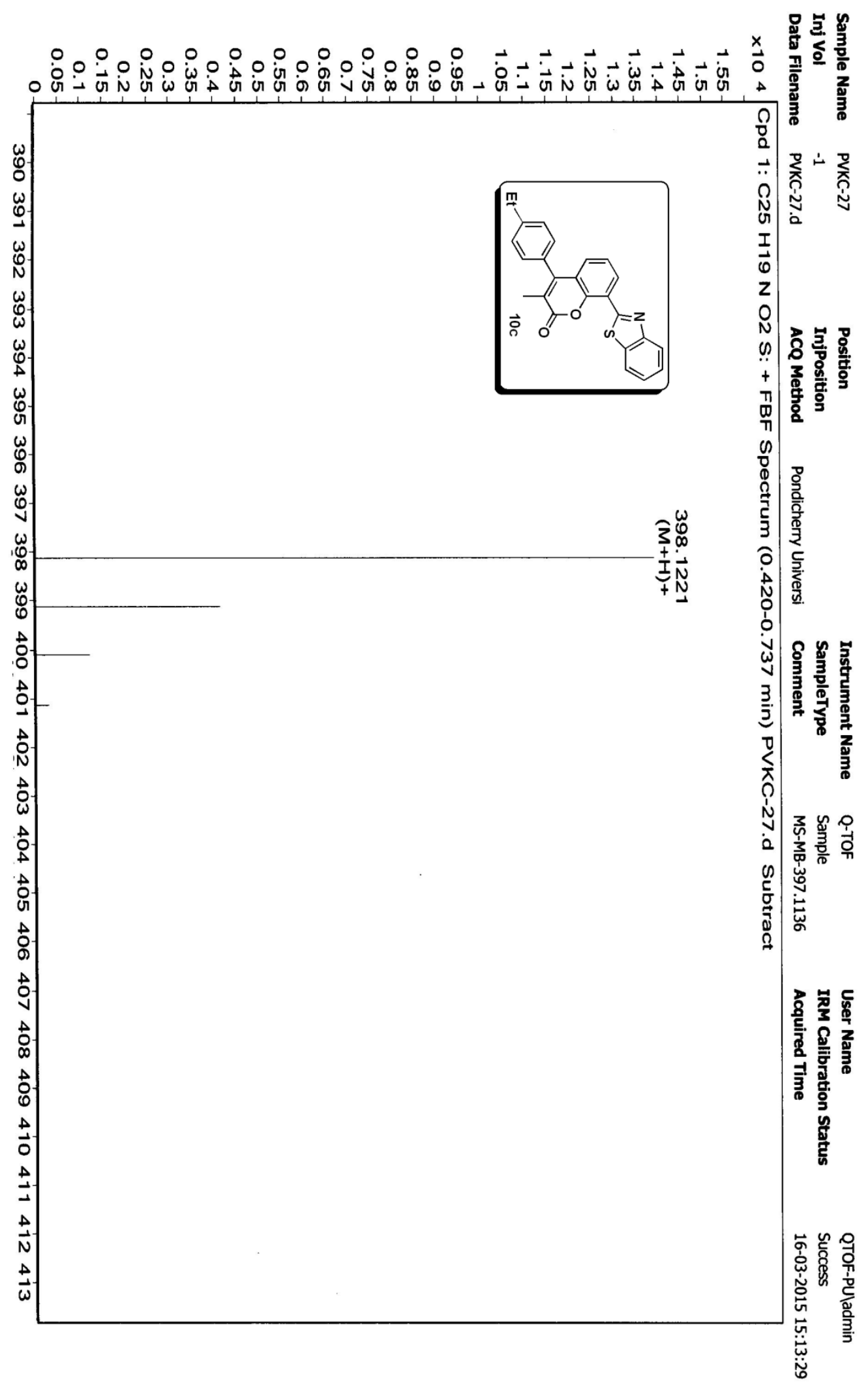




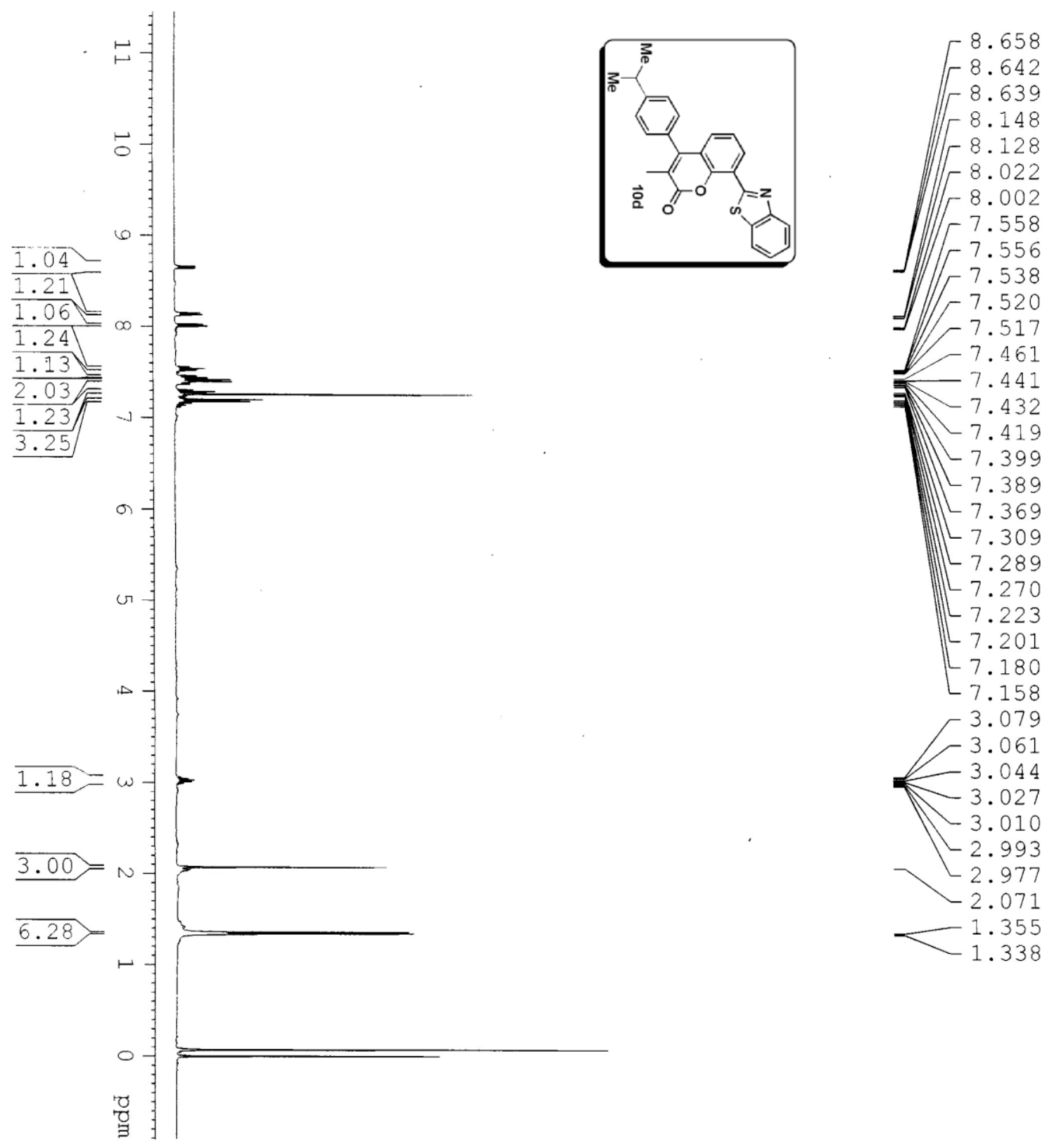




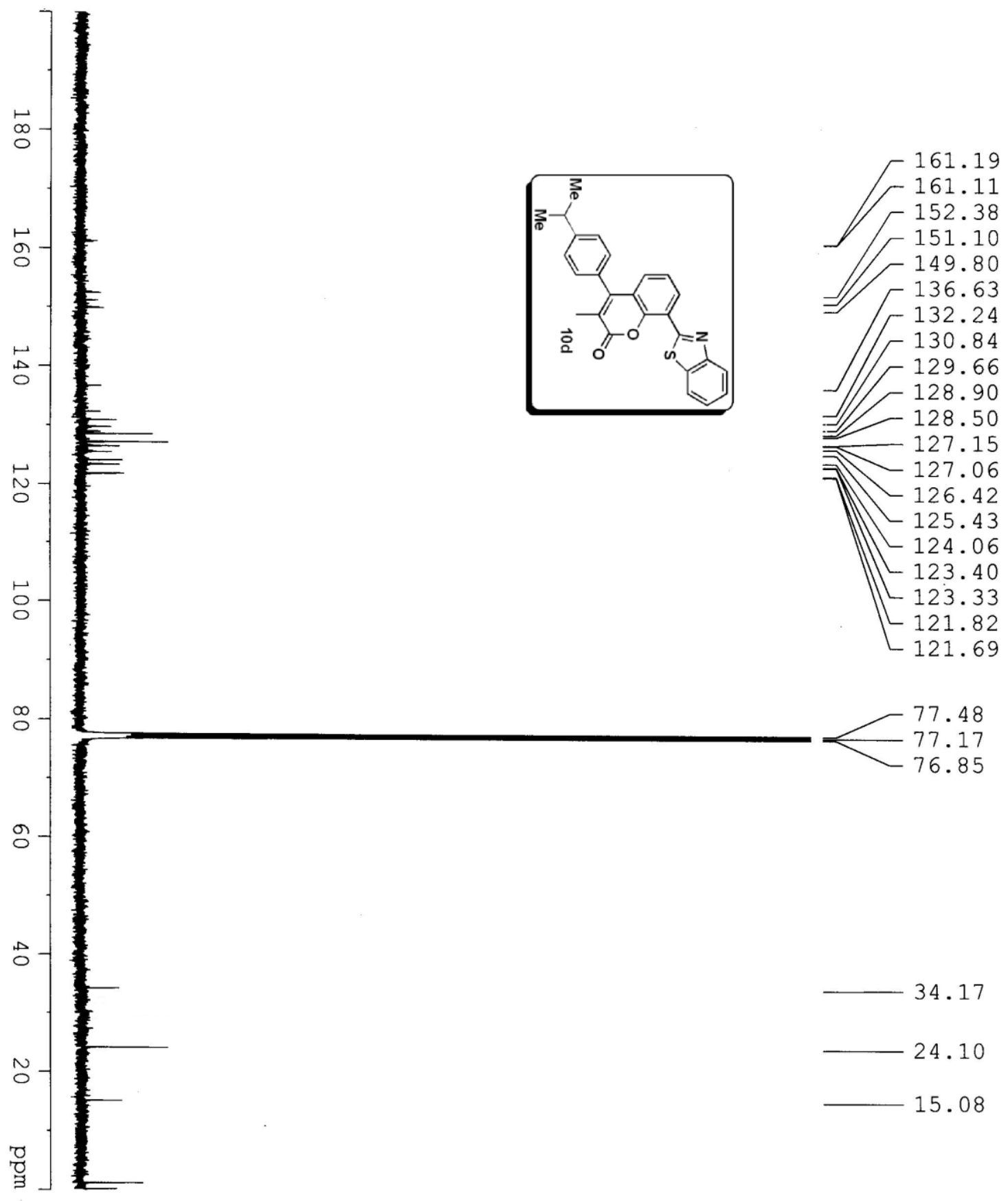




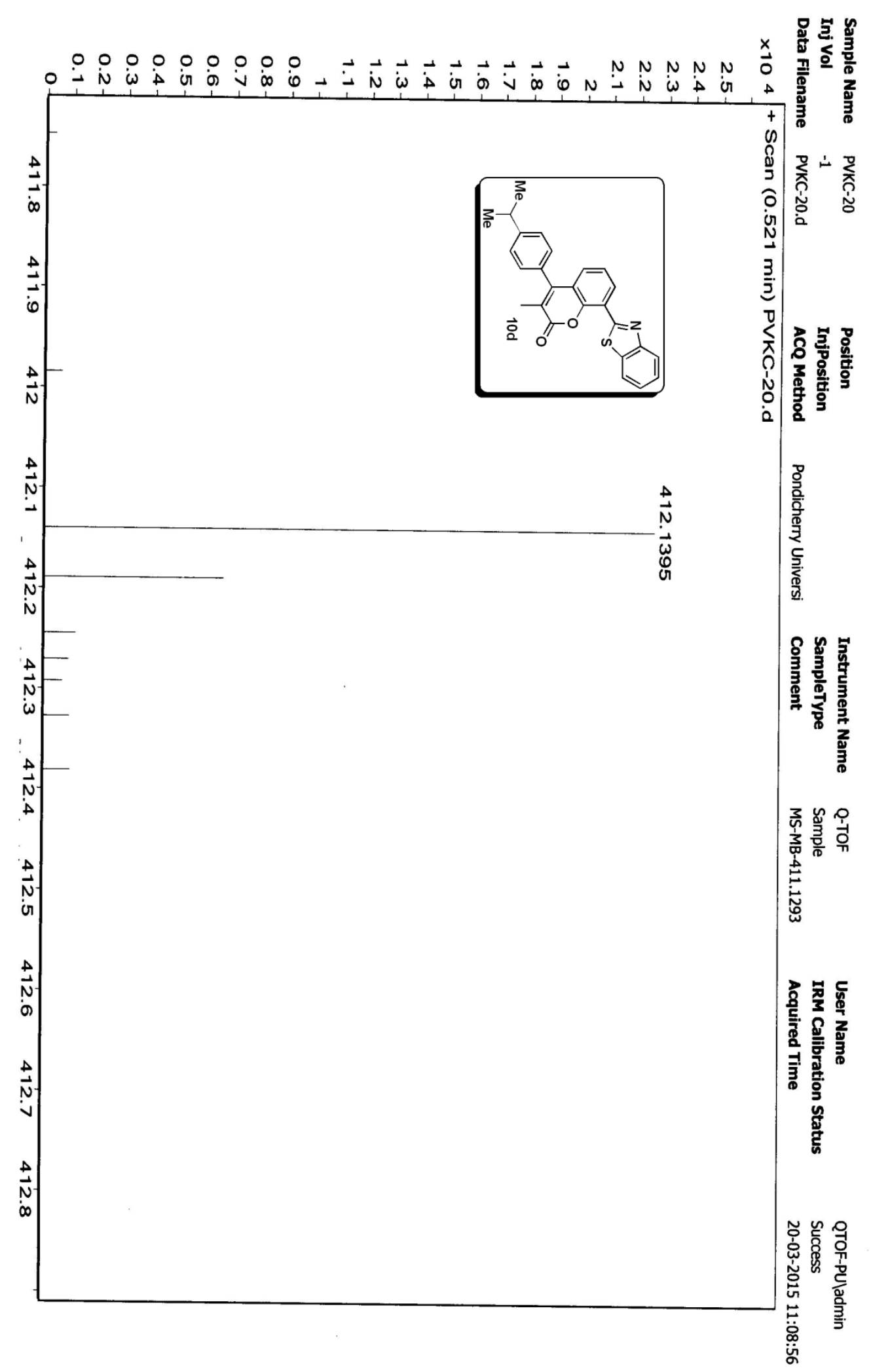




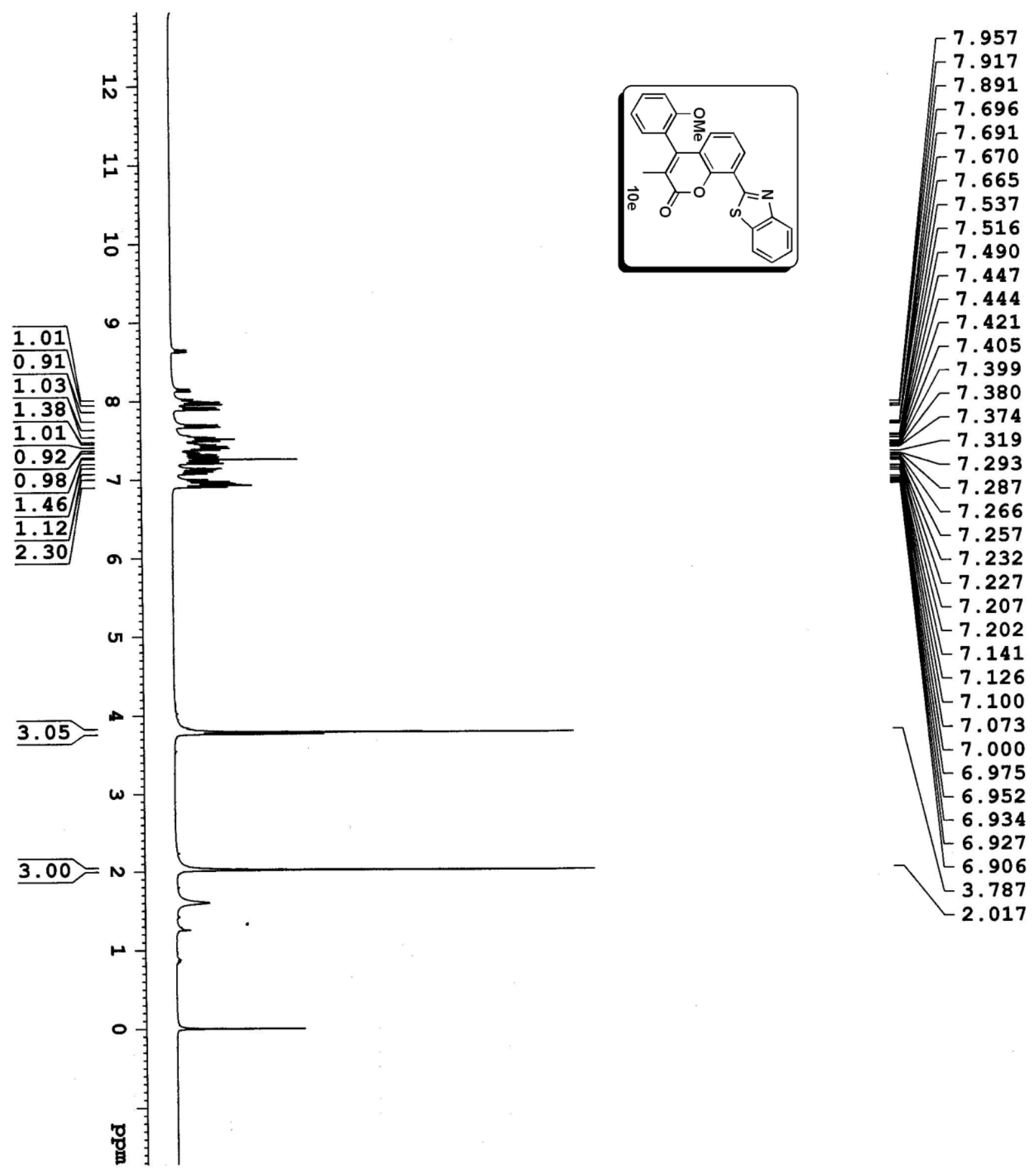



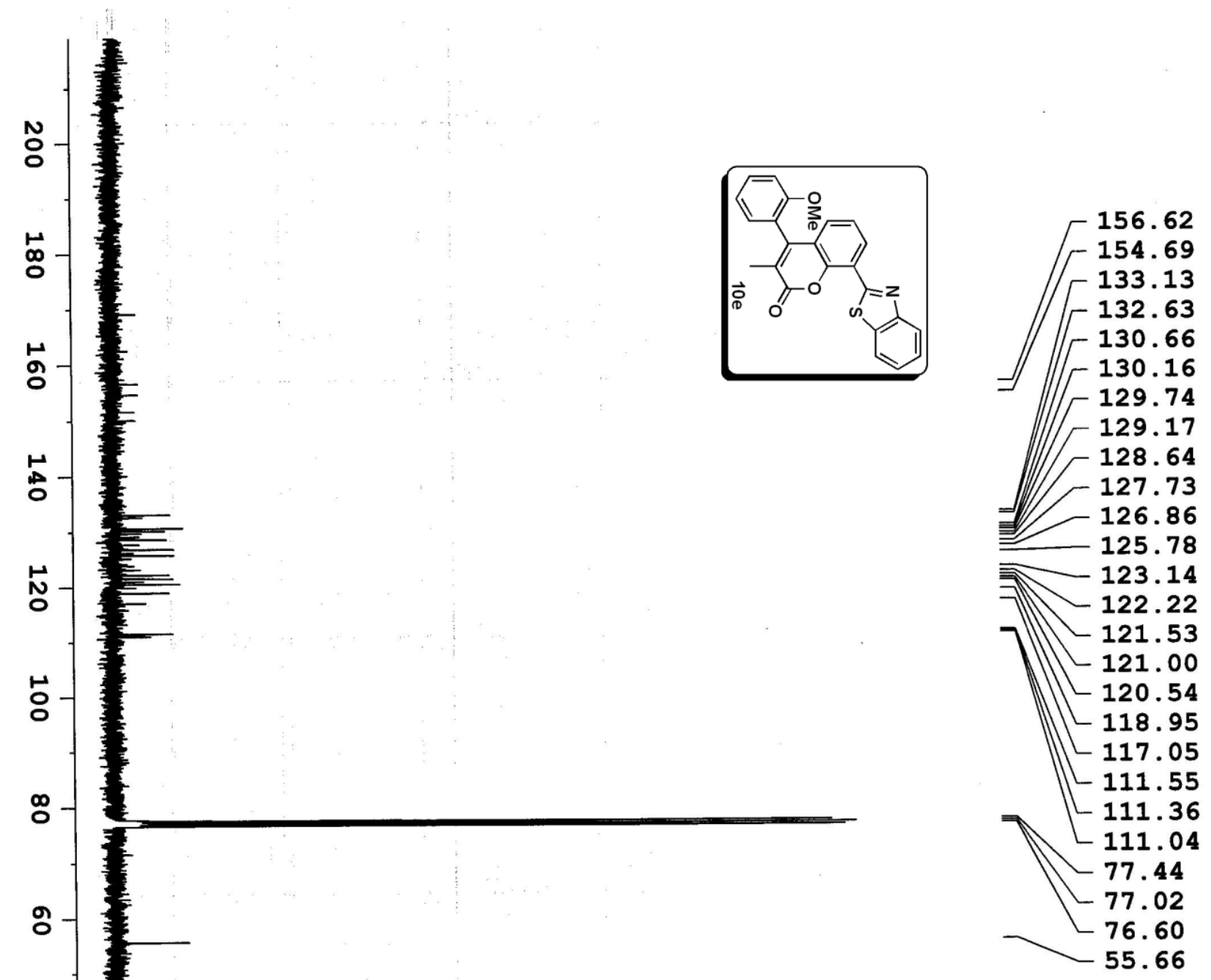

18.67 
Single Mas's Analysis (displaying only valid results)

Tolerance $=200.0 \mathrm{mDa} / \mathrm{DBE}: \min =-1.5, \max =50.0$

Isotope cluster parameters: Separation $=1.0$ Abundance $=1.0 \%$

Monoisotopic Mass, Odd and Even Electron Ions

11 formula(e) evaluated with 1 results within limits (all results (up to 1000) for each mass)

QTOF MICRO

DEPARTMENT OF CHEMISTRY IITM

SPA-ACR-2 1 (0.019) AM (Cen,2, 80.00, Ht,5000.0,0.00,1.00); Sm (Mn, 2×4.00)

100

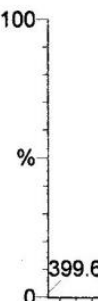

400.1016

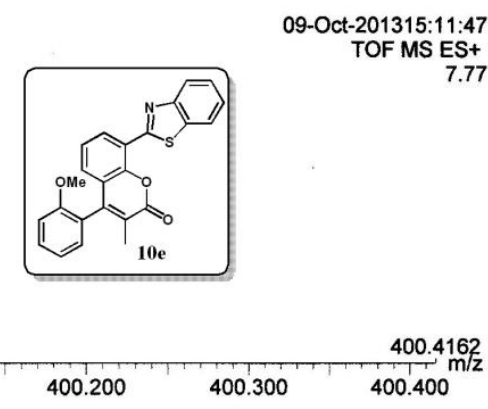

Minimum:

Maximum:

399.700

$399.800 \quad 399.900$

$99.900 \quad 400.000$

-1.5
50.0

Mass Calc. Mass

200.0

5.0

DBE

$\mathrm{mDa} \quad \mathrm{PPM}$

DBE Score

Formula

400.1016

400.1007

0.8

2.1

$16.5 \quad 1$

$\mathrm{C} 24 \mathrm{H} 18 \mathrm{~N} \quad \mathrm{O} 3 \mathrm{~S}$ 

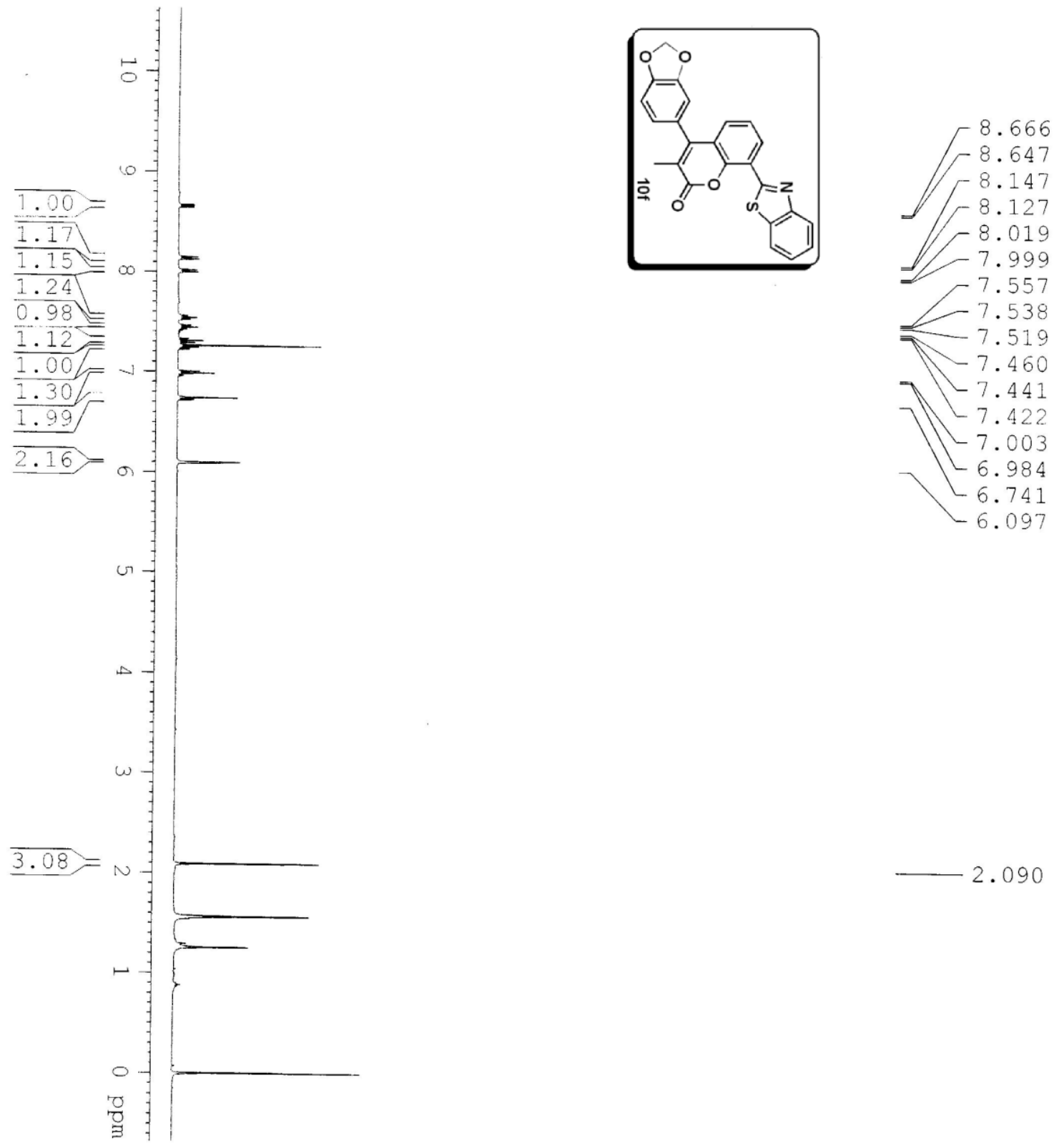

7.999

$-7.538$

$-7.519$

$-7.460$

$-7.441$

$-7.422$

$-7.003$

$-6.984$

6.741

$-6.097$

2.090 


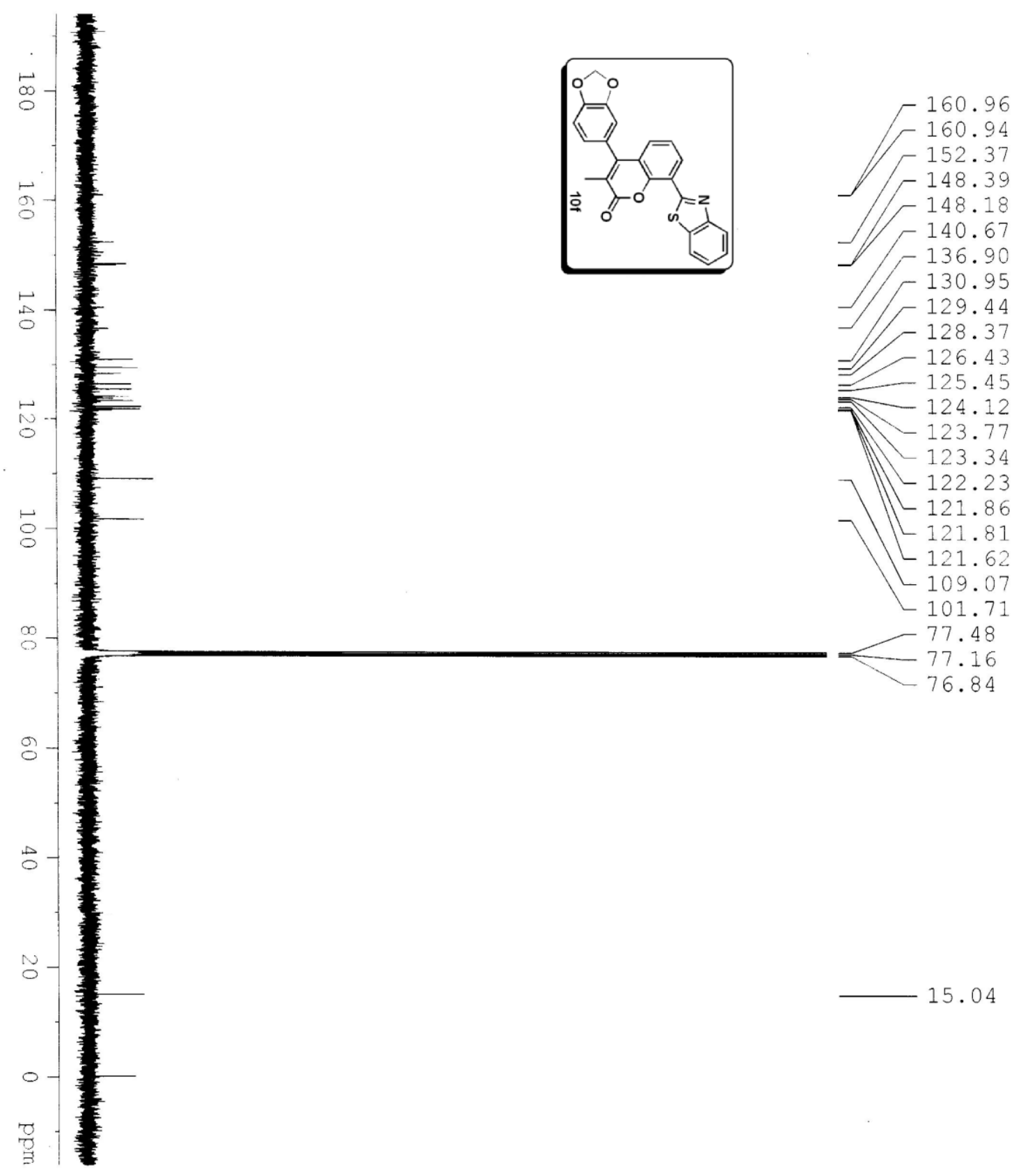




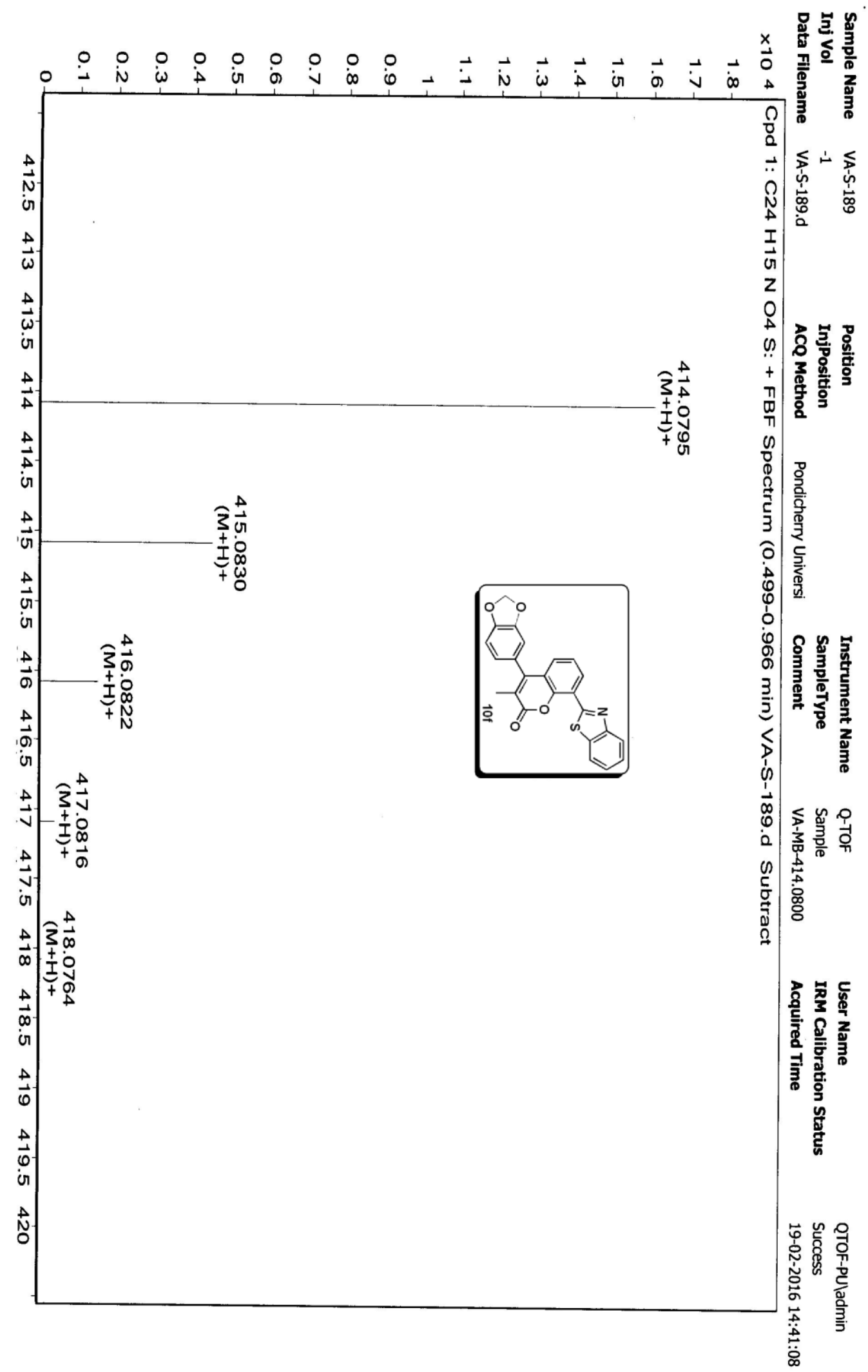



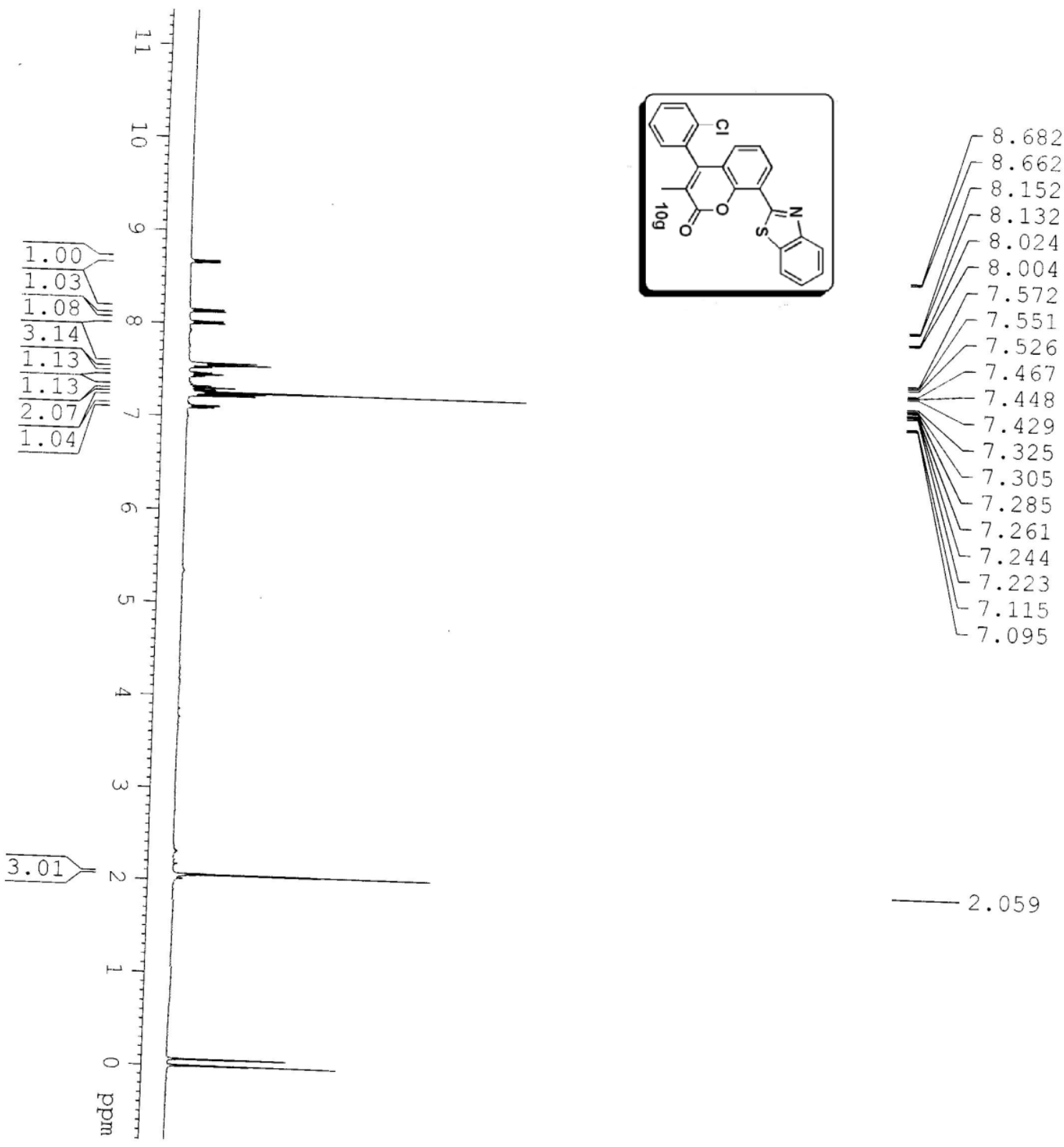


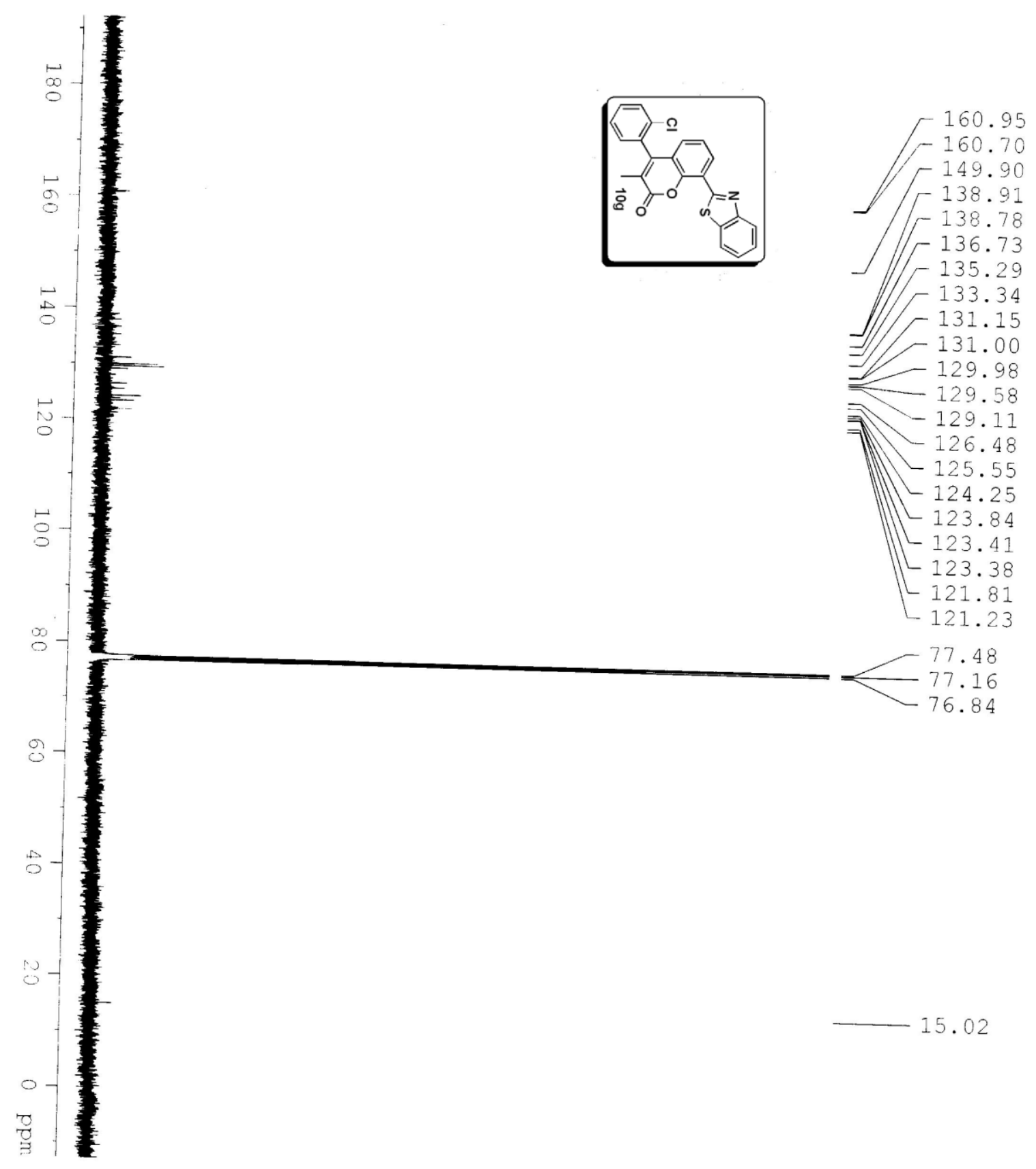




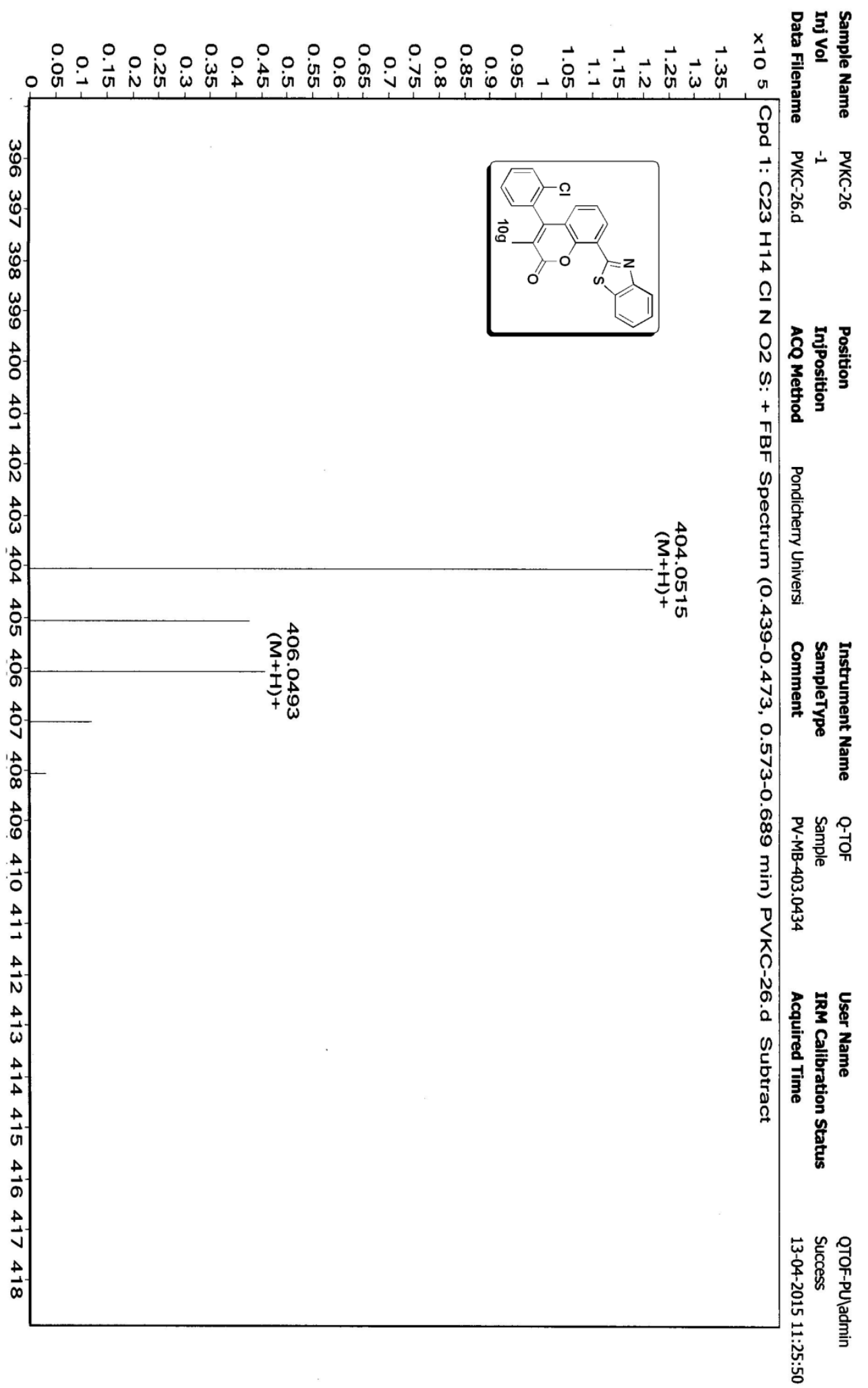




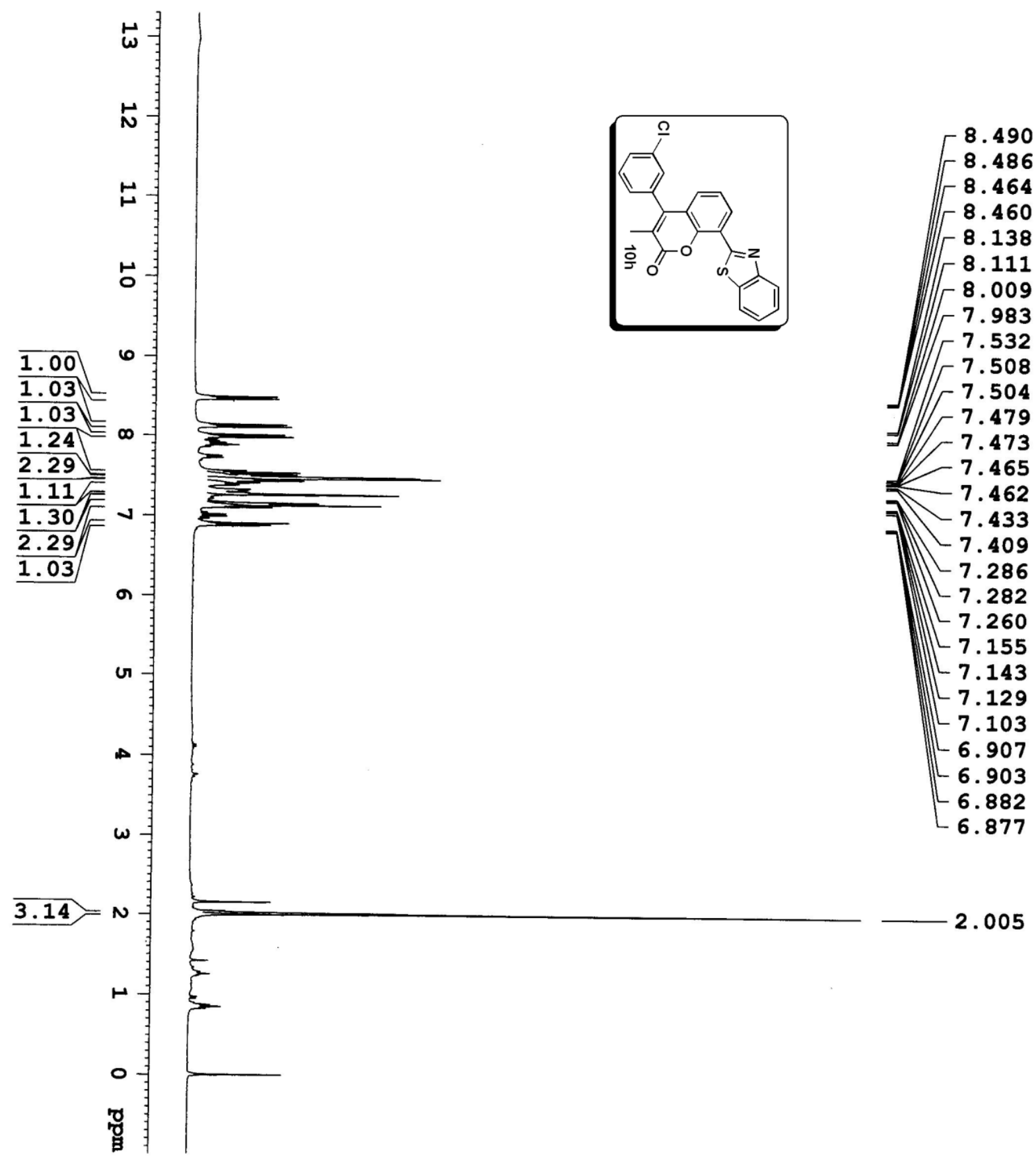



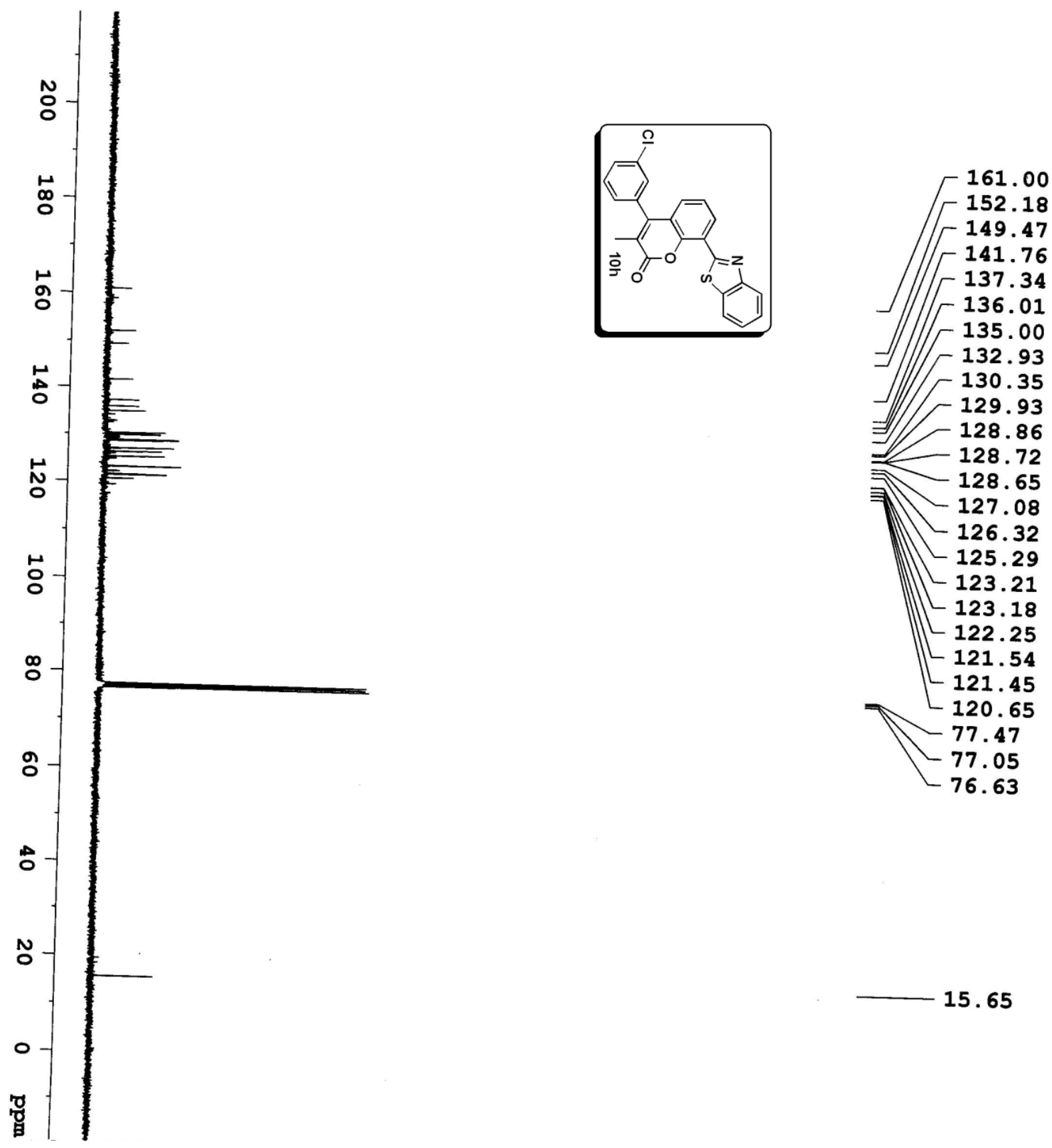

15.65 


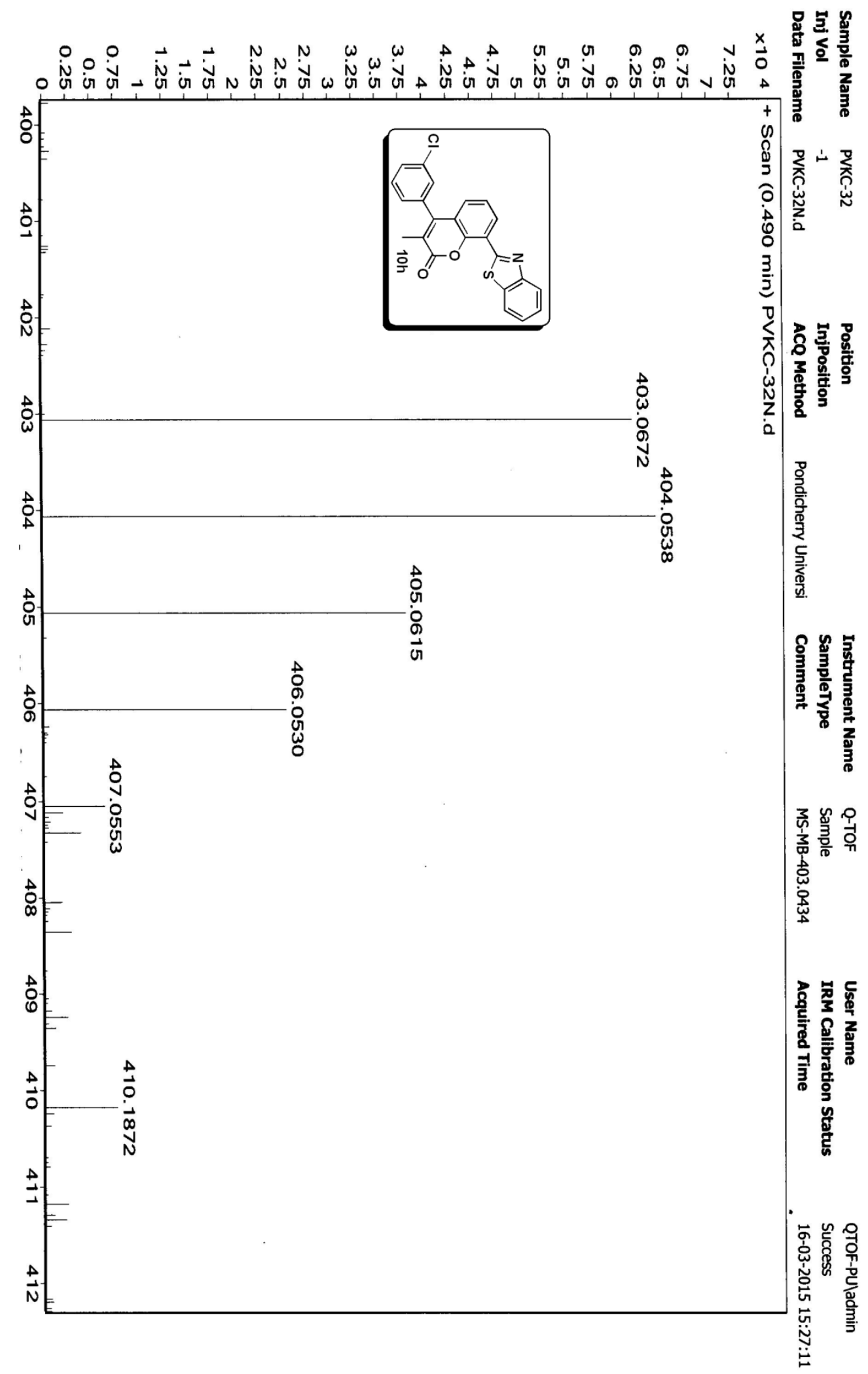



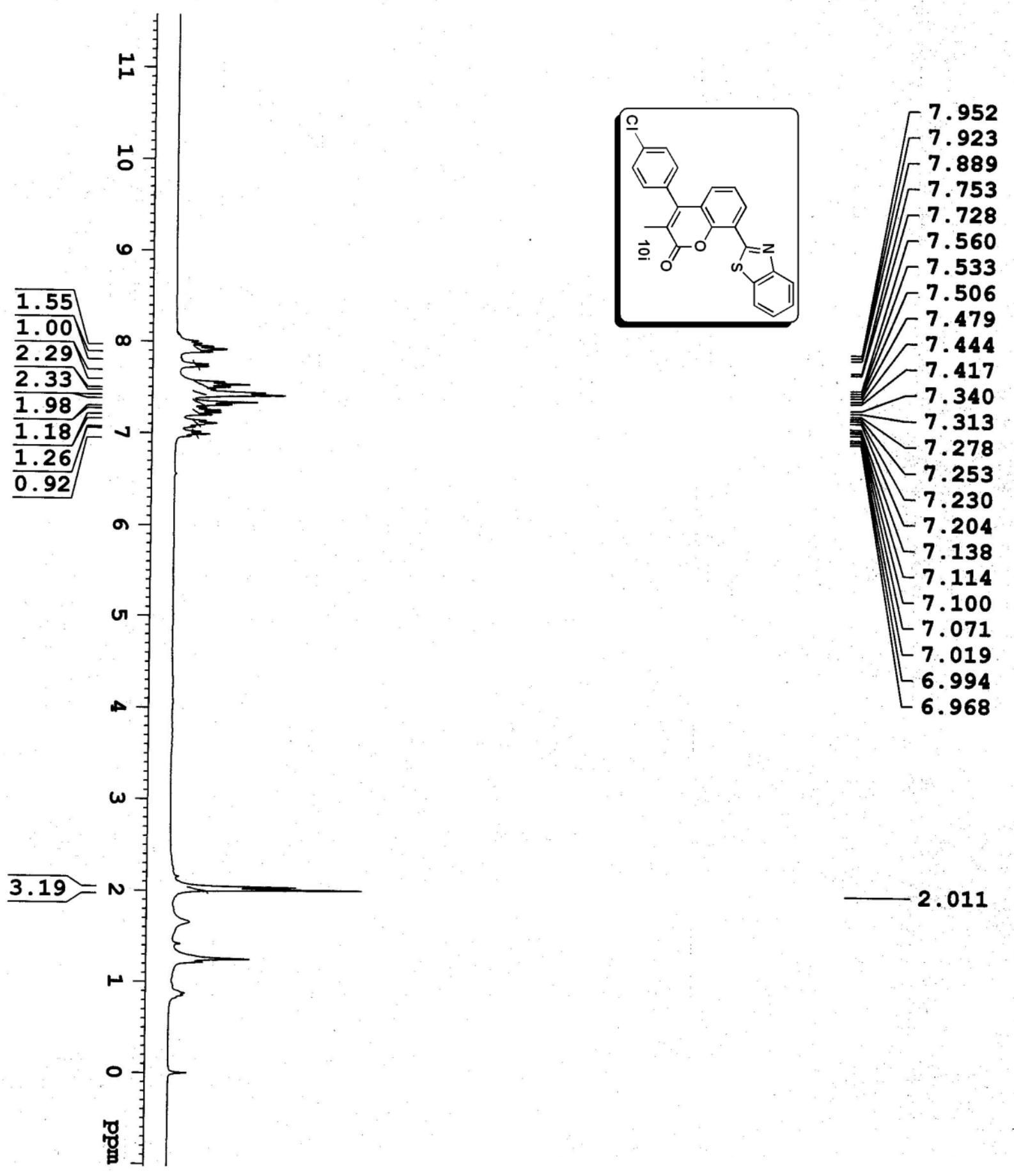

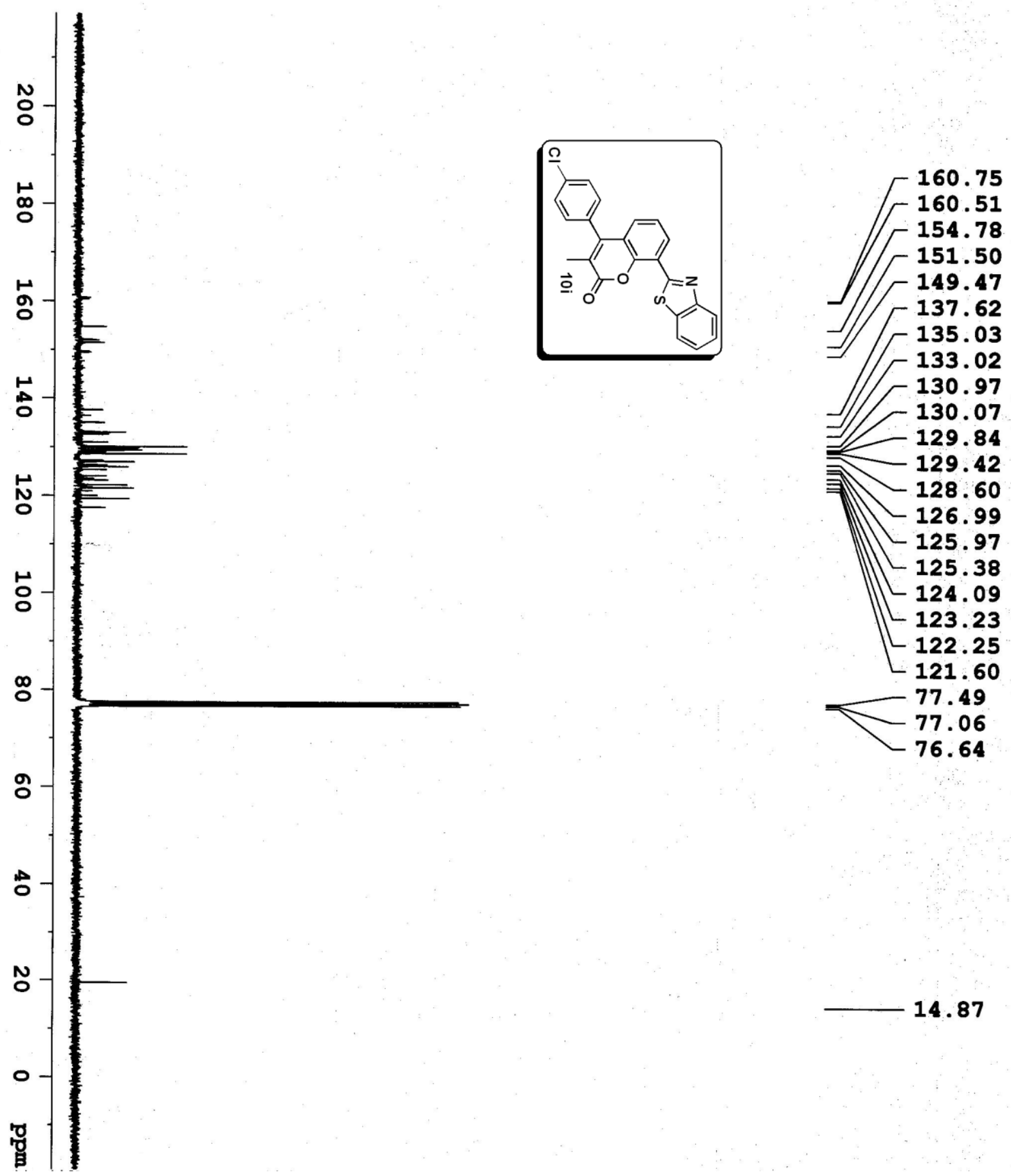

14.87 


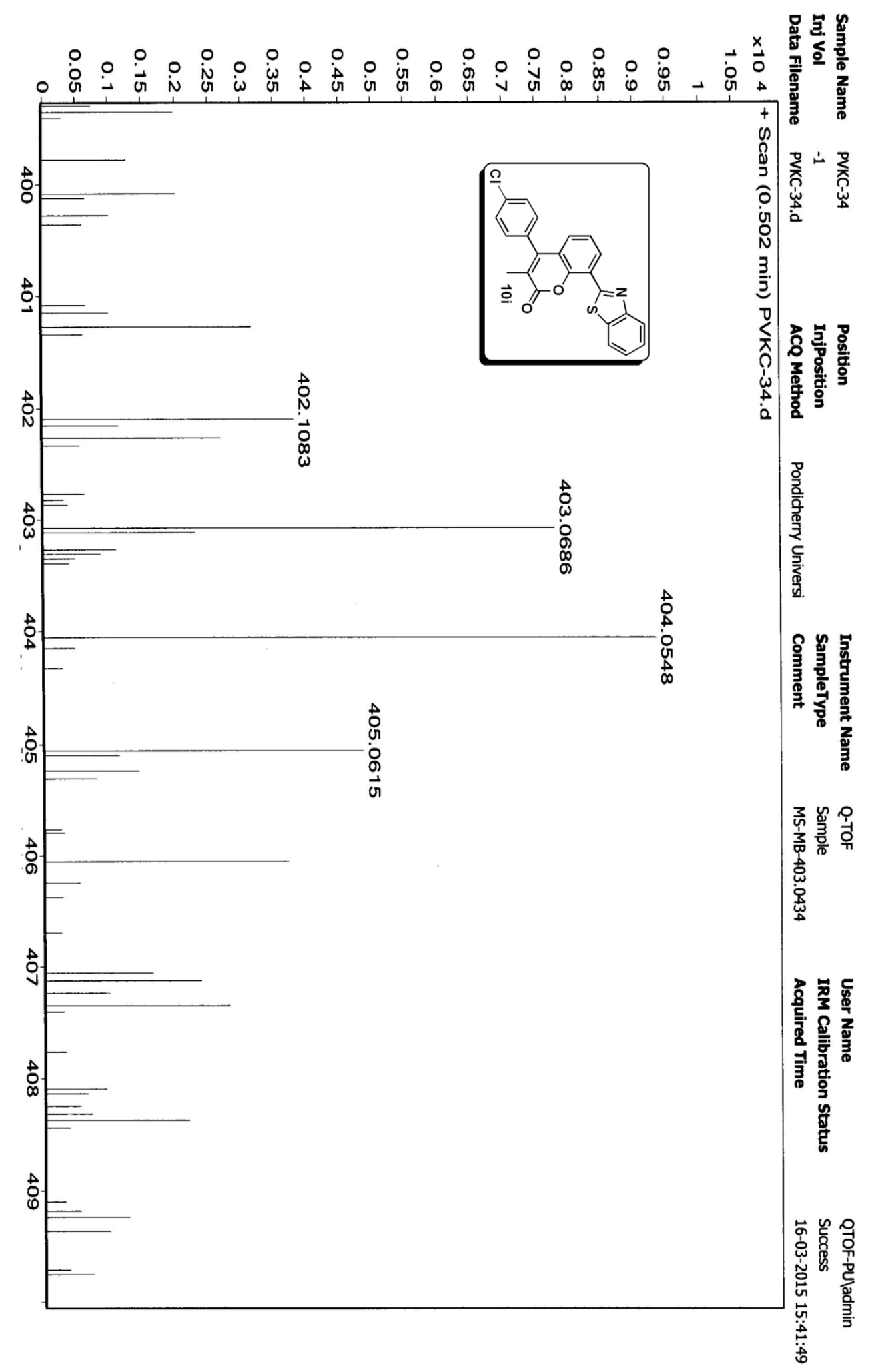



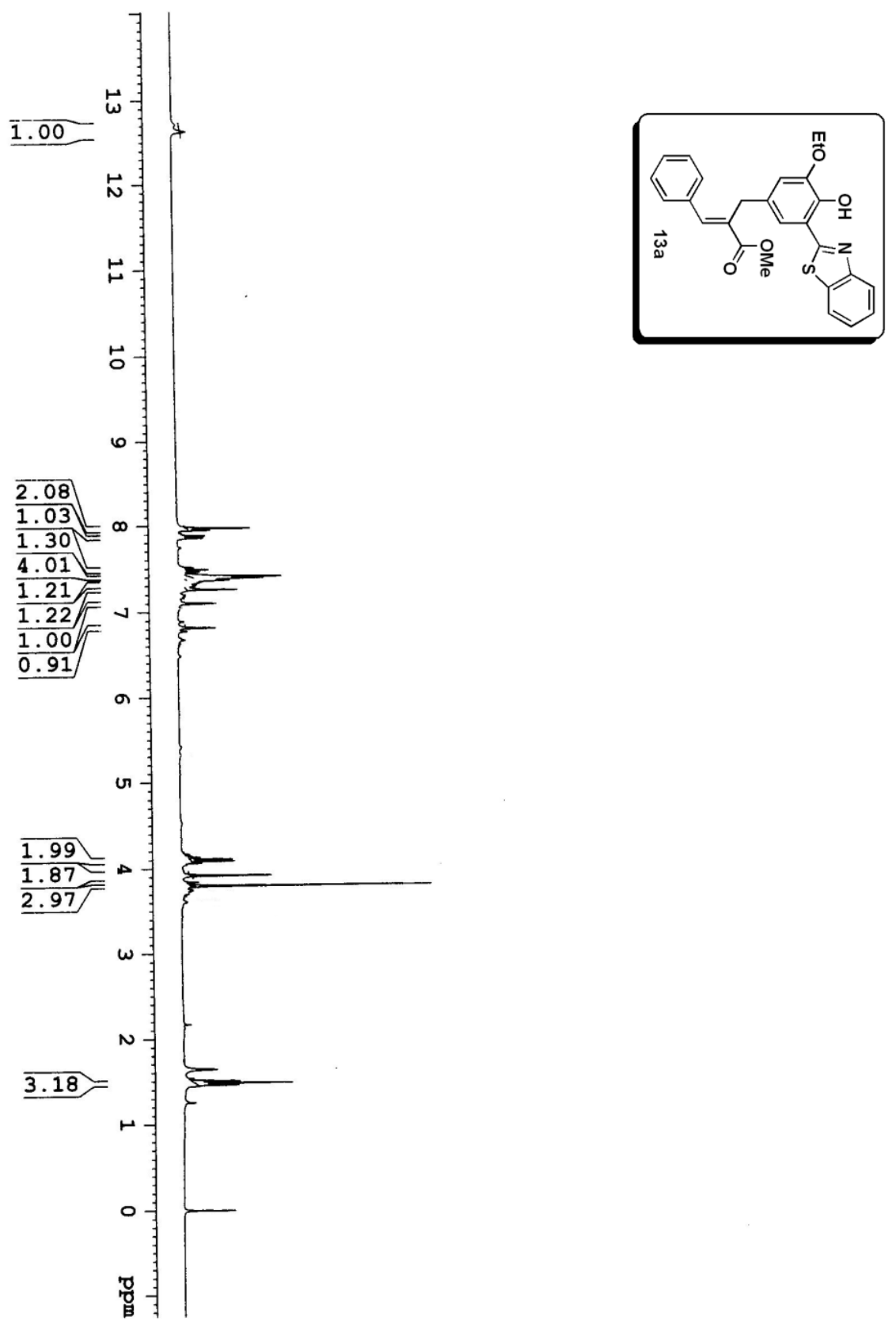

7.973

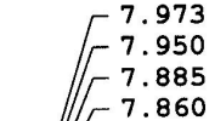

T 7.860

7.516

F 7.489

$-7.465$

7.462

7.392
-7.375

$-7.375$

$-7.366$

7.270

7.259

6.819

6.815

4.135

4.112

4.088

$\checkmark 4.065$

$-3.799$

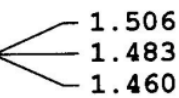

首 

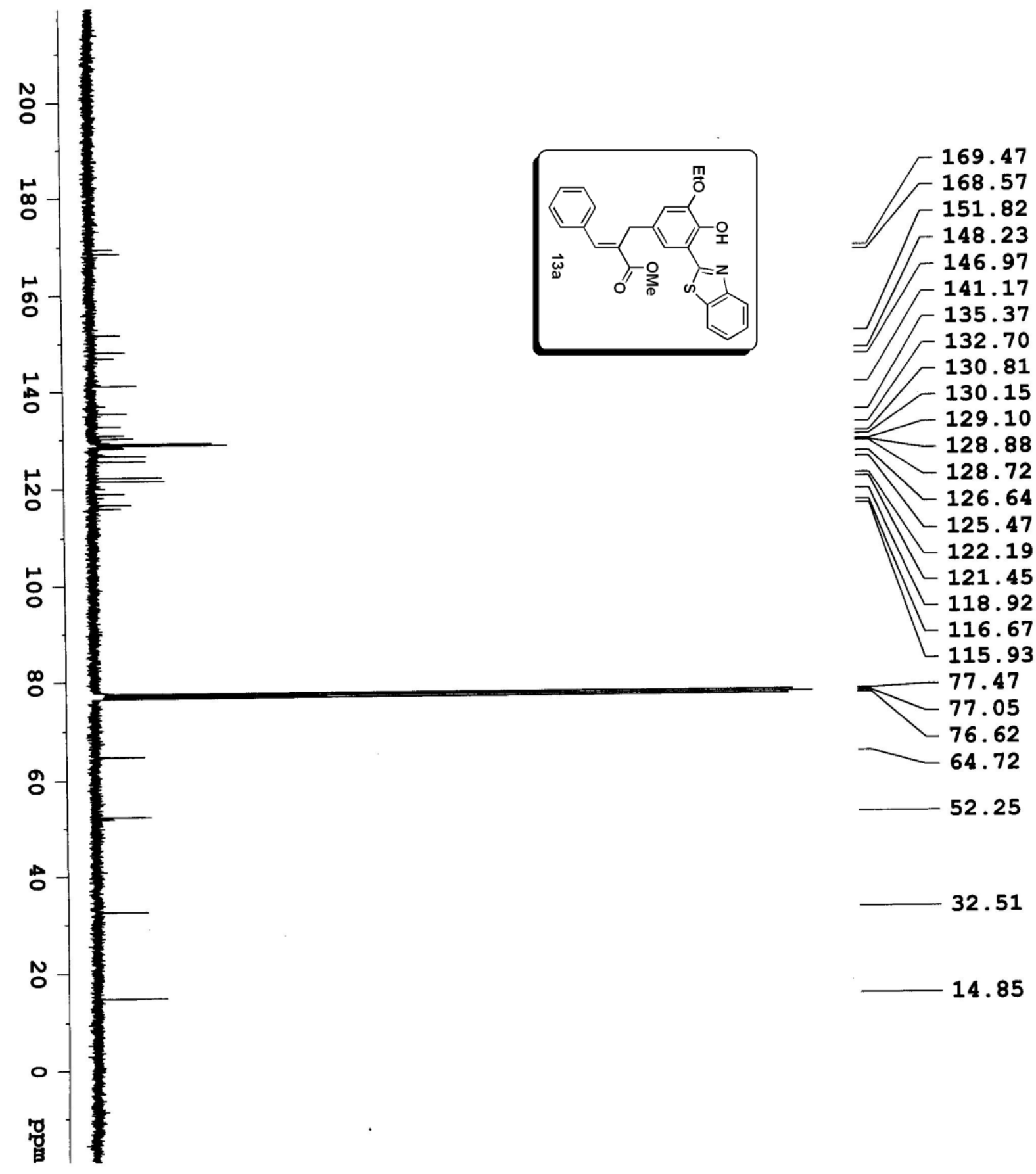


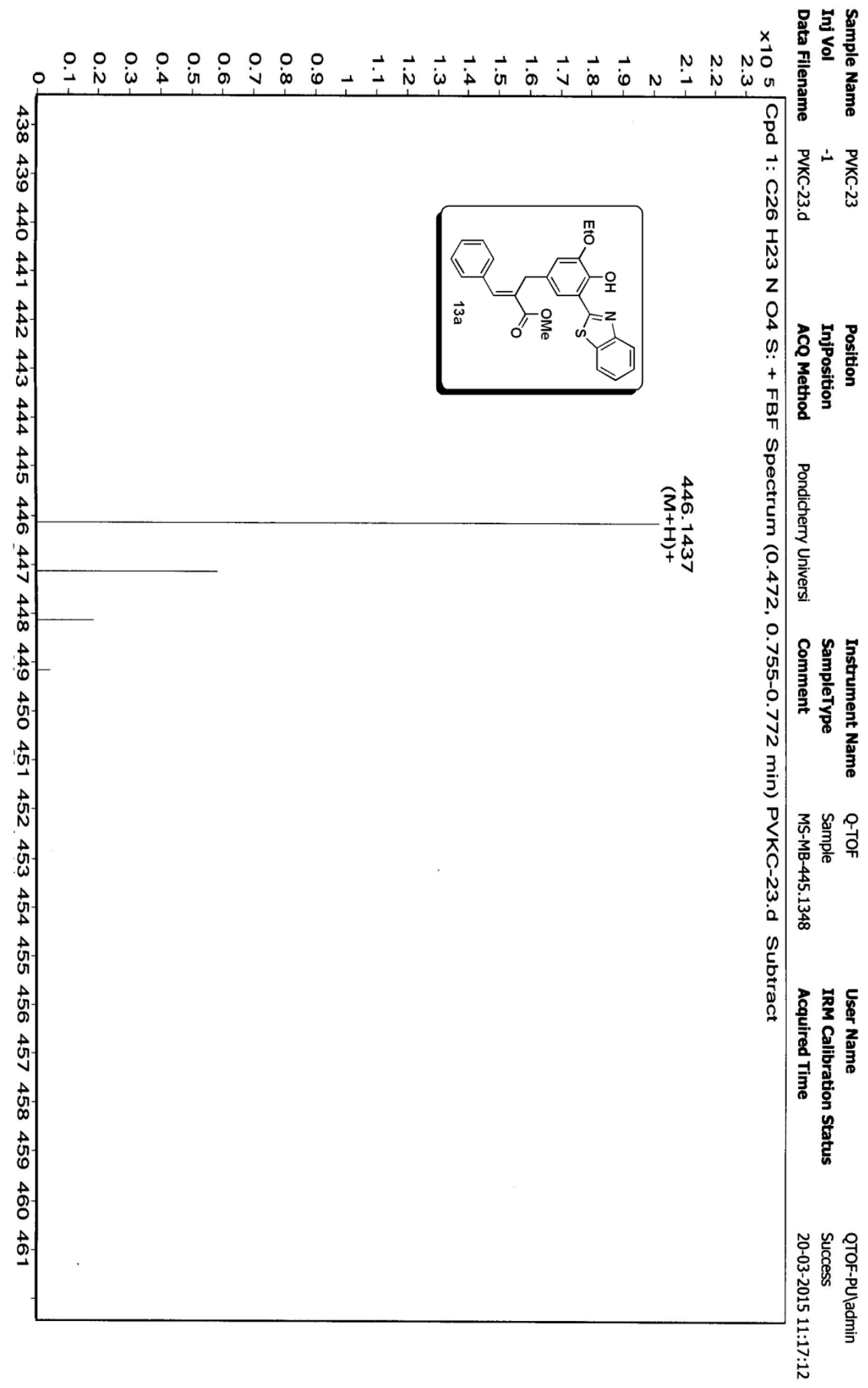



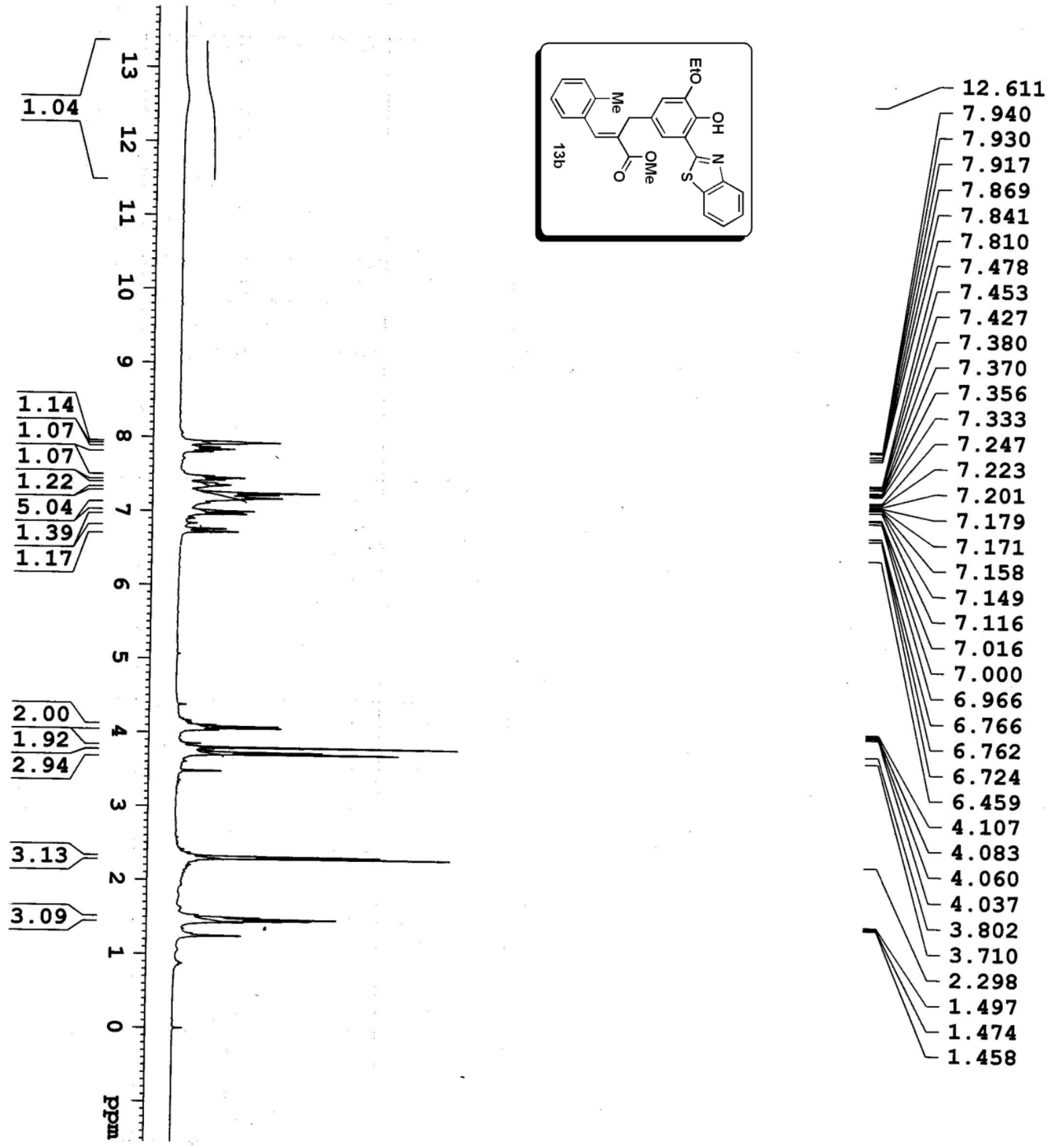

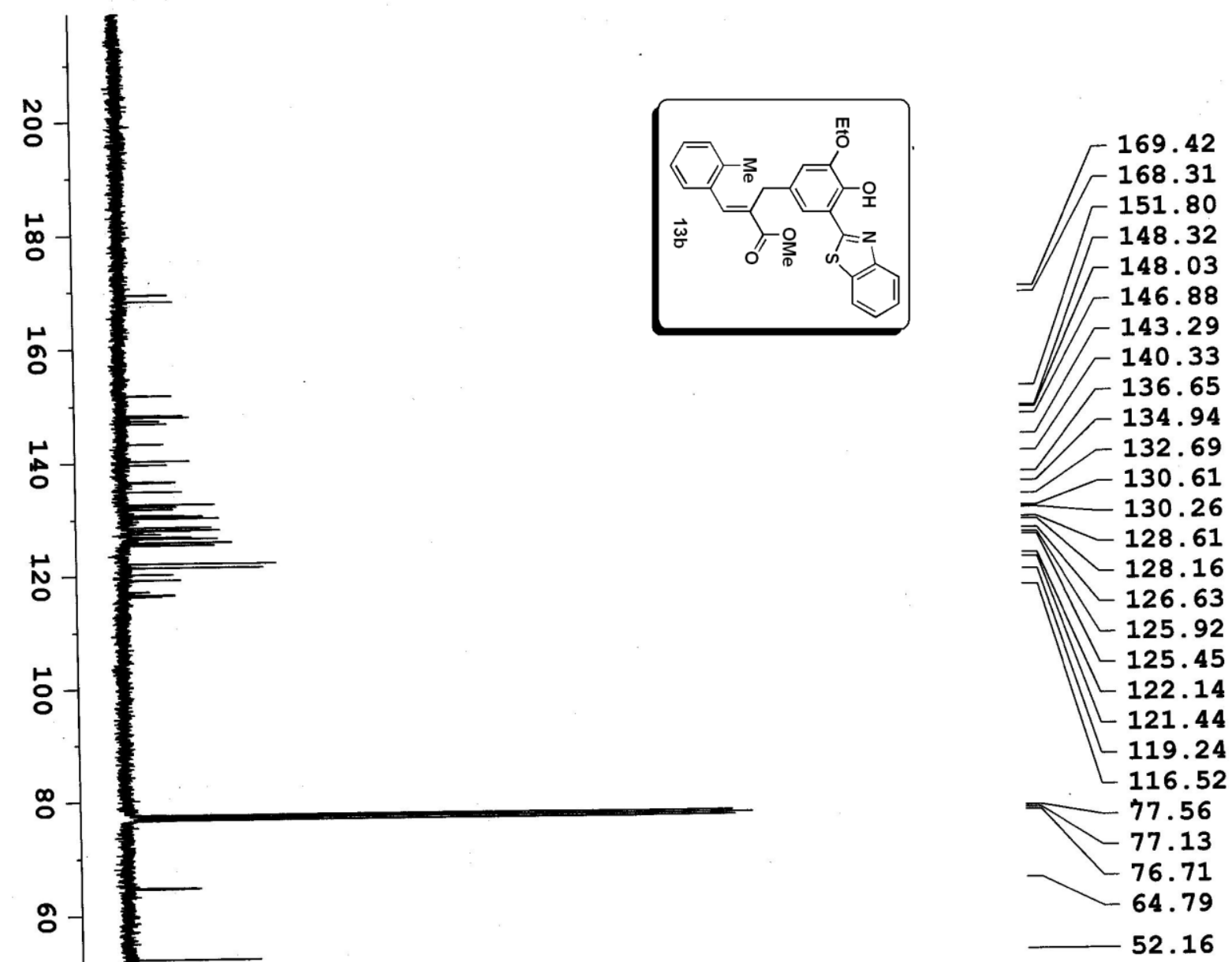

32.41

20.06

14.88 


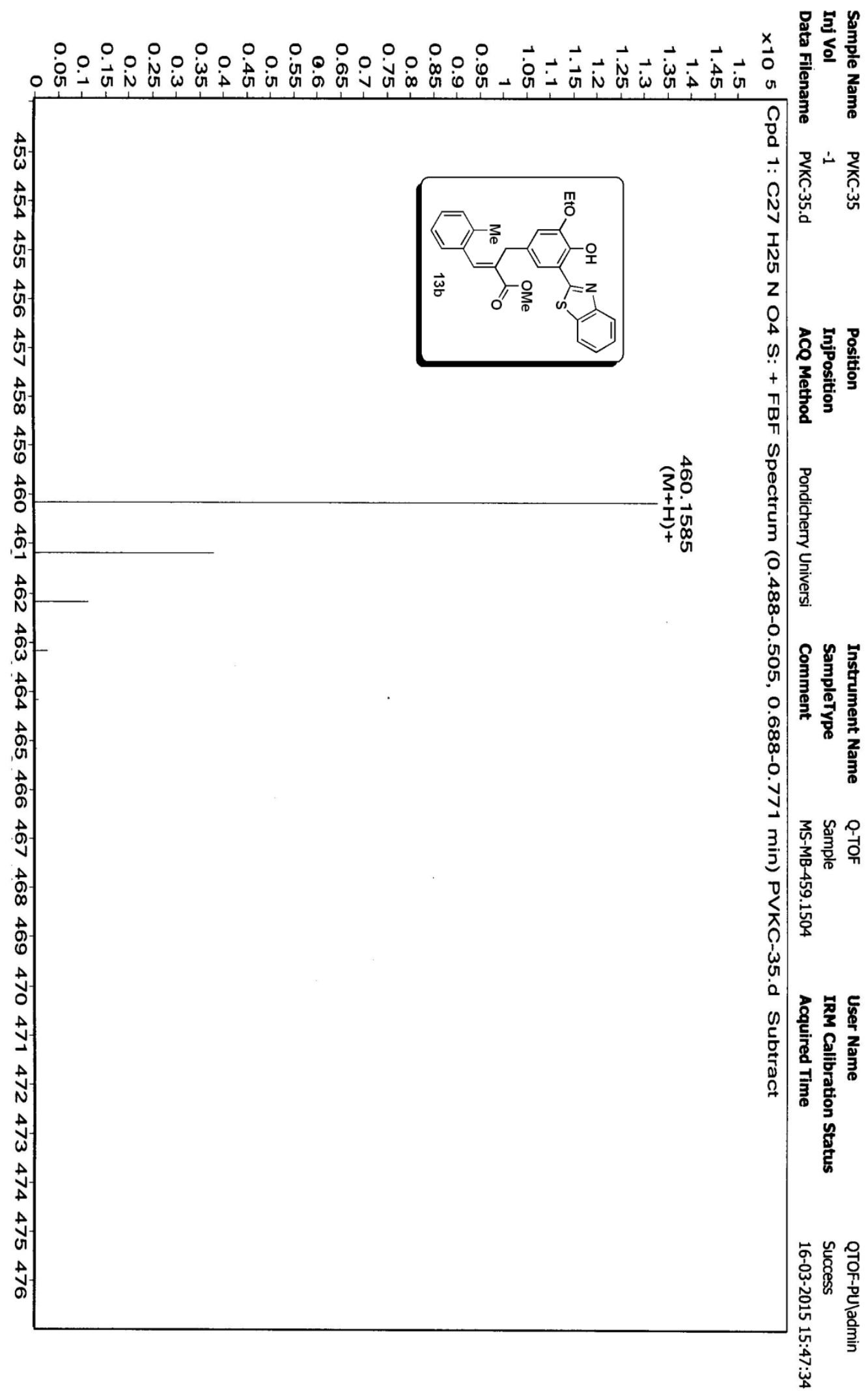



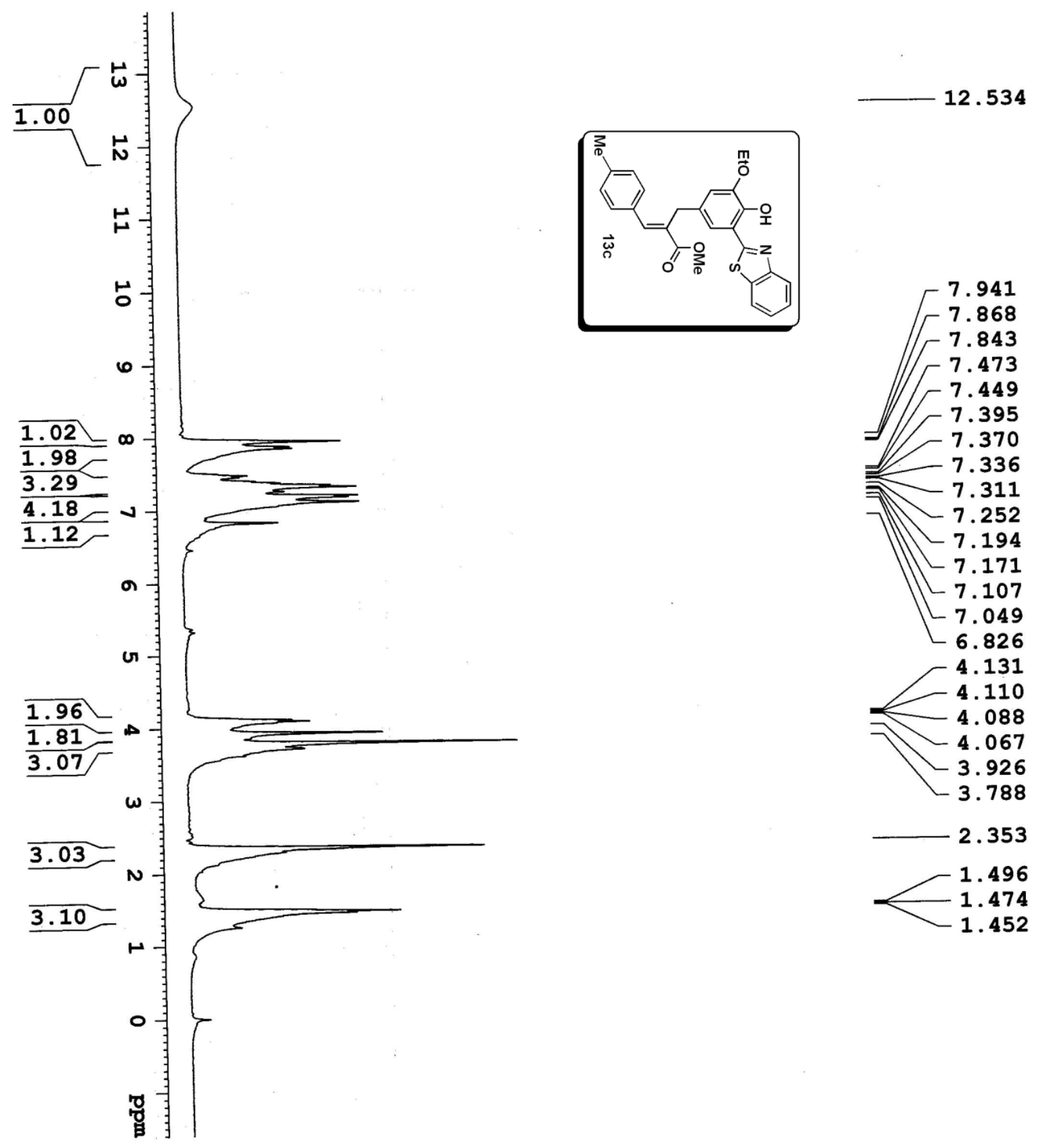

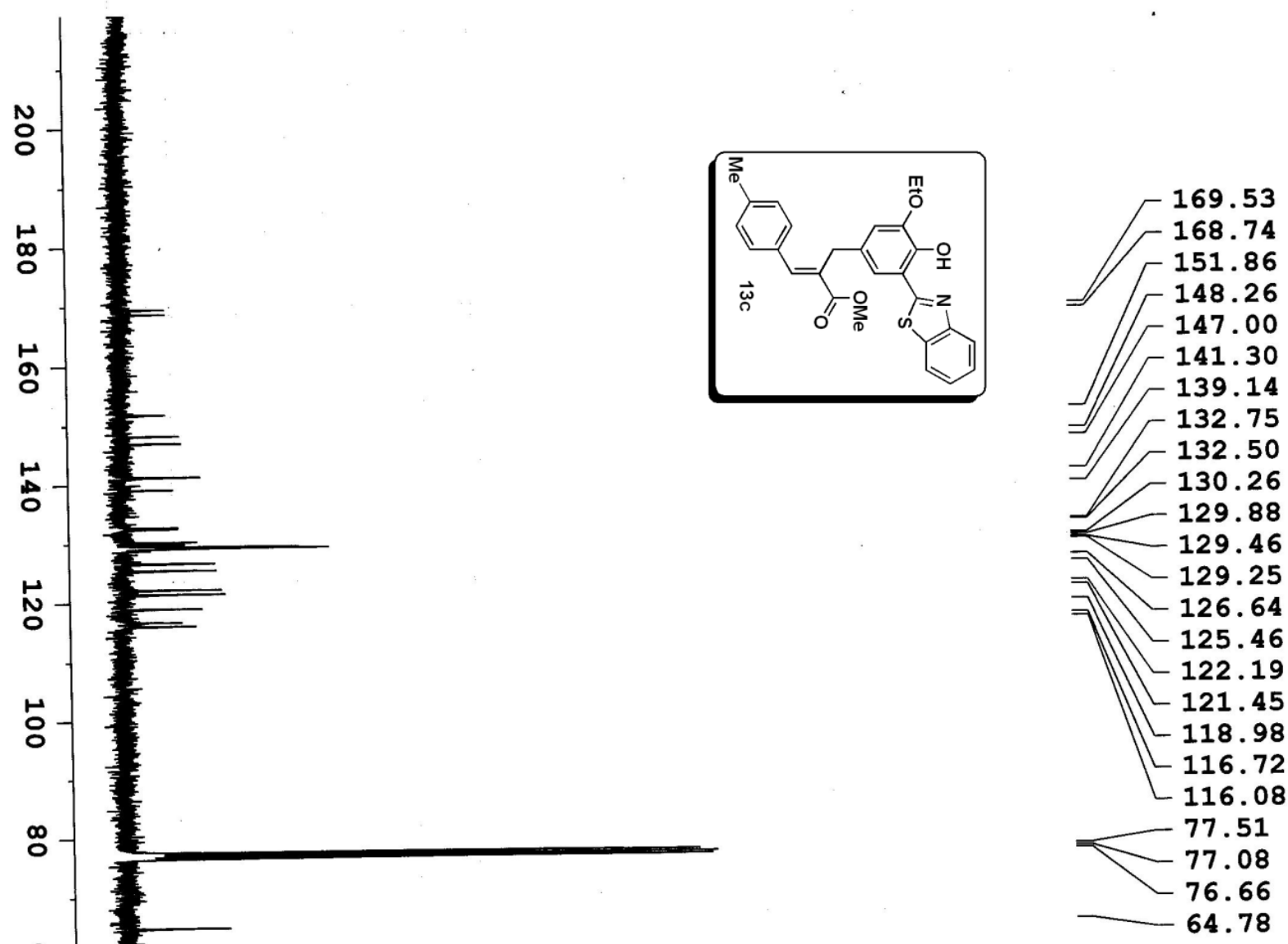

52.18

32.58

21.36

14.87 


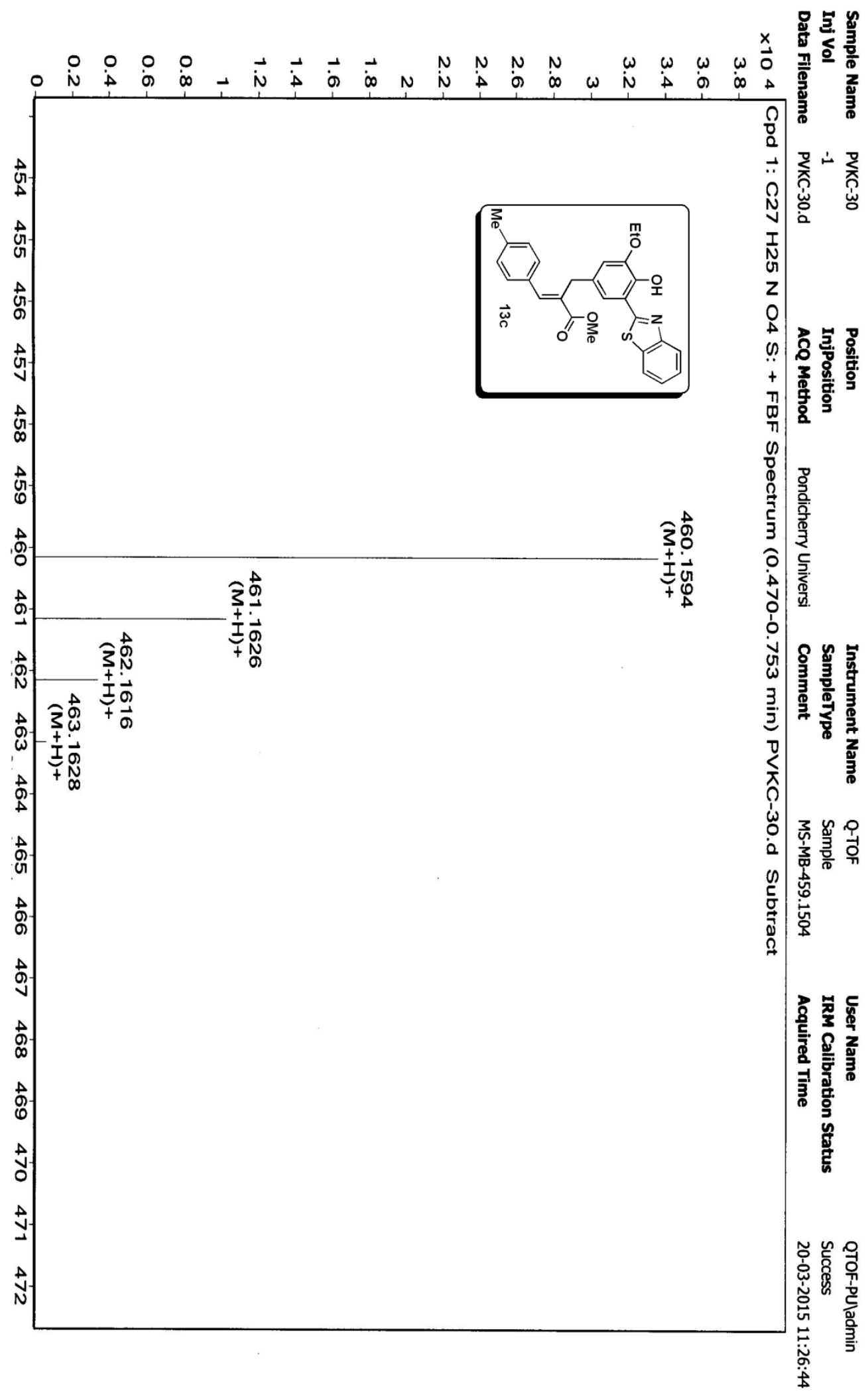




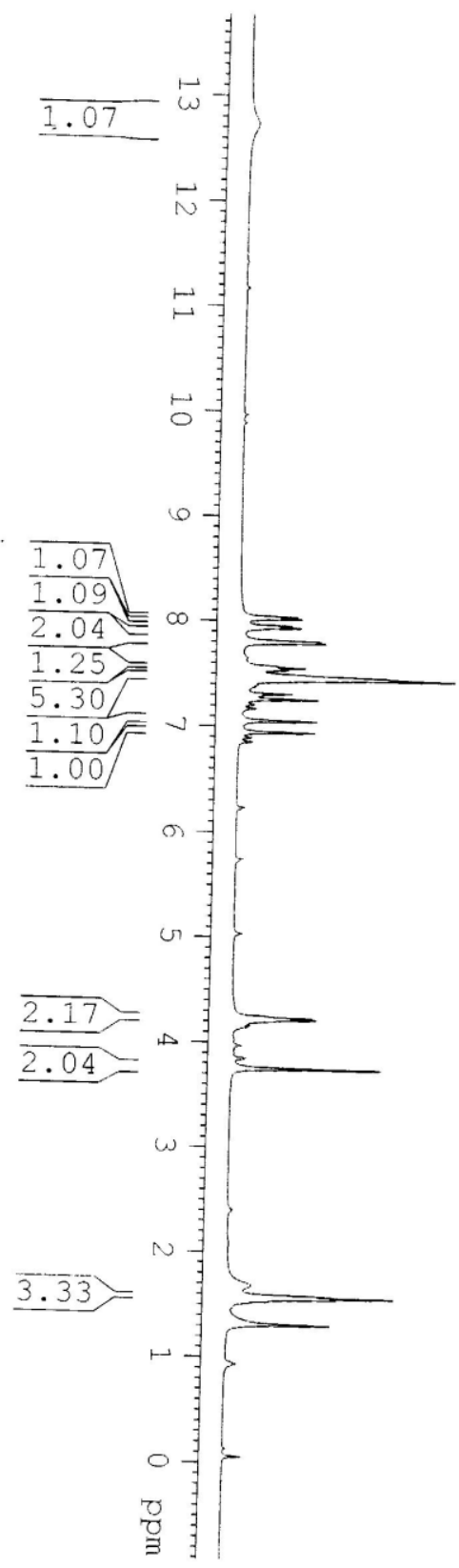

12.734
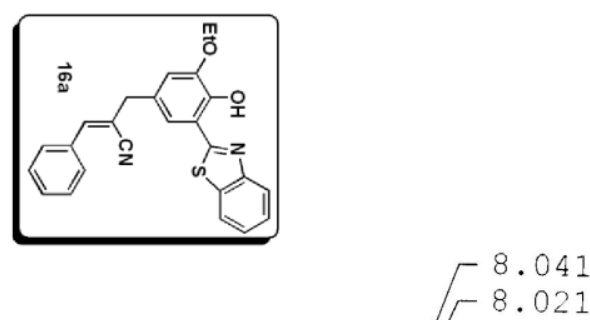

$-7.954$

$-7.935$

7.808

$-7.794$

$-7.574$

$-7.556$

$\mathbf{7}-7.537$

$7-7.472$

$\lcm{-7.457}$

$-7.311$

$-7.259$

$-7.055$

6.946

4.250

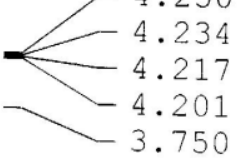

1.588

1.571
-1.555 

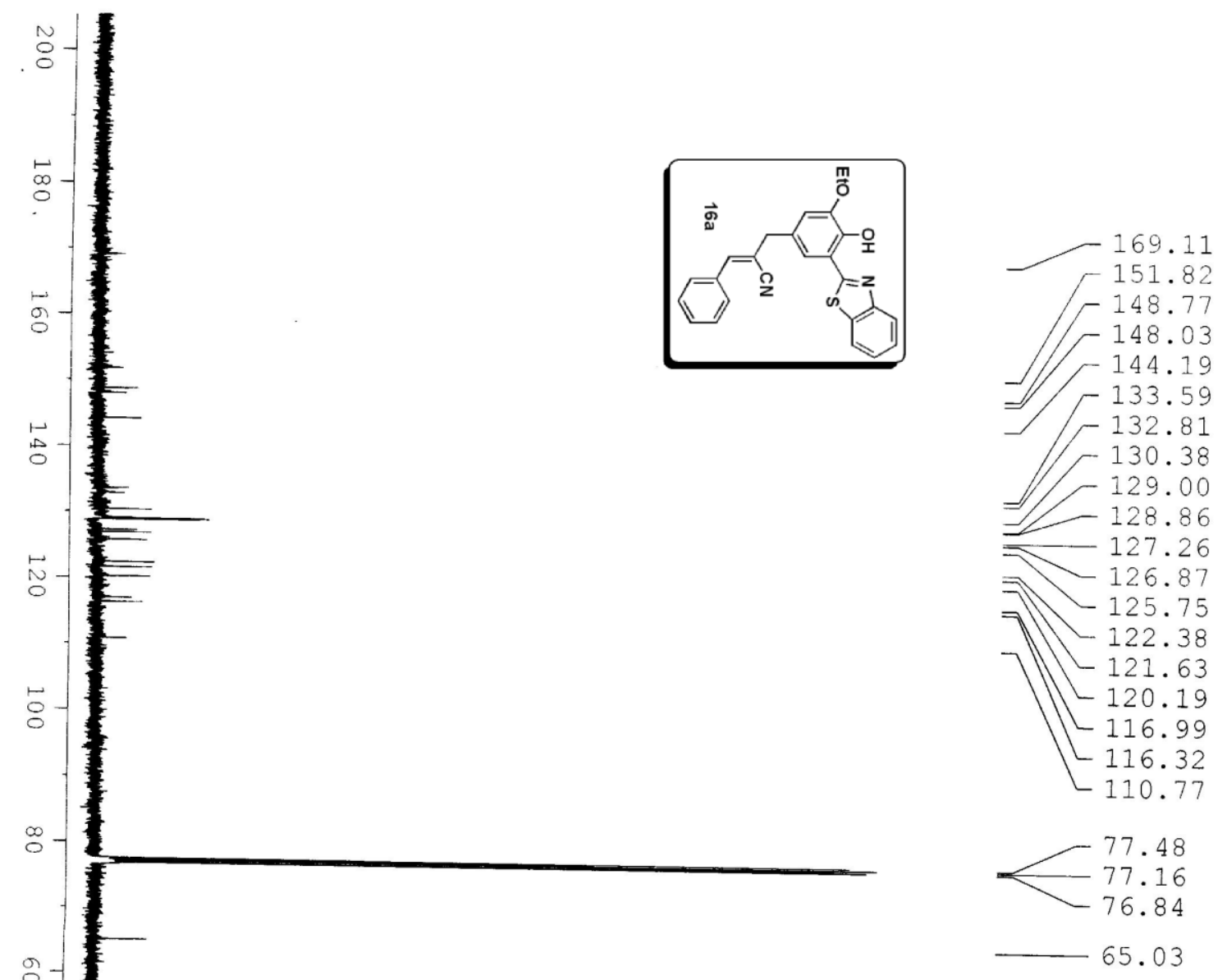

$-41.86$

14.96 


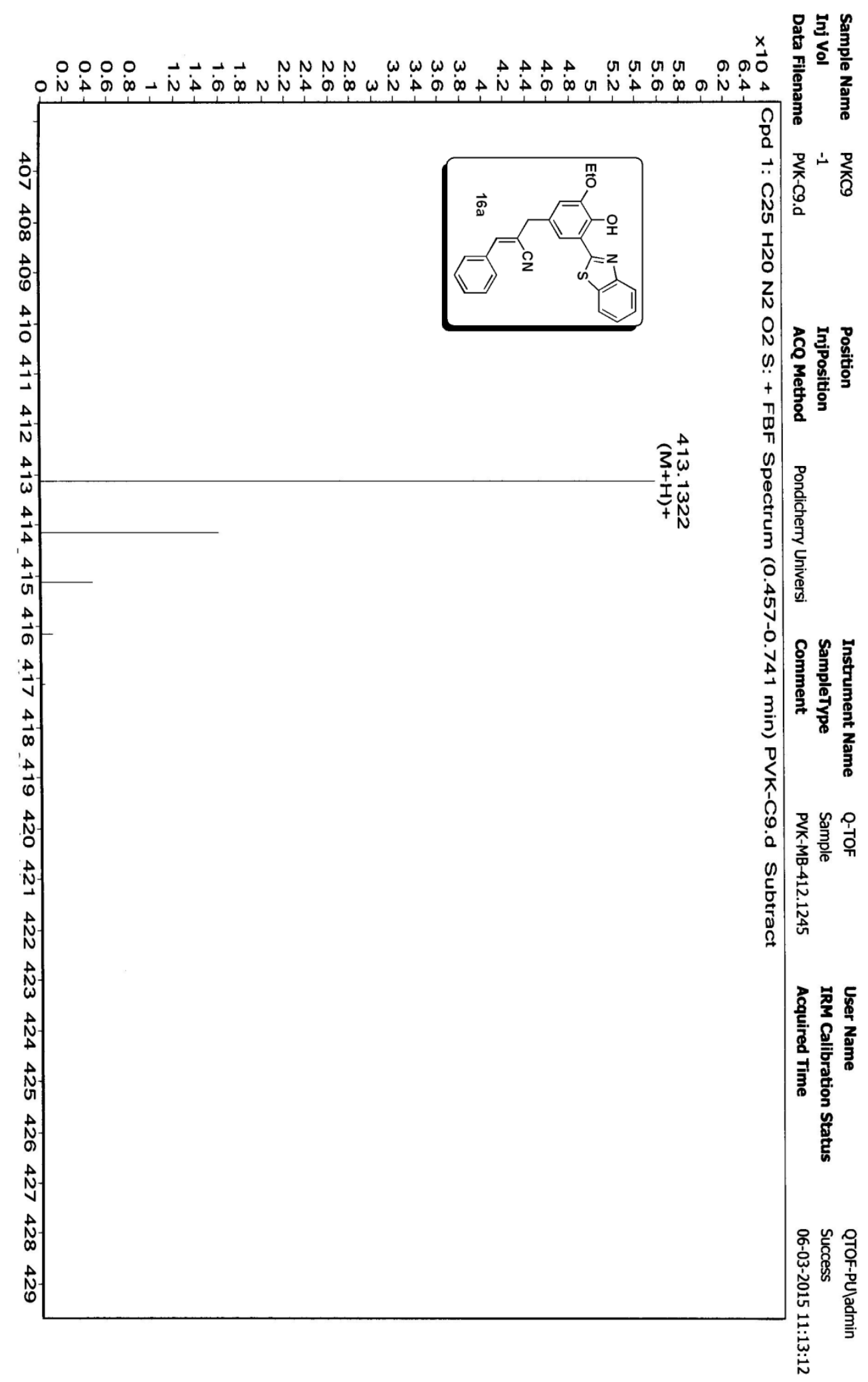



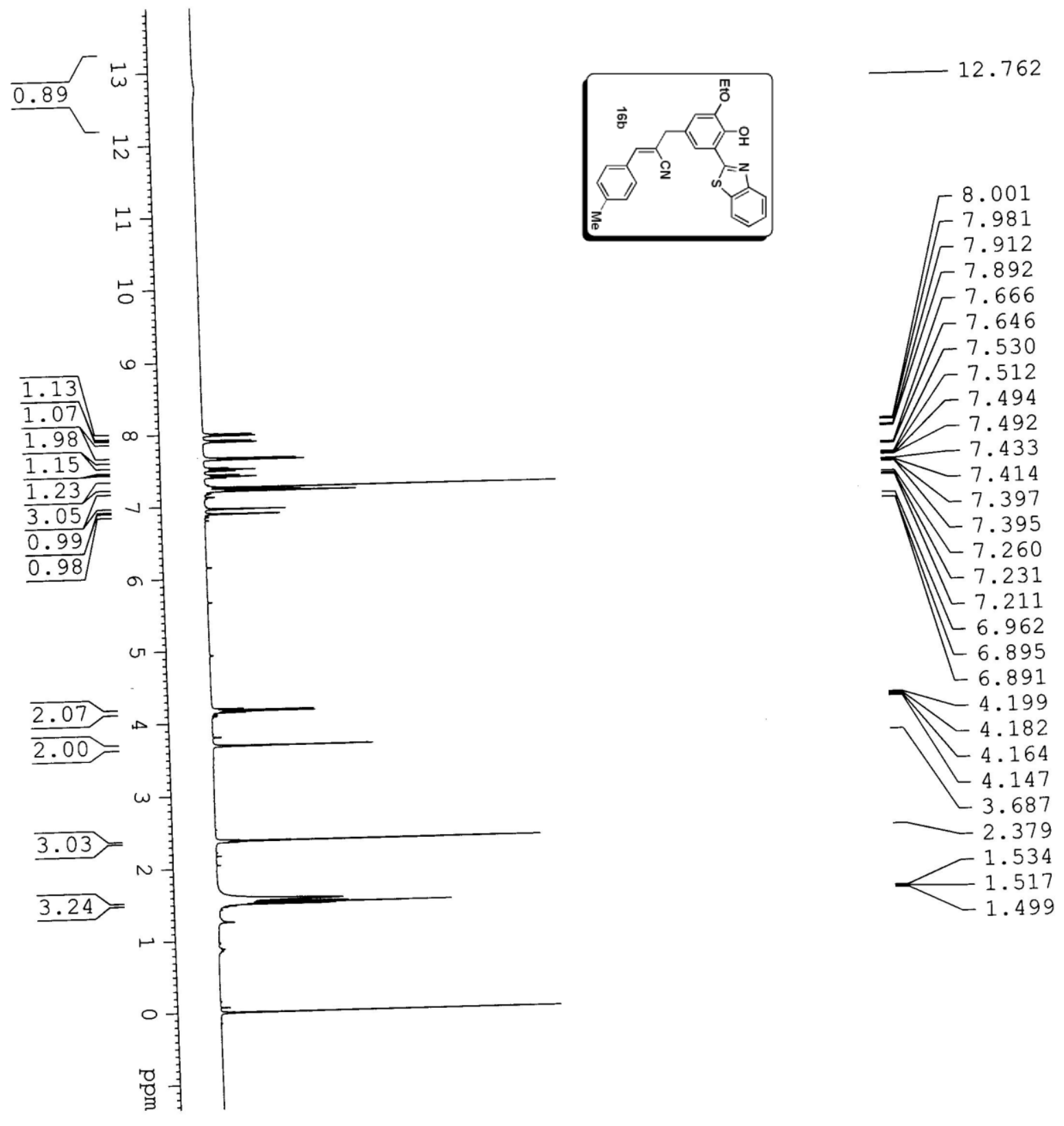


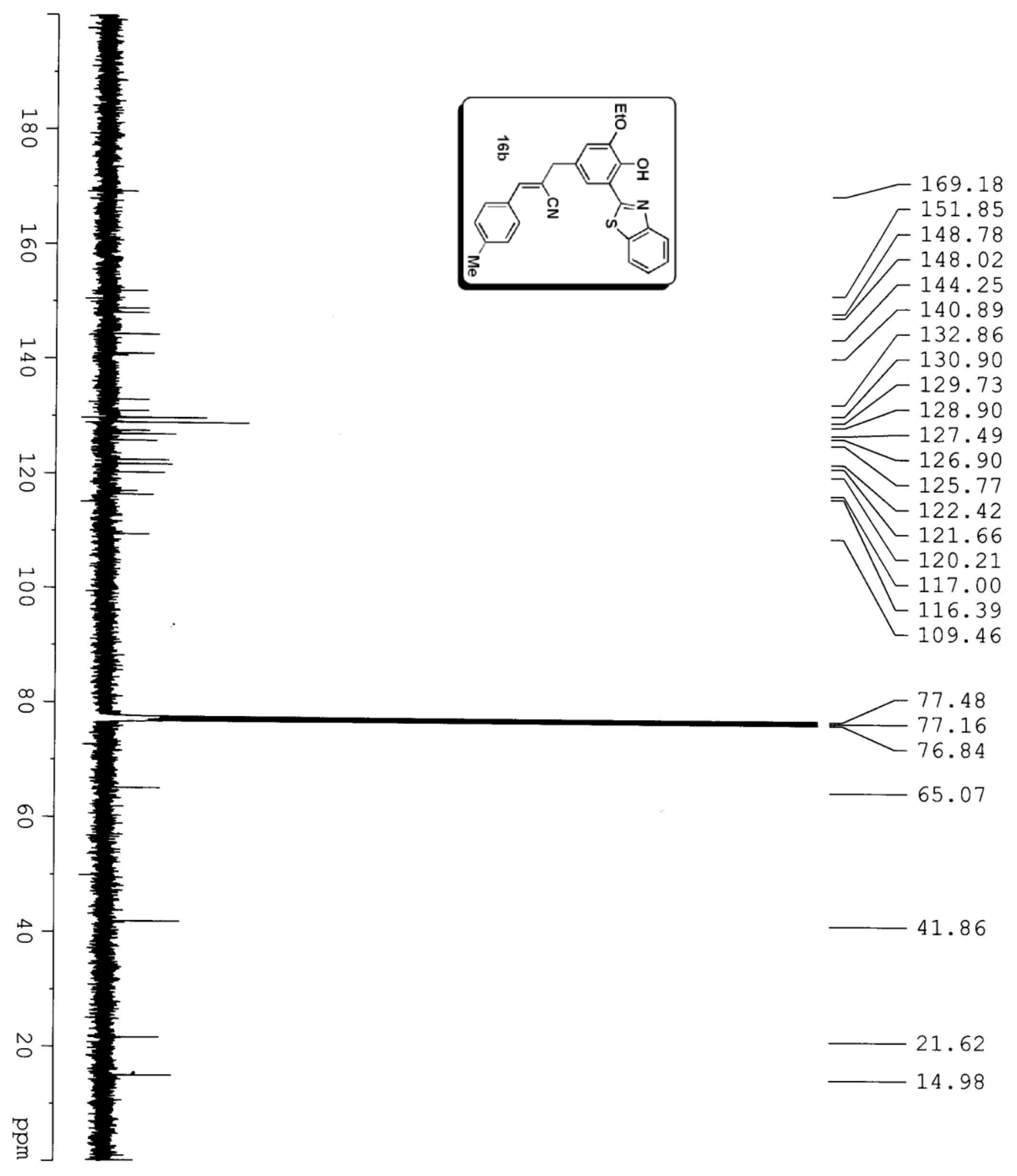




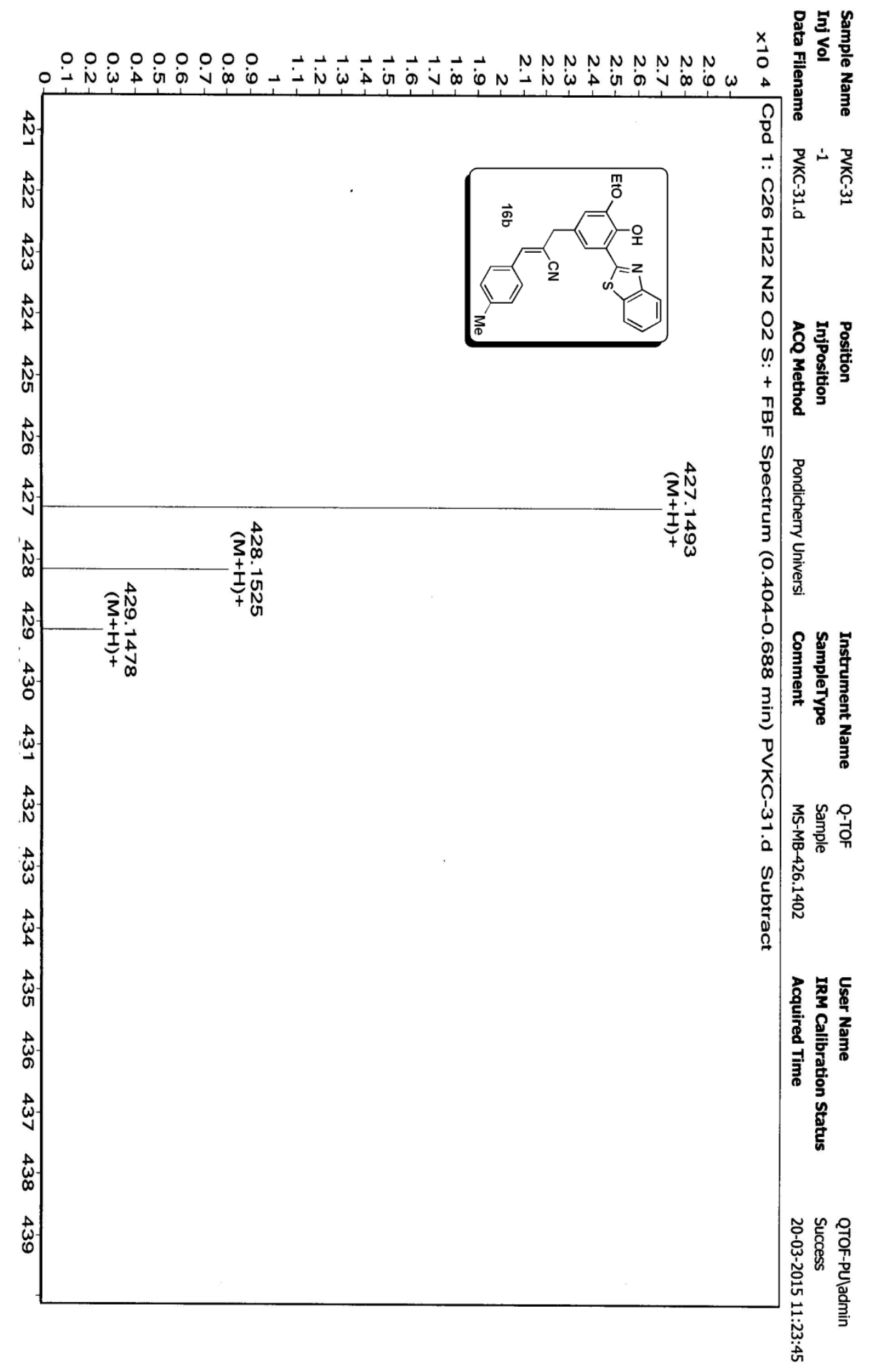



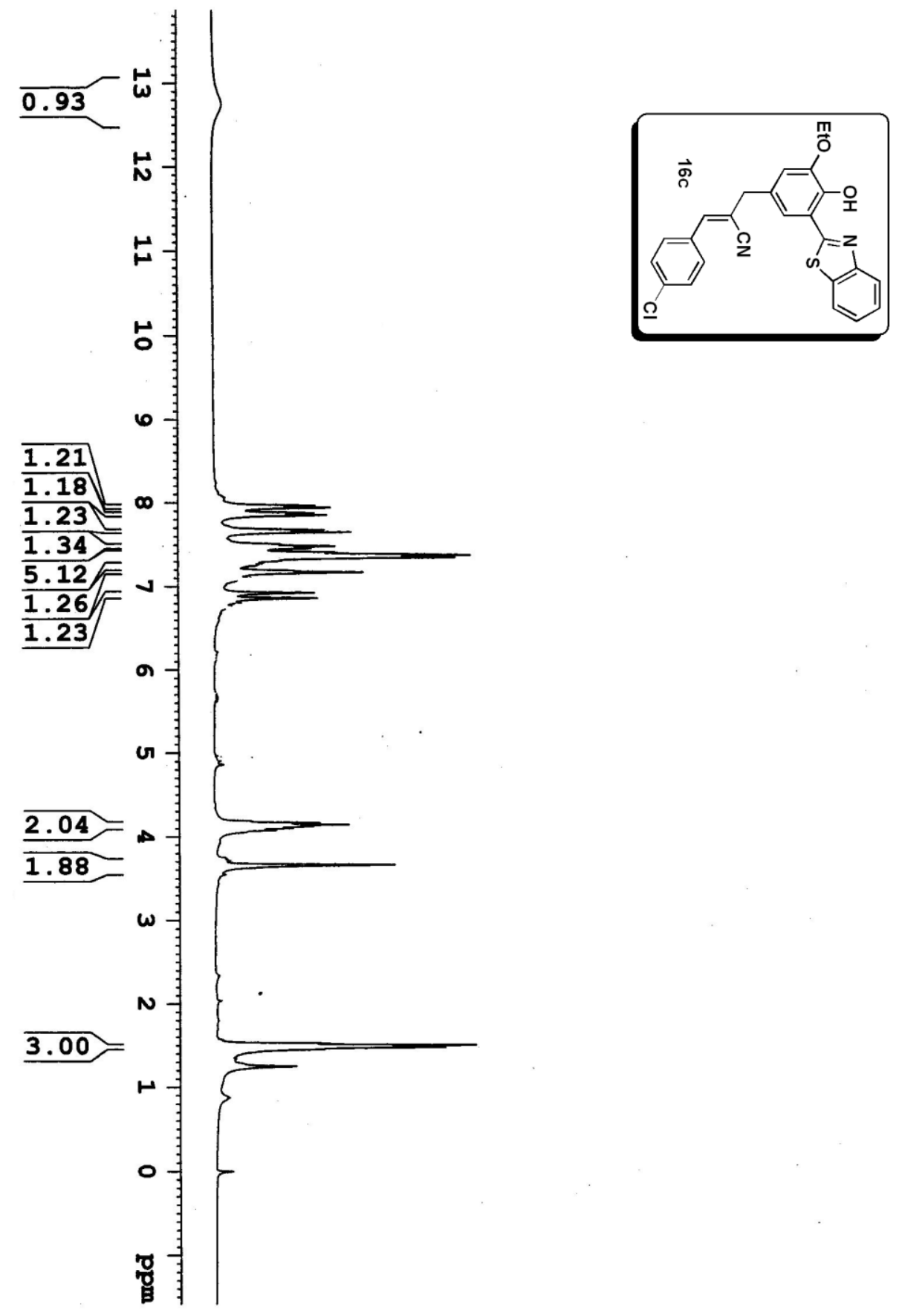

12.773

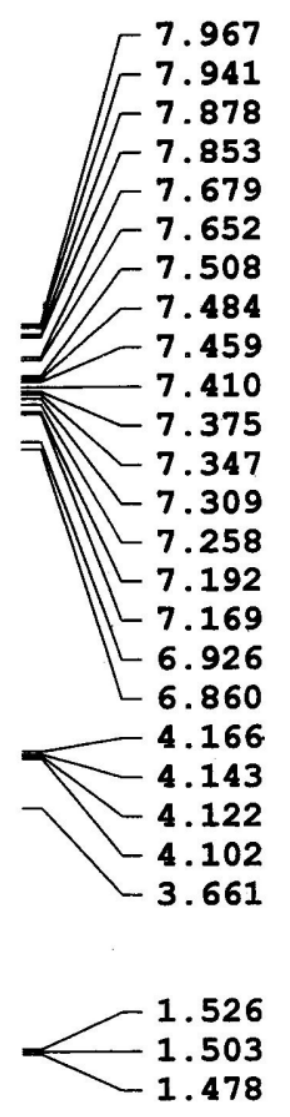




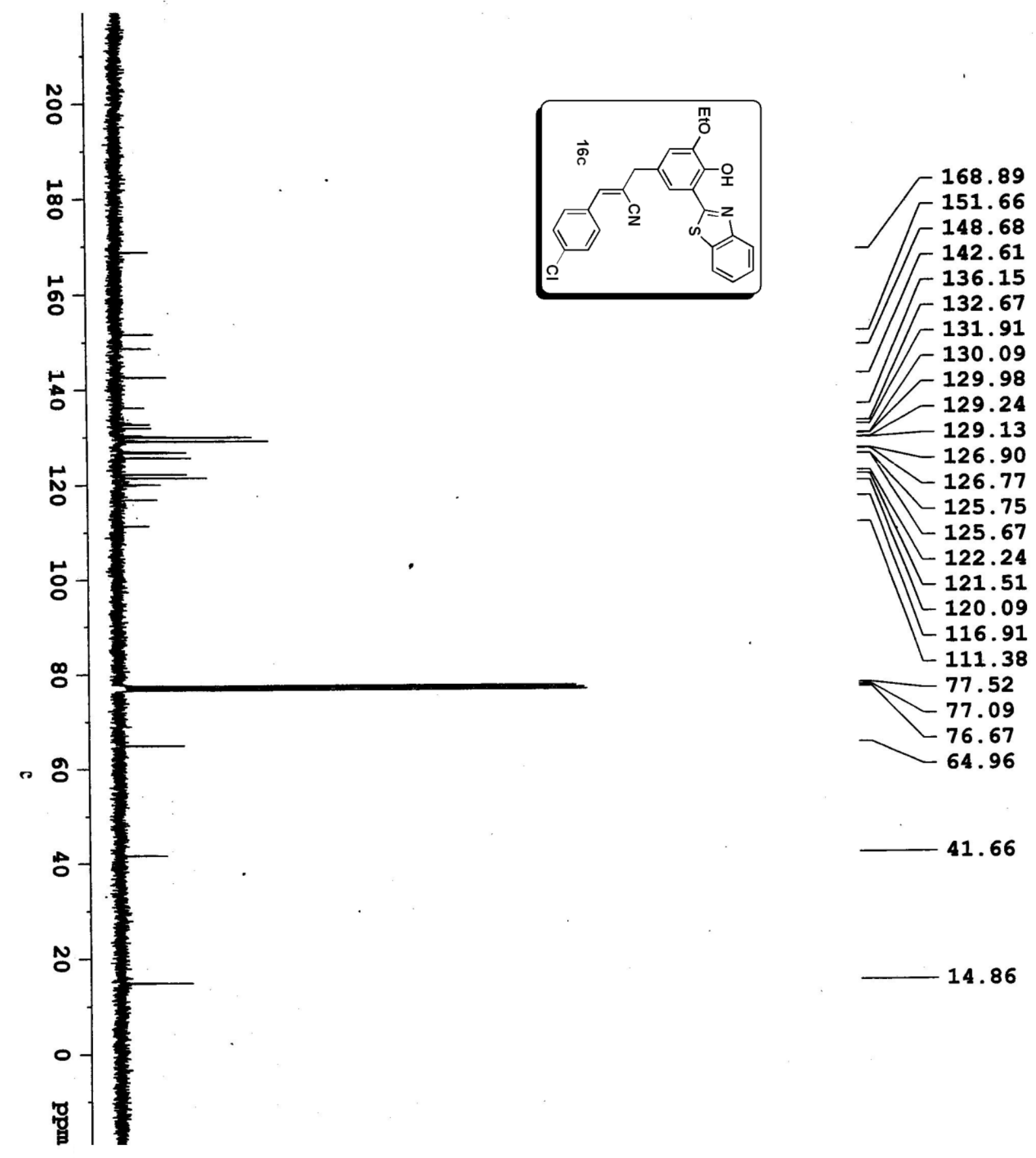




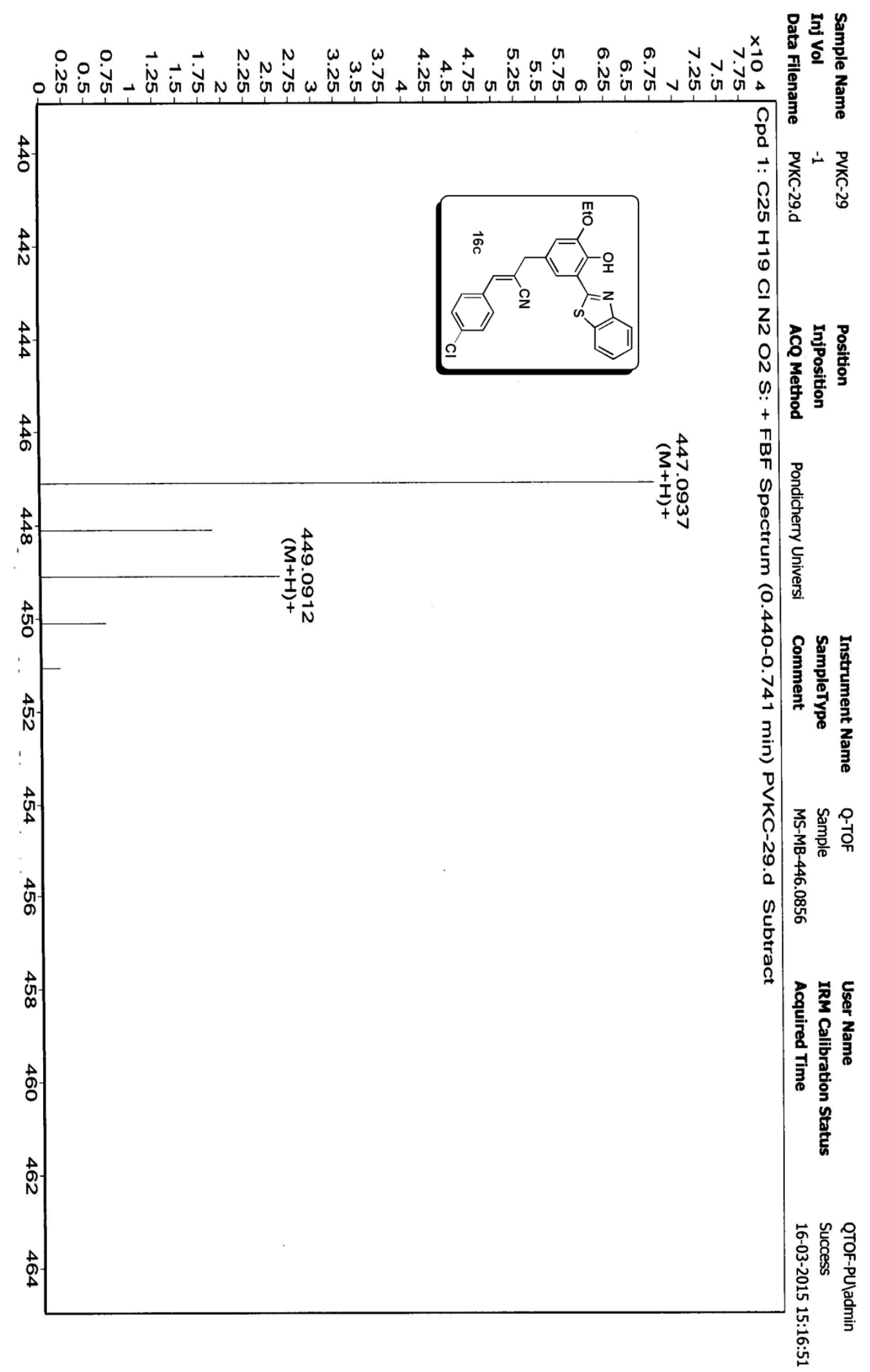




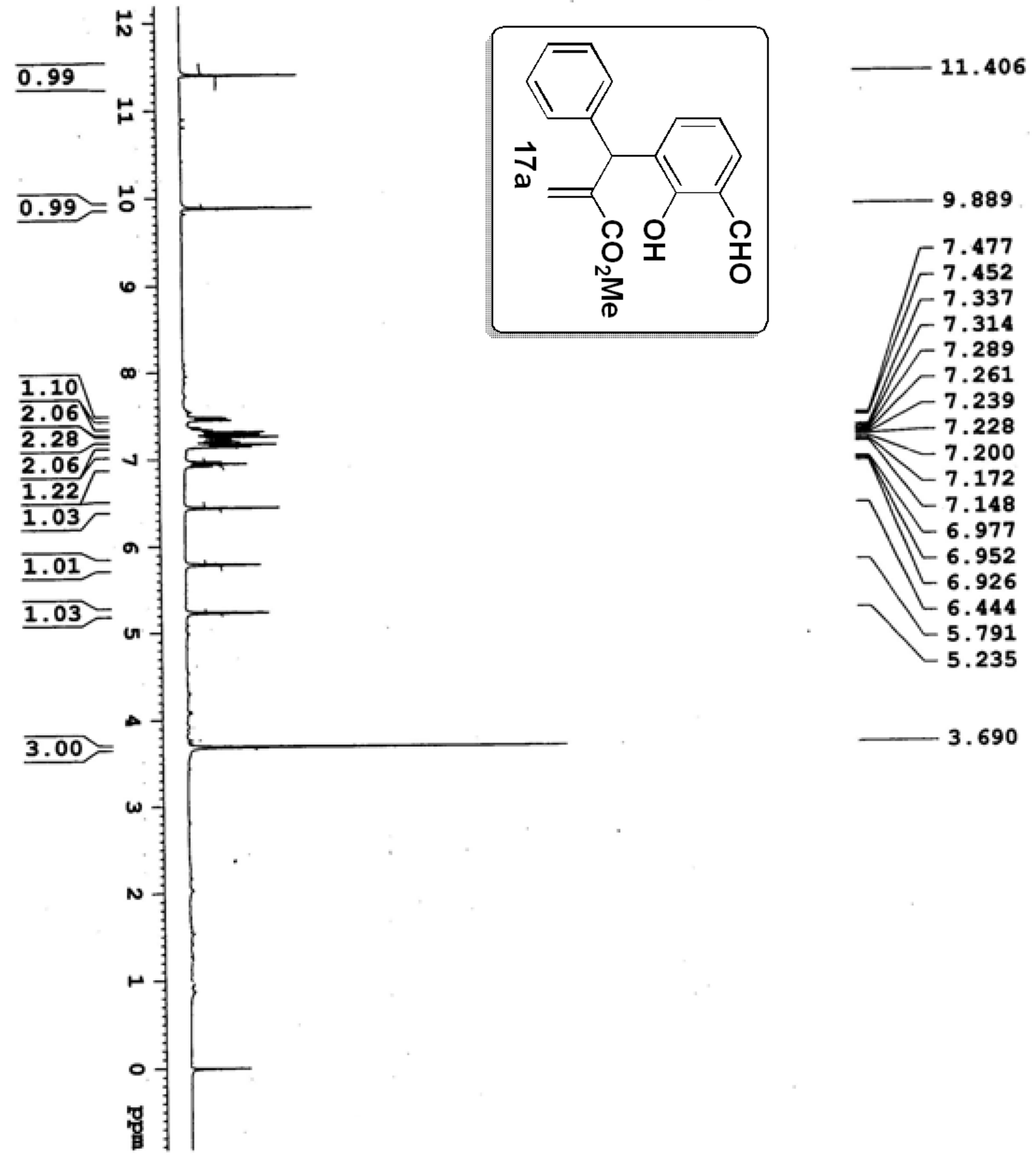




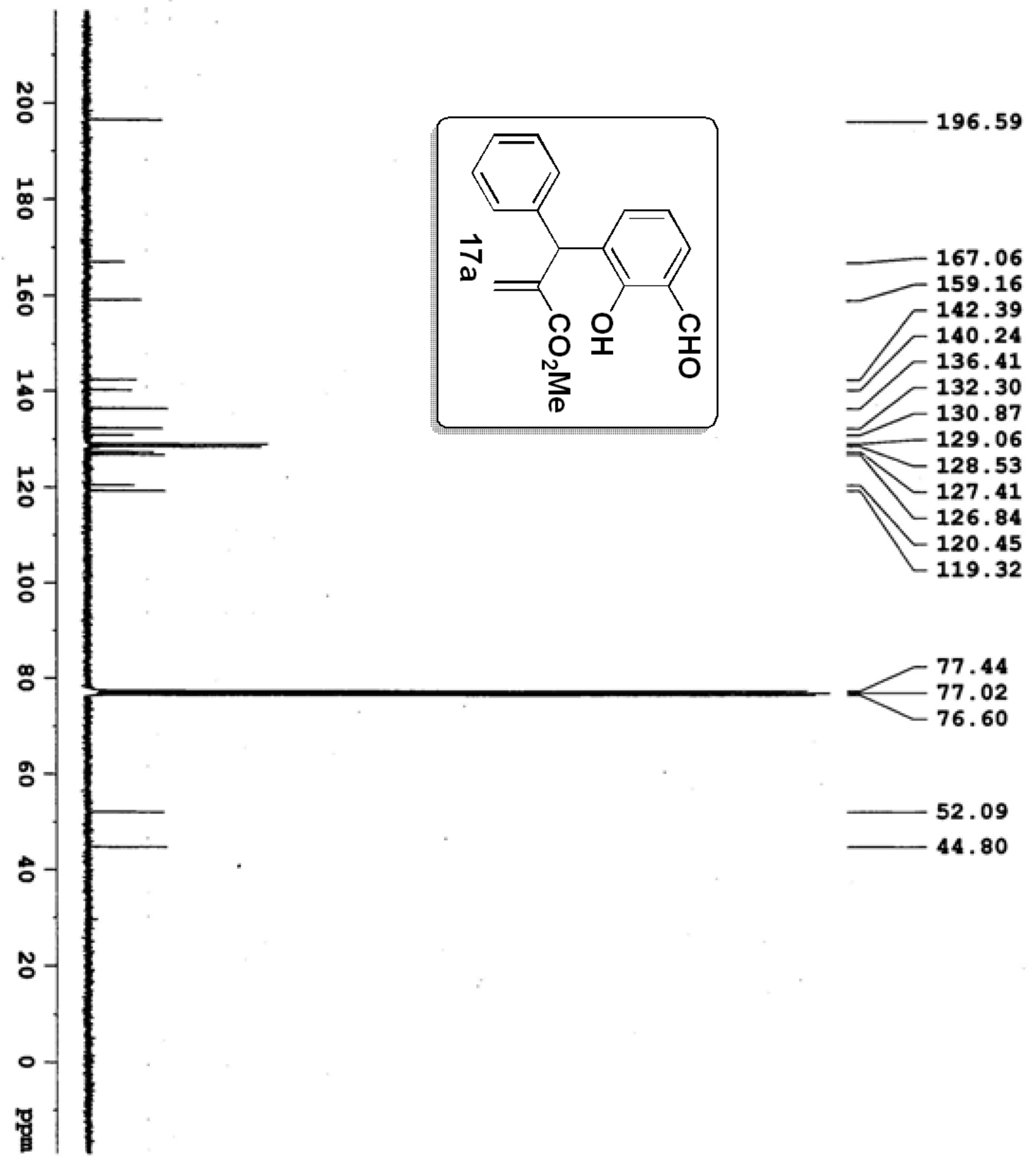




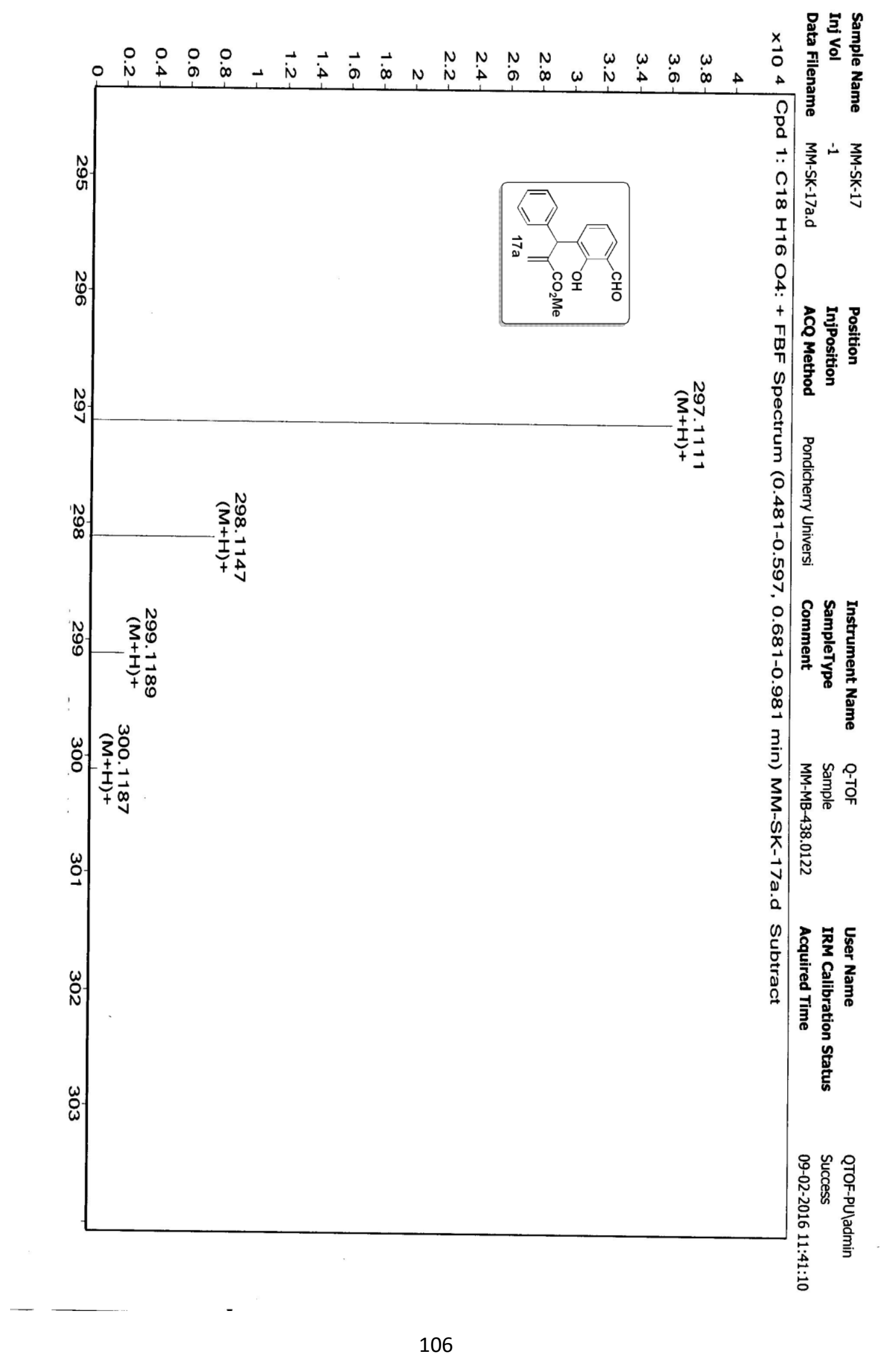

